\title{
The hydrochemical signature of incongruent weathering in Iceland
}

${ }^{1}$ Rice University Department of Earth, Environmental, and Planetary Sciences ${ }^{2}$ California Institute of Technology Division of Geological and Planetary Sciences

- New inverse model can explain the budgets of major and trace elements and their isotope ratios in Icelandic Rivers

- River compositions suggest preferential Na release relative to bulk Icelandic basalts

- Silicate weathering dominates the riverine alkalinity budget in Iceland

non-peer reviewed preprint submitted to EarthArXiv

Corresponding author: Mark A. Torres, mt61@rice.edu 


\begin{abstract}
Basaltic watersheds such as those found in Iceland are thought to be important sites of $\mathrm{CO}_{2}$ sequestration via silicate weathering. However, determining the magnitude of $\mathrm{CO}_{2}$ uptake depends on accurately interpreting river chemistry. Here, we compile geochemical data from Iceland and use them to constrain weathering processes. Specifically, we use a newly developed inverse model to quantify solute supply from rain and hydrothermal fluids as well as allow for different mineral phases within basalts to react at different rates, solutes to be removed via clay formation, and some Ca to be sourced from carbonate dissolution. While some of these processes have been considered previously, they have not been considered together allowing us to newly determine their relative contributions.
\end{abstract}

We find that weathering in Iceland is incongruent in two ways. Firstly, solute release from primary silicates is characterized by a higher proportion of $\mathrm{Na}$ than would be expected from bulk basalts, which may reflect preferential weathering or some contribution from rhyolites. This $\mathrm{Na}$ enrichment is further enhanced by preferential $\mathrm{Mg}$ and $\mathrm{K}$ uptake by clays. No samples in our dataset $(n=537)$ require carbonate dissolution even if isotopic data $\left(\delta^{26} \mathrm{Mg}, \delta^{30} \mathrm{Si}, \delta^{44} \mathrm{Ca}\right.$, and $/$ or $\left.{ }^{87} \mathrm{Sr} /{ }^{86} \mathrm{Sr}\right)$ are included. While some carbonate weathering is allowable, silicate weathering likely dominates. The complexity we observe in Iceland underscores the need for inverse models to account for a wide range of processes and end-members. Given that riverine fluxes from Iceland are more Na-rich than expected for congruent basalt weathering, the characteristic timescale of $\mathrm{CO}_{2}$ drawdown is likely affected.

\title{
Plain Language Summary
}

The chemical composition of rivers can be used to determine how processes occurring at Earth's surface affect the climate. Here, we use measurements from rivers in Iceland, which is an ideal test case as geologic factors are expected to simplify the interpretation of river chemistry. Using a new approach, we identify a range of processes that affect Icelandic rivers and quantify their relative importance. While it was assumed that the results would be "simple", we instead find complicated behavior, which is important to understand when applying similar to approaches to much larger rivers. We also find that the way rivers in Iceland affect the climate is slightly different than originally expected. Nevertheless, these rivers still act to remove carbon dioxide from the atmosphere and thus cool the climate.

\section{Introduction}

Silicate mineral dissolution promotes the removal of $\mathrm{CO}_{2}$ from the ocean-atmosphere system by providing the cations and alkalinity necessary for carbonate mineral burial, which is the primary geologic sink for $\mathrm{CO}_{2}$ released from solid Earth degassing and sedimentary recycling (Berner et al., 1983). Though the dissolution of carbonate minerals also supplies alkalinity to the ocean, carbonate weathering alone cannot drive net carbonate burial and thus influences $\mathrm{CO}_{2}$ consumption over shorter timescales compared to silicate weathering (Broecker \& Sanyal, 1998). Therefore, quantifying the fractional contribution of cations derived from silicate versus carbonate mineral dissolution during chemical weathering is critical to understanding the geologic $\mathrm{C}$ cycle.

The main factors that modulate silicate weathering fluxes are thought to include climate, lithology, and uplift/erosion rates. These mechanisms have been explored through numerous field studies of riverine solute fluxes (e.g., Bluth \& Kump, 1994; West et al., 2005; Eiriksdottir et al., 2013; Ibarra et al., 2016) as well as laboratory experiments (e.g., Chen \& Brantley, 1997; Taylor et al., 2000; Gislason \& Oelkers, 2003; Wolff-Boenisch et al., 2004; Gudbrandsson et al., 2008; Schaef \& McGrail, 2009). Overwhelmingly, these 
investigations highlight lithology as a major control on weathering fluxes and suggest that mafic lithologies ("basalts") chemically weather 2 to 10 times faster than felsic lithologies ("granites"; Bluth \& Kump, 1994; Ibarra et al., 2016). So, despite the fact that basalts occupy only $\sim 5 \%$ of exoreic land surface area, solute fluxes from these areas may contribute disproportionately to $\mathrm{C}$ sequestration by accounting for 30 to $35 \%$ of the global contemporary silicate weathering flux (Dessert et al., 2003). The weathering of mafic lithologies like basalt also factors in to current interpretations of the drivers of geologic climate change. For example, models disagree on whether Cenozoic cooling reflects an increase (Park et al., 2020) or decrease (G. Li \& Elderfield, 2013) in global basalt weathering fluxes, highlighting the need for a more mechanistic understanding of mafic weathering processes.

The interpretation that basalts contribute disproportionately to modern silicate weathering fluxes is based on measurements of the dissolved chemistry of rivers and therefore is predicated on our ability to accurately partition riverine solutes between different solute sources such as atmospheric deposition, silicate mineral dissolution, and carbonate mineral dissolution (Négrel et al., 1993; Bickle et al., 2015; Torres et al., 2016; P. Kemeny et al., 2020). While common igneous rock types are nominally considered to contain purely silicate minerals, they often contain accessory carbonate minerals in trace amounts (White et al., 1999, 2005). Due to their high reactivity, carbonates can contribute significantly to solute loads even when present at low abundances in bedrock (D. Li et al., 2014).

Existing global analyses of basaltic weathering fluxes based on river chemistry have mostly assumed that there is a negligible contribution from accessory carbonates (Dessert et al., 2003; Ibarra et al., 2016; G. Li et al., 2016). If this assumption about solute sources is in error, as implied by interpretations of either the stable isotopic compositions of dissolved calcium and strontium (Jacobson et al., 2015; Andrews \& Jacobson, 2017) or major element concentrations (Georg et al., 2007) in some basalt-draining watersheds in Iceland, then our understanding of global basalt weathering may be incomplete. On the other hand, the chemical signals in river waters that are thought to be indicative of carbonate mineral dissolution (i.e., differences in elemental and stable isotopic ratios relative to primary silicates) can be generated by other geochemical processes such as secondary silicate mineral ("clay") formation (Hindshaw et al., 2013). If it is the case that carbonate weathering meaningfully contributes to solute fluxes in basaltic watersheds, prior studies could potentially have over-emphasized the role of basaltic landscapes in stabilizing the geologic carbon cycle by sequestering atmospheric $\mathrm{CO}_{2}$.

Evidence that secondary clay formation modulates the chemical composition of Icelandic rivers, and basalt-draining rivers in general, exists in the form of mineral mass balance calculations (Moulton et al., 2000), reaction path modelling (Stefánsson \& Gíslason, 2001), the isotopic composition of dissolved Si and Li (P. A. Pogge von Strandmann et al., 2006; Georg et al., 2007; Opfergelt et al., 2013), and direct measurements of clay mineralogy and elemental composition (Crovisier et al., 1992; Wada et al., 1992; Moulton et al., 2000; Ehlmann et al., 2012; Thorpe et al., 2019). However, explanations of river chemistry that appeal to multiple solute sources (carbonate vs. silicate) or fractionation by secondary clay formation are not mutually exclusive. As such, effective hypothesis testing requires models that consider a range of processes together. Specifically, recent work has shown that the formation of secondary minerals biases inferences of carbonate versus silicate mineral weathering in river chemistry data such that models must explicitly account for both processes in order to yield accurate results (Bickle et al., 2015; Emberson et al., 2017, 2018).

In some past work on weathering in Iceland, it has been assumed that silicate weathering processes release solutes in similar ratios to bulk basalts (Gíslason et al., 1996; Stefánsson et al., 2001; Jacobson et al., 2015; P. C. Kemeny et al., 2021) or some mixture of bulk basalts and bulk rhyolites (Louvat et al., 2008). The assumption of congruent solute release (i.e., similar elemental ratios for rivers as in bulk rocks) may be reasonable for catch- 
ments where volcanic glass weathering dominates as experiments show the congruent release of major cations from basaltic glass (Gislason \& Eugster, 1987). However, for more crystalline bedrock, the fact that not all minerals react at the same rate under like conditions may lead to effective solute release ratios that are substantially different from the bulk rock composition (Gislason \& Eugster, 1987; Ryu et al., 2011; Emberson et al., 2017). Deviations in effective end-member compositions relative to the bulk rock depend on a myriad of factors (e.g., weathering duration; Ferrier \& Kirchner, 2008) such that compositions near the bulk rock value may be reasonably accurate for some crystalline lithologies under some circumstances. Nevertheless, observations of differential rates of primary mineral depletion in basaltic soil profiles from Hawaii (Ryu et al., 2014) suggests that this process must be considered alongside secondary clay formation when trying to interpret river chemistry in terms of the lithologic sources of solutes.

The details affecting river water chemistry are ultimately important as they can influence the magnitude of $\mathrm{CO}_{2}$ drawdown by weathering and the characteristic timescales over which this drawdown applies. In much previous work, the effects of basaltic watersheds on the $\mathrm{C}$ cycle have been determined using bicarbonate fluxes (Dessert et al., 2003; Ibarra et al., 2016; G. Li et al., 2016), which implicitly assumes that all dissolved cations contribute to $\mathrm{CO}_{2}$ drawdown equally over the same timescales. This is not the case, however, as the major processes that remove seawater alkalinity associated with $\mathrm{Na}^{+}, \mathrm{K}^{+}$, and $\mathrm{Mg}^{2+}$ ions (i.e., "reverse weathering"; F. Mackenzie \& Garrels, 1966) are different from those that remove seawater alkalinity associated with $\mathrm{Ca}^{2+}$ ions. By altering the proportion of silicate weathering derived alkalinity associated with Ca relative to what is implied by the bulk bedrock composition, varying rates of primary mineral dissolution and/or extent of solute uptake into secondary minerals can affect the links between weathering and the long-term $\mathrm{C}$ cycle. Additionally, significant cation retention in secondary minerals effectively decreases the amount of alkalinity generated by weathering and could be one of the factors that explains observed differences in solute generation between basaltic watersheds (Dessert et al., 2003; Ibarra et al., 2016; G. Li et al., 2016).

To make progress on understanding silicate weathering in volcanic terrains, we combine published measurements of bedrock and water chemistry from Iceland and analyze them using an inverse model that allows for multiple solute sources (rainwater, hydrothermal fluids, silicates, and carbonates) and solute fractionation mechanisms (clay mineral formation and heterogeneous dissolution rates). Our definition of solute fractionation aligns with the more generic term incongruent weathering, which, in the literature, has been used to refer to instances where solutes released by weathering are taken up into secondary phases (Misra \& Froelich, 2012) as well as when solutes are released into solution in a different ratio relative to the bulk solid, but no new phases are formed (e.g., due to different rates of primary mineral dissolution; Rickli et al., 2013; Bickle et al., 2015). For clarity, we separate these two concepts and refer to them as secondary phase incongruence and primary mineral incongruence, respectively. The structure of our modelling approach allows us to discern how primary and secondary incongruence influence the partitioning of solute loads between carbonate and silicate sources in a system where the bedrock chemistry is relatively uniform and well-known. Understanding solute source apportionment in such systems is a prerequisite for interpreting more lithologically-complex river systems in terms of their effects on the global $\mathrm{C}$ cycle.

\section{Methods}

\subsection{Hydrochemistry}

\subsubsection{Data Compilation}

Previously published solute concentrations, water quality parameters ( $\mathrm{pH}$, temperature, and water type classification) as well as geospatial data for water samples collected 


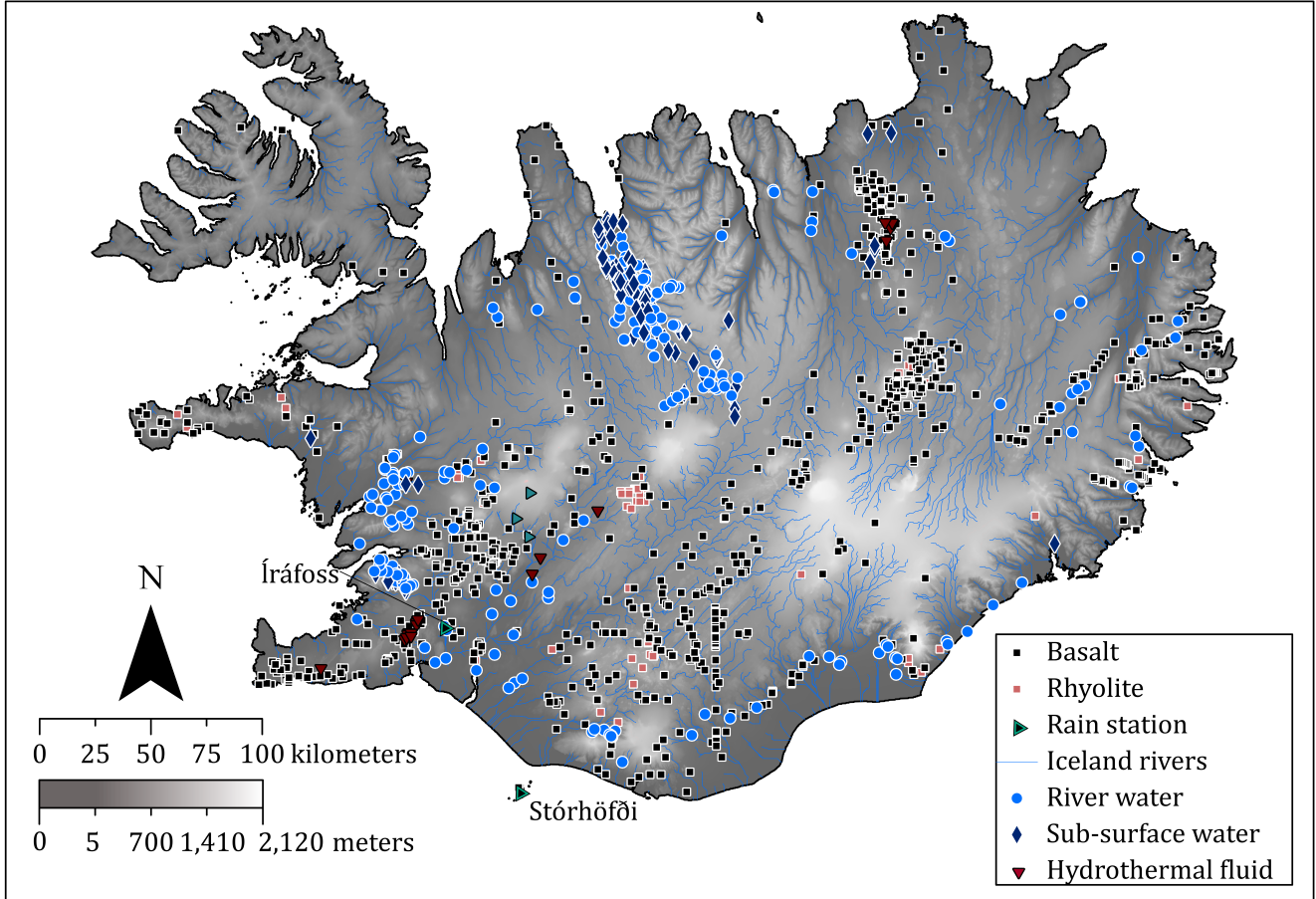

Figure 1. Shaded relief map showing the sampling locations for the river waters (light blue circles), sub-surface waters (dark blue diamonds), rain station (light blue triangle with black center), rain waters (light blue triangles), hydrothermal fluids (red triangles), basalts (black squares), and rhyolites (light red squares) used in this study.

in Iceland were identified through Web of Knowledge and transcribed into an Excel@database through a combination of electronic transfer and manual tabulation. For this work, we emphasized data from rivers, but our compilation includes a range of other water sample types. Specifically, we distinguish ten water types: rain waters, cold springs, glacial rivers, groundwater wells, hydrothermal fluids, lake waters, multi-sourced rivers, nonglacial rivers, soil pore waters, and unclassified rivers (Supplementary Table S1). In addition to these classifications, we also group all of the river water data types together (labeled river waters) as well as group the groundwater well, cold spring, and soil pore water samples together (labeled sub-surface waters; Figure 1). We focused on collecting data for major solute concentrations (i.e., $\mathrm{Cl}, \mathrm{SO}_{4}, \mathrm{Na}, \mathrm{K}, \mathrm{Ca}, \mathrm{Mg}, \mathrm{Si}$ ), but if additional trace elements and isotopic ratio data were available, we included them in our database. In our database, Ca isotopic ratios are reported as both ${ }^{44} \mathrm{Ca} /{ }^{42} \mathrm{Ca}$ and ${ }^{44} \mathrm{Ca} /{ }^{40} \mathrm{Ca}$ values normalized to either the SRM915a or OSIL seawater standard, respectively. For the analyses reported here, we converted all $\mathrm{Ca}$ isotopic data to ${ }^{44} \mathrm{Ca} /{ }^{40} \mathrm{Ca}$ values normalized to the OSIL seawater standard.

When geographical coordinates of sampling locations were provided, they were converted to datum ISN1993 and recorded in decimal degrees. If a sample location was not provided but a map was, an attempt was made to approximate the sample location using Google Earth@(Gíslason et al., 1996; Stefánsson \& Gíslason, 2001; Mutonga et al., 2010; Scott et al., 2014; Oskarsson et al., 2013). Coordinates for the sampling locations 
associated with the data reported in Gislason and Arnórsson (1993) and Stefánsson et al. (2001) are not available due to a lack of sample location map or provided locality data. A map showing all of the sample locations is provided in Figure 1.

An effort was made to classify river water types (i.e., glacial or non-glacial river) if a description was not provided but a sample location was by using visual observations of river turbidity in Google Earth imagery. We note that the data reported by Gíslason et al. (1996) and Moulton et al. (2000) represent average concentrations from multiple measurements and that the individual data points were not provided by the authors. In some cases, time-series of multiple observations from an individual site were reported (e.g., Eiriksdottir et al., 2013) and, in our analysis, each sample is considered independently. Other sources report single observations from a given locality (e.g., Jacobson et al., 2015). In total, 22 publications were compiled amounting to 1432 observations (Louvat et al., 2008; Andrews \& Jacobson, 2017; Arnórsson et al., 2002; Eiriksdottir et al., 2013; Gannoun et al., 2006; Gíslason et al., 2006; Georg et al., 2007; Gíslason et al., 1996; Gislason \& Arnórsson, 1993; Hindshaw et al., 2013; Jacobson et al., 2015; Moulton et al., 2000; Olsson et al., 2014; P. A. Pogge von Strandmann et al., 2006; P. A. E. Pogge von Strandmann, Olsson, et al., 2019; Stefánsson et al., 2001; Stefánsson \& Gíslason, 2001; Vigier et al., 2006, 2009; Mutonga et al., 2010; Oskarsson et al., 2013; Scott et al., 2014).

Data for the chemical composition of Icelandic rainwater was taken from the Cooperative programme for monitoring and evaluation of the long-range transmission of air pollutants in Europe (EMEP). The EMEP provides time-series data for two sites in Iceland: Íráfoss and Stórhöfði (Figure 1). Here, we primarily focus on 96 monthly and annually averaged rainwater samples from the Íráfoss site, which has measurements for major cations and anions for the time period 2006 to 2012 as well as 2015. Rainwater data from the Stórhöfði site match the elemental ratios expected for seawater and show much higher solute concentrations than at Íráfoss. The higher concentrations observed at the Stórhöfði site may relate to the fact that this site is much closer to the ocean compared to Íráfoss (Figure 1). The monthly data from the Íráfoss site are more variable in terms of solute concentrations and ratios compared to the Stórhöfði site, but still encompass seawater-like elemental ratios.

\subsubsection{Data Quality Control}

For the river and subsurface water analyses, we removed samples where concentrations for either $\mathrm{Cl}, \mathrm{Na}, \mathrm{K}, \mathrm{Ca}, \mathrm{Mg}$, or $\mathrm{Si}$ were missing or reported as zero in the primary publication. We also removed river and subsurface water where the total charge of major anions $\left(\mathrm{Cl}\right.$ and $\left.\mathrm{SO}_{4}\right)$ exceeded the total charge of major cations $(\mathrm{Na}, \mathrm{K}, \mathrm{Ca}$, and $\mathrm{Mg}$ ). For thermodynamic calculations (see below), we applied a more stringent threshold to the river and subsurface waters by only accepting samples where the absolute value of the calculated charge balance error was less than $10 \%$. With a full speciation calculation (i.e., taking into account the speciation of weak acids and ion pair formation), charge balance error takes the absolute values of measured concentrations in units of charge equivalents and normalizes the difference between the sums of all positively and negatively charged species by the sum of all charged species. For the remaining water types, namely the rain and hydrothermal waters, we did not apply any quality control procedures.

\subsubsection{Thermodynamic Calculations}

Mineral saturation indices (SI) were evaluated for river and sub-surface water samples using PHREEQC with the thermodynamic databases phreeqc and wateq4f and measurements of temperature, $\mathrm{pH}$, cation concentrations $\left(\mathrm{Al}^{3+}, \mathrm{Ca}^{2+}, \mathrm{Fe}^{2+}, \mathrm{K}^{+}, \mathrm{Mg}^{2+}, \mathrm{Na}^{+}\right.$, and/or $\left.\mathrm{NH}_{4}^{+}\right)$, strong anion concentrations $\left(\mathrm{Cl}^{-}, \mathrm{F}^{-}, \mathrm{SO}_{4}^{2-}, \mathrm{NO}_{2}^{-}\right.$, and $/$or $\left.\mathrm{NO}_{3}^{-}\right)$, the total Si concentration, and either alkalinity (Gíslason et al., 1996; Moulton et al., 2000; P. A. Pogge von Strandmann et al., 2006; Gannoun et al., 2006; Vigier et al., 2006; Gíslason et al., 2006; 
Georg et al., 2007; Louvat et al., 2008; Vigier et al., 2009; Eiriksdottir et al., 2013; Hindshaw et al., 2013; Jacobson et al., 2015; Andrews \& Jacobson, 2017) or total dissolved inorganic carbon (Gislason \& Arnórsson, 1993; Stefánsson et al., 2001; Stefánsson \& Gíslason, 2001; Arnórsson et al., 2002; Olsson et al., 2014; P. A. E. Pogge von Strandmann, Olsson, et al., 2019; Mutonga et al., 2010; Scott et al., 2014; Oskarsson et al., 2013) as inputs. We focused on saturation indices for a set of primary (albite, anorthite, diopside, forsterite, calcite, and K-feldspar) and secondary (Ca-montmorillonite, illite, kaolinite, laumontite, sepiolite, and $\mathrm{AlOH}$ ) minerals for which thermodynamic data is available in the phreeqc and watequf databases. Accordingly, samples lacking dissolved $\mathrm{Al}$ concentrations could only be used to constrain SI values for calcite, forsterite, diopside, and sepiolite.

\subsubsection{Data Normalization and Principle Component Analysis}

For many of our analyses, we use ratios of solute concentrations in order to focus on variations in solute sources instead of other factors, such as evaporation, dilution, and variable extent of reaction, that can independently influence measured concentrations. Multiple options are available to convert a solute concentration $(X ; \mu \mathrm{M})$ to a ratio. For example, individual cations (X/Na; Négrel et al., 1993), sums of a subset of cations (X/Na+Ca), or sums of cations and anions $\left(\mathrm{X} / \mathrm{Na}+\mathrm{SO}_{4}\right.$; Blattmann et al., 2019) could all be used as normalization variables. The choice of normalization variable is important as mixing analyses cannot model end-members that contribute solely to an element that is not in the normalization variable. For example, if $\mathrm{Na}$ is used as the normalization variable, it must be assumed that carbonate dissolution also contributes to the Na budget.

For visualization and principle component analysis (PCA), we normalize the individual solute concentrations by the sum of $\mathrm{Na}, \mathrm{K}, \mathrm{Ca}$, and $\mathrm{Mg}$ concentrations $\left(\Sigma^{+} ; \mu \mathrm{M}\right)$ because most end-member solute sources contribute to the budget of at least one major cation. For inverse analysis of solute sources (see below), we use the sum of $\Sigma^{+}$and sulfate concentrations $\left(\Sigma^{ \pm} ; \mu \mathrm{M}\right)$ as a normalization variable in order to model sulfide mineral oxidation as an independent process that releases sulfate, but not major cations. This approach of normalizing by sums of solute concentrations has some important implications for data analysis. For example, the $X / \Sigma^{+}$values for $\mathrm{Na}, \mathrm{K}, \mathrm{Ca}$, and $\mathrm{Mg}$ have the property of each being confined to the interval 0 to 1 and, for a single sample, the four ratios must all sum to a value of 1 (unit sum constraint). For elements not included in the denominator term, which, for $\Sigma^{+}$, includes $\mathrm{Si}, \mathrm{Cl}$, and $\mathrm{SO}_{4}, X / \Sigma^{+}$can exceed 1. However, $\mathrm{SO}_{4} / \Sigma^{+}$or $\mathrm{Cl} / \Sigma^{+}$values much greater than 1 would imply a charge imbalance unless other cations (e.g., $\mathrm{Fe}^{2+}$ and/or $\mathrm{H}^{+}$) were present at sufficient levels in solution. For elements that are included in the denominator term, uncertainties in $X / \Sigma^{+}$ values are correlated.

The auto-correlation inherent in normalizing by either $\Sigma^{+}$or $\Sigma^{ \pm}$as well as the unit sum constraint can impact calculations such as linear regression and PCA (Pearson, 1897; Aitchison, 1983). We note that similar issues could arise in the case where solute concentrations were normalized by a single cation (e.g., X to Na ratios). To remove this autocorrelation and enable PCA, we normalize solute concentration ratios using the centered $\log$-ratio transformation $(\mathrm{clr})$, which, here, is calculated for normalization with $\Sigma^{+}$as:

$$
\operatorname{clr}\left(X_{i} / \Sigma^{+}\right)=\frac{X_{i} / \Sigma^{+}}{\left(\prod_{i=1}^{4} X_{i} / \Sigma^{+}\right)^{1 / 4}}
$$

where the subscript $i$ indexes the individual elements used in the calculation of the normalization variable $\Sigma^{+}$. The $c l r$ transformation normalizes each concentration ratio for a sample by the geometric mean of all of the concentration ratios values for that sample, which transforms proportions so that they are no longer restricted to the interval 0 to 1 . This transformation can only be applied to data where all of the elemental ra- 
tios are non-zero. While no water samples in our culled dataset have a value of zero for any of the required solute concentrations, this non-zero constraint affects projecting endmembers into the space defined by the PCA. This further motivates normalizing by $\Sigma^{+}$ as including $\mathrm{Cl}, \mathrm{SO}_{4}$ and/or $\mathrm{Si}$ in the normalization variable would hamper visualizing the silicate and rainwater end-members.

To perform PCA on $c l r$-transformed ratio data, we used the MATLAB function $\mathrm{pca}($ ), which applies a singular value decomposition algorithm. Inputs for PCA were restricted to the river and sub-surface water observations and, prior to analysis, we centered the data by subtracting the mean value for each variable. To project putative endmembers into the principle component space defined by the river and sub-surface water observations, we used the coeff output of the pca() function. Again, we perform PCA on the $c l r$-transformed data to remove the auto-correlation that arises from normalizing all solutes by the same normalization variable as well as the unit-sum constraint that arises by choosing $\Sigma^{+}$as the normalization variable. While concentration data could be used for PCA, the result would not necessarily separate samples based on their solute sources as solute concentrations can be decoupled from elemental ratios by a variety of processes (e.g., evaporation, dilution, variable water-to-rock ratios, and/or variable extents of reaction).

\subsection{Solid Phase Compositions: Compilation and Analysis}

Icelandic bedrock elemental abundances and sampling locations were primarily taken from the Geochemistry of Rocks of the Oceans and Continents (GEOROC) database. Additional solid-phase geochemical data, including measurements of sieved sediment samples and soils as well as mineral abundances, were taken from the literature (Moulton et al., 2000; Thorpe et al., 2019). All bedrock samples were classified into different rock types (basalt, dacite, rhyolite, etc.) according to a scatterplot of the sum of sodium and potassium concentrations and silica concentrations.

As a quality control measure for the GEOROC dataset, samples where any of the concentrations of $\mathrm{Al}, \mathrm{Ca}, \mathrm{K}, \mathrm{Mg}, \mathrm{Na}$, or $\mathrm{Si}$ deviated more than three scaled median absolute deviations from the median concentration for that element were excluded from our data analysis, which was accomplished using the MATLAB function isoutlier(). In total, 6,887 bedrock samples were retained out of initial dataset of 7,849 and used in subsequent analyses ( $88 \%$ retention).

To constrain the composition of secondary precipitates, we used soil and sediment samples in our database where the authors sieved to $<2 \mu \mathrm{m}$ prior to analysis (Moulton et al., 2000; Thorpe et al., 2019). While analyses presented in these original publications confirm that such samples are enriched in phyllosilicate mineral phases, it is unlikely that they are perfectly pure and may instead contain some finely ground primary minerals. Accordingly, we use these data as a loose guide on the composition of secondary phyllosilicates. Furthermore, for the data from Moulton et al. (2000), we consider their reported measurements with and without a correction for contamination from atmospheric deposition based on the $\mathrm{Cl}$ concentrations reported in the original publication and assuming seawater element to chloride ratios (see discussion in Stefánsson \& Gíslason, 2001).

\subsection{Solute mass balance modelling using MEANDIR}

\subsubsection{Overview}

Models for interpreting the chemical composition of rivers in terms of weathering processes range in complexity. For example, the mineral mass balance approach of Garrels and Mackenzie (1967) allows for multiple mineral phases to both dissolve and precipitate with the important constraint that the composition of each phase must be known (Moulton et al., 2000). In contrast, the inversion approach of Négrel et al. (1993) groups 
all silicate minerals together and does not allow for any secondary mineral formation, but is less demanding in terms of the prior knowledge required to employ the model. Here, we utilize an intermediate complexity approach that accounts for secondary mineral formation without the strict data requirements of a full mineral mass balance. Our method is similar to the approach of Bickle et al. (2015), but differs in that we consider secondary silicate phases rather than secondary carbonate phases and are more flexible in our definition of the silicate end-member. A full description of our inversion model is given in P. Kemeny and Torres (2021) and the associated software, titled "Mixing Elements and Dissolved Isotopes in Rivers (MEANDIR)", is available as MATLAB code. Below, we describe relevant aspects of the model and its application to the Icelandic dataset.

Based on expectations from prior research, we assume that rivers in Iceland source solutes from rain water, hydrothermal fluids, silicate mineral dissolution, low-Mg carbonate mineral dissolution, and sulfide mineral oxidation. Additionally, solutes may be removed by the formation of secondary clay minerals. For the silicate end-member, we utilize four separate components (i.e., one for each major cation). In effect, this results in 9 unique end-members. Using our solution scheme (see below), it is possible to solve for the fractional contributions from this set of 9 end-members using $\mathrm{Cl}, \mathrm{SO}_{4}, \mathrm{Na}, \mathrm{K}, \mathrm{Ca}$, $\mathrm{Mg}$, and Si concentration measurements alone, which are available for 537 quality-controlled river water samples. To evaluate the results we obtain using only major elements as model constraints, we perform additional simulations using the subset of river samples with additional trace element and isotopic data. Specifically, we use a subset of 24 samples with measurements of $\mathrm{Sr}$ concentrations, ${ }^{87} \mathrm{Sr} /{ }^{86} \mathrm{Sr}$, and $\delta^{44} \mathrm{Ca}$ as well as a subset of 7 river water samples where measurements of $\delta^{26} \mathrm{Mg}$ and $\delta^{30} \mathrm{Si}$ are also available in addition to $\mathrm{Ca}$ and $\mathrm{Sr}$ isotopic ratios.

\subsubsection{MEANDIR inversion equations}

For $\mathrm{Na}, \mathrm{K}, \mathrm{Ca}, \mathrm{Mg}, \mathrm{Sr}, \mathrm{Si}, \mathrm{SO}_{4}$, and $\mathrm{Cl}$, we utilize the mass balance equation:

$$
\left(\frac{X_{i}}{\Sigma^{ \pm}}\right)_{r i v}=\sum_{j=1}^{n} f_{j} \cdot\left(\frac{X_{i}}{\Sigma^{ \pm}}\right)_{j}
$$

where $X_{i} / \Sigma^{ \pm}$is the ratio of element $i$ to the sum of major cations ( $\mathrm{Na}, \mathrm{K}, \mathrm{Ca}$, and $\mathrm{Mg}$ ) and sulfate measured in a river sample (subscript riv) or assumed for an end-member (subscript $j$ ) and $f_{j}$ is the fractional contribution of end-member $j$ to the net budget of the normalization variable. To force primary minerals to dissolve and secondary minerals to precipitate, we constrain the model to only find solutions where the $f_{j}$ values are either positive (dissolution) or negative (precipitation) depending on the end-member.

To add strontium isotopic ratios to our mass balance framework, we utilize the equation:

$$
\left(\frac{87 S r}{86 S r}\right)_{r i v} \cdot\left(\frac{S r}{\Sigma^{ \pm}}\right)_{r i v}=\sum_{j=1}^{n} f_{j} \cdot\left(\frac{87 S r}{{ }^{86} S r}\right)_{j} \cdot\left(\frac{S r}{\Sigma^{ \pm}}\right)_{j}
$$

While Equation 3 represents a relatively standard approach for incorporating isotopic data into river inversion models (Négrel et al., 1993), we note that our application here is complicated by the fact that we allow for solutes to be removed from solution by secondary mineral formation (i.e., $f_{j}$ for the clay end-member is constrained to be $\leq 0$ ). Consequently, it is mathematically possible for the extent of clay formation to shift dissolved ${ }^{87} \mathrm{Sr} /{ }^{86} \mathrm{Sr}$ values if, for example, the isotopic composition of Sr supplied by weathering, atmospheric deposition, and/or hydrothermal inputs does not match the isotopic composition of $\mathrm{Sr}$ incorporated into clays. In order to avoid such a mathematical fractionation of ${ }^{87} \mathrm{Sr} /{ }^{86} \mathrm{Sr}$ by clay formation, we set the ${ }^{87} \mathrm{Sr} /{ }^{86} \mathrm{Sr}$ of clays to be equal to the weighted average isotopic composition of all of the solute sources in each model simulation.

In contrast to ${ }^{87} \mathrm{Sr} /{ }^{86} \mathrm{Sr}$, we do expect clay formation to naturally fractionate $\mathrm{Mg}$, $\mathrm{Si}$, and $\mathrm{Ca}$ isotopic ratios. Accordingly, we incorporate these isotopic systems using a 
different approach. To model the isotopic fractionation associated with clay formation, we adapt the model of Bouchez et al. (2013), which relates the isotopic composition of river water to the extent of element uptake using the expression:

$$
\delta_{\text {riv }}^{X}-\delta_{\text {source }}^{X}=F_{\text {clay }}^{X} \cdot \Delta^{X}
$$

where $\delta_{\text {riv }}^{X}$ is the isotopic ratio of element $\mathrm{X}$ measured in a river sample, $\delta_{\text {source }}^{X}$ is the contribution-weighted average isotopic ratio of element $\mathrm{X}$ supplied from all solute sources, $F_{\text {clay }}^{X}$ is the fraction of all of element $\mathrm{X}$ supplied to the weathering system that is taken up into secondary clays, and $\Delta^{X}$ is the fractionation factor for element $\mathrm{X}$ incorporation into secondary clays. We use the Bouchez et al. (2013) model as mixing in river systems causes departures from Rayleigh-type behavior that can be approximated by this type of linear model (Druhan \& Maher, 2017). For each simulation, $F_{\text {clay }}^{X}$ is constrained by the calculated $f_{j}$ values and selected end-member compositions. To determine $\delta_{\text {source }}^{X}$, we weight end-member isotopic ratios for rainwater, silicates, carbonates, and hydrothermal fluids (Table 1) by the inversion model results for their fractional contributions. We specify an allowable range for $\Delta^{X}$ for each isotopic system based on published experimental and field data (Section 2.3.5; Table 1).

\subsubsection{MEANDIR solution scheme}

We utilize a Monte-Carlo approach to sample the full range of possible end-member compositions. Specifically, we generated random sets of end-member ratios from their defined ranges assuming uniform distributions (Section 2.3.5; Table 1) excluding combinations that violated the unit sum constraint. All inversion model formulations are solved using a cost-function that minimizes the proportional error of each solute using the MATLAB function fmincon(). For isotopic systems expressed in delta notation, this approach requires converting the delta values to absolute isotopic ratios. When using only the major elements as model constraints, an additional Monte-Carlo draw of the relative contributions from the Na- and K-silicate end-members is necessary prior to performing the constrained optimization (see NaK-silicate end-member in Table 1). In effect, this makes the parameter search less efficient (i.e., more model iterations are required), but full range of possible silicate end-member compositions is still sampled.

For a given set of end-members, the constrained solution that minimizes the costfunction need not satisfy the observed mass or charge balance of the river water sample. In other words, it is possible that the products of the model predicted mixing fractions $\left(f_{j}\right)$ and constrained end-member compositions do not exactly match the river observations. This generic issue affecting most inversion models has various potential solutions, including accepting only a subset of "best-fitting" results (Torres et al., 2016; Hemingway et al., 2020). Here, we avoid poor-fitting parameter combinations by constraining the model to only accept simulations where the predicted values for all solute concentration ratios were within $\pm 20 \%$ of observations, predicted $\delta^{26} \mathrm{Mg}, \delta^{30} \mathrm{Si}$, and $\delta^{44} \mathrm{Ca}$ values were within $\pm 0.2 \%$ of observations, and predicted ${ }^{87} \mathrm{Sr} /{ }^{86} \mathrm{Sr}$ was within \pm 0.002 of observations. In effect, this approach accounts for the analytical uncertainty of the riverine measurements and, as means to cull poor-fitting simulations results, is preferable to accepting a fixed percentage of the best-fitting model results. We performed a sufficient number of simulations to generate either 500 (major elements only) or 200 (isotope constrained) results that matched the above constraints for each river sample. In a set of preliminary experiments, we generated 5000 isotope-constrained model results for a subset of samples and, by downsampling, verified that 200 results were sufficient for characterizing the posterior distributions.

\subsubsection{MEANDIR analysis and model metrics}

The calculated mixing fractions $\left(f_{j}\right)$ from MEANDIR are used to calculate the proportion of all weathering-derived cations (i.e., those sourced from both carbonate and 
silicate dissolution) that are sourced from carbonate weathering $(R)$ where:

$$
R=\frac{\Sigma_{\text {carbonate }}^{ \pm}}{\Sigma_{\text {carbonate }}^{ \pm}+\Sigma_{\text {silicate }}^{ \pm}}=\frac{f_{\text {carbonate }}}{f_{\text {carbonate }}+f_{\text {Na-silicate }}+f_{K-\text { silicate }}+f_{\text {Ca-silicate }}+f_{M g-\text { silicate }}}
$$

Because we assume that the silicate and carbonate end-members do not contribute to the $\mathrm{SO}_{4}$ budget, the calculated values of $R$ only reflect the cation contributions. Following Torres et al. (2016), we report $R$ in units of charge equivalents to match C cycle predictions based on alkalinity fluxes. We note here that $R$ can be calculated for both the gross weathering budget (before clay mineral formation; $R_{\text {gross }}$ ) and net weathering budget (after clay mineral formation; $R_{n e t}$ ) and that these two measures of $R$ need not be the same. For example, if clays only remove $\mathrm{K}$ from solution, which is a cation derived from silicate weathering and not carbonate weathering, then $R_{n e t}$ will be higher than $R_{\text {gross. }}$. This is discussed further in Section 4.3.1.

To characterize the degree of primary mineral incongruence, we combine the model results for the relative contributions from the multiple silicate end-members to determine the composition of the overall silicate end-member. Accordingly, the overall silicate endmember for each simulation is calculated by summing the products of the selected $\mathrm{X} / \Sigma^{ \pm}$ values for each of the individual silicate end-members and their calculated gross mixing fractions (i.e., the mixing fractions re-normalized to sum to 1). Using $\mathrm{Na}$ as an example, the fact that only the Na-silicate end-member contributes to the $\mathrm{Na}$ budget and that the value of $\mathrm{Na} / \Sigma^{ \pm}$for this end-member is 1 means that the $\mathrm{Na} / \Sigma^{ \pm}$of the overall silicate end-member can be calculated from the inversion results as

$$
N a / \Sigma_{\text {silicate }}^{ \pm}=\frac{f_{N a-\text { silicate }}}{f_{N a-\text { silicate }}+f_{K-\text { silicate }}+f_{\text {Ca-silicate }}+f_{M g-\text { silicate }}}
$$

Analogous equations can be written for the other cations. Again, because we assume that the silicate weathering does not contribute to the $\mathrm{SO}_{4}$ budget, ratios normalized to $\Sigma^{ \pm}$ and $\Sigma^{+}$are equivalent for the silicate end-members (i.e., $\mathrm{Na} / \Sigma_{\text {silicate }}^{ \pm}$calculated from the model can be compared directly with $\mathrm{Na} / \Sigma^{+}$values measured in basalts). Accordingly, we report all estimates of the composition of the overall silicate end-member as $X / \Sigma_{\text {silicate }}^{+}$values for clarity.

To assess secondary mineral congruence, we utilize the estimated fraction of the normalization variable taken up into secondary clays $\left(f_{\text {clay }}\right)$. Alone, this value represents the fraction of the observed concentration of $\Sigma^{ \pm}$that was taken up into secondary phases. So, we re-normalize $f_{\text {clay }}$ so that it instead expresses the fraction of gross solute release taken up into secondary phases $\left(F_{\text {clay }}^{\Sigma^{ \pm}}\right)$where:

$$
F_{\text {clay }}^{\Sigma^{ \pm}}=\frac{-f_{\text {clay }}}{1-f_{\text {clay }}}
$$

This equation assumes that the model perfectly reproduces the river observations, but can be adjusted slightly for cases where there is some mismatch between the model predictions and river observations. The value of $f_{\text {clay }}$ can also be combined with the individual $\mathrm{X} / \Sigma^{ \pm}$values for the clay end-member and gross elemental budgets to assess, for each element, the proportion of the gross solute release that was sequestered into secondary phases.

\subsubsection{End-member definitions}

For rainwater Na-, $\mathrm{K}-, \mathrm{Ca}-, \mathrm{Mg}-, \mathrm{Cl}-$, and $\mathrm{SO}_{4}$ to $\Sigma^{ \pm}$ratios, we use the full range of major element compositions displayed by monthly values at the Irafoss site in the EMEP. Further, we assume that rainwater contains negligible Si and that seawater Sr to Ca ratios can be used to estimate the rainwater $\mathrm{Sr}$ to $\Sigma^{ \pm}$ratio based on our assumed range of $\mathrm{Ca} / \Sigma^{ \pm}$. For rainwater $\mathrm{Ca}, \mathrm{Mg}$, and $\mathrm{Sr}$ isotopic ratios, we use seawater values assum- 
ing that seawater-derived aerosols are the primary source of these elements in rainwater.

For the hydrothermal end-member, we take the range defined by the measurements of samples in our database with temperatures over $100^{\circ} \mathrm{C}$ as these are assumed to better represent "pure" hydrothermal fluids. We assume that hydrothermal fluids contain negligible $\mathrm{Mg}\left(\mathrm{Mg} / \Sigma^{ \pm}=0\right)$ and allow $\mathrm{SO}_{4} / \Sigma^{ \pm}$to range from 0 to 0.1. For $\mathrm{Ca}, \mathrm{Mg}, \mathrm{Sr}$, and Si isotopic ratios, we use data from Elderfield and Greaves (1981), P. Pogge von Strandmann et al. (2008), Hindshaw et al. (2013), and Opfergelt et al. (2013).

For the carbonate end-member, we assume that it contains negligible amounts of $\mathrm{Na}$ and $\mathrm{K}$, but allow $\mathrm{Mg} / \Sigma^{+}$to range between 0 (stoichiometric carbonate) and 0.05 , which is in line with measurements of Icelandic carbonates (Harstad \& Stipp, 2007). We parameterize that $\mathrm{Sr} / \Sigma^{+}, \delta^{44} \mathrm{Ca}$, and ${ }^{87} \mathrm{Sr} /{ }^{86} \mathrm{Sr}$ of the carbonate end-member using measurements from Jacobson et al. (2015) and Andrews and Jacobson (2017). We use data from (P. A. E. Pogge von Strandmann, Olsson, et al., 2019) to parameterize the Mg isotopic composition of hydrothermal carbonate.

For the clay end-member, we make slight adjustments to the ranges of elemental ratios displayed by the data presented in Moulton et al. (2000) and Thorpe et al. (2019). Specifically, we allow for lower $\mathrm{Ca} / \Sigma^{ \pm}$values $(0.2$ to 0.45 instead of the 0.3 to 0.5 range displayed by the data) and higher $\mathrm{Mg} / \Sigma^{ \pm}$values (0.75 to 1 instead of the 0.3 to 0.4 range displayed by the data). These differences are justified because the grain-size separates from Moulton et al. (2000) and Thorpe et al. (2019) may contain some primary silicate minerals in addition to secondary phyllosilicates. Further, we allow $\mathrm{Si} / \Sigma^{ \pm}$to range between 2 and 10, which is wider than the observed range of 2.5 to 6 . The higher $\mathrm{Si} / \Sigma^{ \pm}$ values are included to account for the possibility of some formation of amorphous $\mathrm{Si}$ and/or aluminosilicates (e.g., allophane and immogolite) that may only sequester low concentrations of cations via adsorption. For $\mathrm{Sr} / \Sigma^{ \pm}$, we assume a wide range from $1 \times 10^{-5}$ to $3 \times 10^{-3}$ given the lack of direct measurements.

In lieu of specifying the $\mathrm{Ca}, \mathrm{Mg}$, and $\mathrm{Si}$ isotopic ratios of clay minerals, we instead specify a range of allowable fractionation factors for each isotope system. Moreover, we deliberately select a slightly wider range of fractionation factors relative to existing observations to account for uncertainties and limit the influence of a priori distribution on the modelling results. By examining the posterior distributions of fractionation factors, we are able to examine whether or not "extreme" values much greater than existing observations are required to explain the observations. For each isotopic system, we also allow for fractionation factors of $0 \%$, which, in effect, requires all observed variations in isotopic ratios to be driving by the mixing of isotopically distinct sources. So, even though we include clay minerals as a solute sink in our model, we are able to directly test their importance to isotopic budgets by including scenarios where they have no impact.

For $\mathrm{Si}$ isotopic ratios, we use a range of $\Delta^{30} \mathrm{Si}$ from -2 to $+1 \%$. Though most clays preferentially take up ${ }^{28} \mathrm{Si}$ (i.e., negative $\Delta^{30} \mathrm{Si}$; Ziegler, Chadwick, White, \& Brzezinski, 2005; Cornelis et al., 2014; Baronas et al., 2020), we allow for slightly positive Si fractionation factors given experimental data for amorphous Si (Roerdink et al., 2015; Zheng et al., 2019) and the possibility that it may serve as a precursor for clays and/or affect river chemistry by adsorbing cations. Likewise, we use a range from -1.5 to $+1 \%$ for $\Delta^{26} \mathrm{Mg}$ based on experimental data showing that the sign of the $\mathrm{Mg}$ fractionation factor can be variable for clays depending on the $\mathrm{Mg}-\mathrm{O}$ bond length (Hindshaw et al., 2020). For the Ca isotopic system, there is limited experimental data for clay minerals. Nevertheless, adsorption onto clay surfaces imparts a range of fractionation factors from 2.7 to +0.06 (Ockert et al., 2013; Brazier et al., 2019), though the largest fractionation factors are observed at seawater ionic strength. Accordingly, we use a prior distribution of $\Delta^{44} \mathrm{Ca}$ from -1.5 to +0.5 to account for the present uncertainty. 
For the composition of the silicate end-member, we use a novel approach that allows for primary mineral incongruent weathering. Specifically, we break the silicate endmember into four separate components: Na-silicate $\left(\mathrm{Na} / \Sigma^{ \pm}=1\right), \mathrm{K}$-silicate $\left(\mathrm{K} / \Sigma^{ \pm}=\right.$ 1), Ca-silicate $\left(\mathrm{Ca} / \Sigma^{ \pm}=1\right)$, and $\mathrm{Mg}$-silicate $\left(\mathrm{Mg} / \Sigma^{ \pm}=1\right)$. In effect, this allows the silicate end-member to take on any composition and uses the data to constrain the bestfitting values. This contrasts with the approach used in prior inversion models where a single silicate end-member is used and assumed to have a composition similar to bulk Icelandic basalts. In effect, this restricts the expression of primary mineral incongruence to the uncertainty assigned to the silicate end-member composition. We assign all silicate end-members the same prior distributions for $\mathrm{Sr} / \Sigma^{ \pm},{ }^{87} \mathrm{Sr} /{ }^{86} \mathrm{Sr}$, and $\delta^{30} \mathrm{Si}$. However, since each of the four silicate end-members are independent, they need not have identical values for these ratios in a given simulation. In effect, this captures the slight differences in isotopic ratios between igneous materials that results from magmatic differentiation (e.g., Savage et al., 2011). For Ca and Mg isotopic ratios, we use constraints from Jacobson et al. (2015), Andrews and Jacobson (2017), and P. Pogge von Strandmann et al. (2008).

\section{Results}

\subsection{Bedrock Chemistry}

Tholeiitic basalts represent $\sim 80 \%$ of the compiled database followed by rhyolite $(\sim 9 \%)$, dacite $(3 \%)$, trachyte $(2 \%)$, and to a lesser extent andesite, trachyandesite, trachybasalt, picro basalt and basanite $(\sim 6 \%)$. This generally matches the areal extent of basalt ( $80-$ $85 \%)$ and rhyolite $(\sim 10 \%)$ based on 1:250,000 scale geologic maps (Gíslason et al., 1996; Louvat et al., 2008).

Using the element to sum of major cations $\left(\mathrm{X} / \Sigma^{+}\right)$normalization, rhyolites and basalts define Na-rich and Ca-rich end-members, respectively (Figure 2). The other rock types (not shown) mostly have intermediate compositions between the rhyolite and basalt end-members, as expected. The values of $\mathrm{Na} / \Sigma^{+}$and $\mathrm{Ca} / \Sigma^{+}$for the culled basalts range from 0.07 to 0.33 and 0.31 to 0.55 , respectively with mean values of 0.18 and 0.44 , respectively. Rhyolite $\mathrm{Na} / \Sigma^{+}$and $\mathrm{Ca} / \Sigma^{+}$values range from 0.444 to 0.767 and 0.007 to 0.247 , respectively with an average $\mathrm{Na} / \Sigma^{+}$of $0.62(1 \sigma=0.04)$.

\subsection{Hydrochemical data ranges}

In the original publications from which our compilation is based, many of the general characteristics of the solute chemistry of natural waters in Iceland were discussed including proposed differences between water types (e.g., glacial versus non-glacial rivers). For completeness, we re-analyze and re-state some of these observations using our larger dataset. While we will primarily focus on the river water samples, various aspects of the other sample types are discussed as they relate to interpreting the river water samples. After quality control (Section 2.1.2), our database includes 96 rain water samples, 32 cold springs samples, 213 glacial river samples, 86 groundwater well samples, 154 hydrothermal fluid samples, 4 lake water samples, 93 multi-sourced river samples, 201 non-glacial river samples, 54 soil pore water samples, and 30 unclassified river samples. Initially, all of the reported concentrations or ratio values will be for samples where no correction for rainwater-derived solutes has been applied. In Section 3.5, we discuss the results of the inverse solute mass balance model, which allows us to correct the data for atmospheric and hydrothermal contributions.

For all of the river water samples, the concentrations of $\mathrm{Cl}, \mathrm{SO}_{4}, \mathrm{Na}, \mathrm{K}, \mathrm{Ca}, \mathrm{Mg}$, and $\mathrm{Si}$ have median values and ranges (given in parenthesis) of $77 \mu \mathrm{M}$ (9 to $1084 \mu \mathrm{M}$ ), $20 \mu \mathrm{M}(2$ to $2830 \mu \mathrm{M}), 238 \mu \mathrm{M}(22$ to $2780 \mu \mathrm{M}), 8 \mu \mathrm{M}(2$ to $225 \mu \mathrm{M}), 109 \mu \mathrm{M}$ ( 8 to 7780 $\mu \mathrm{M}), 58 \mu \mathrm{M}(7$ to $4330 \mu \mathrm{M})$, and $114 \mu \mathrm{M}(20$ to $764 \mu \mathrm{M})$, respectively (Figure 3$)$. River 


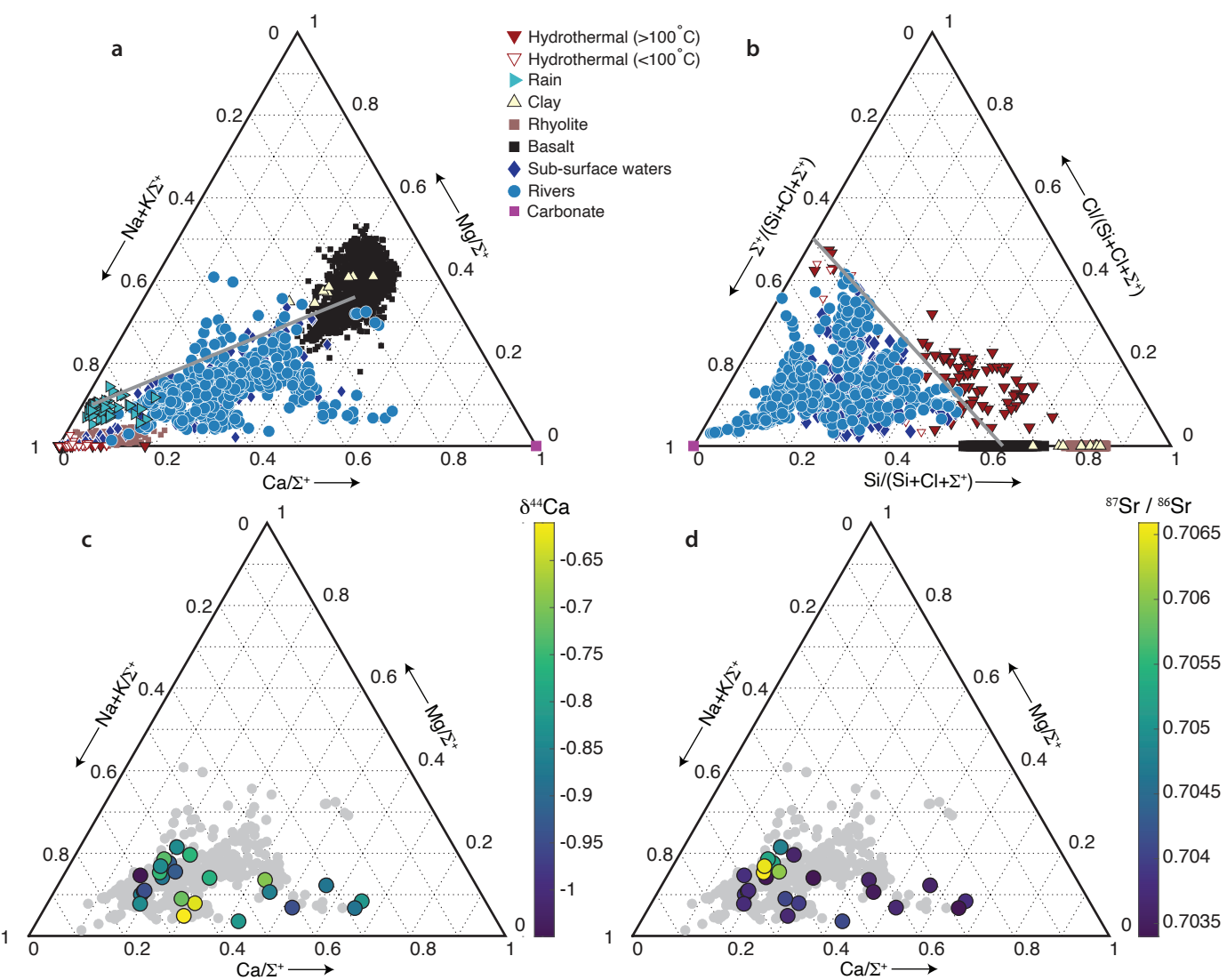

Figure 2. Solid and dissolved phase elemental ratios. (a) Ternary plot showing the proportions of $\mathrm{Na}+\mathrm{K}, \mathrm{Ca}$, and $\mathrm{Mg}$ in river waters (light blue circles), sub-surface waters (dark blue diamonds), rain (light blue triangle), hydrothermal fluids (red triangles), bulk basalts (black squares), bulk rhyolites (light red), clays (yellow triangles), and Ca-carbonates (purple square). (b) Ternary plot showing the proportions of $\Sigma^{+}$, Si, and $\mathrm{Cl}$ using the same symbology as panel a. In both panels a and $\mathrm{b}$, the grey line shows the expected mixing relationship between solutes sourced from basalt dissolution and atmospheric deposition with a seawater composition. (c) Ternary plot showing the proportions of $\mathrm{Na}+\mathrm{K}, \mathrm{Ca}$, and $\mathrm{Mg}$ in the river waters color-coded by $\delta^{44} \mathrm{Ca}$ (river samples without isotopic measurements are shown in gray). (d) same as in panel c, but with color-coding by ${ }^{87} \mathrm{Sr} /{ }^{86} \mathrm{Sr}$.

water temperatures range between -0.3 and $26{ }^{\circ} \mathrm{C}$ with a median of $5.2{ }^{\circ} \mathrm{C}$. River water $\mathrm{pH}$ ranges between 6 and 9.8 with a median of 7.6 . The river water samples tend to have higher concentrations of major solutes relative to rain waters (Figure 3), but are generally less concentrated than the sub-surface and hydrothermal waters. The river water samples have a similar, but slightly lower concentration of $\mathrm{Cl}$ compared to the monthly rain data, which may reflect contributions from snow/ice melt (Figure 3a). The sub-surface and hydrothermal waters tend to be much more concentrated in $\mathrm{Cl}$ relative to the river waters.

With or without removing outliers, a two sample Kolmogorov-Smirnov (K-S) test suggests significant differences in the distributions of solute concentrations, temperature, and $\mathrm{pH}$ between glacial and non-glacial rivers with the exception of $\mathrm{Na}$ concentrations, which are not significantly different between the two sample types (Figure 3c). In general, glacial river waters are lower in temperature, $\mathrm{K}, \mathrm{Si}$, and $\mathrm{Cl}$, but higher in $\mathrm{pH}, \mathrm{Ca}$, 

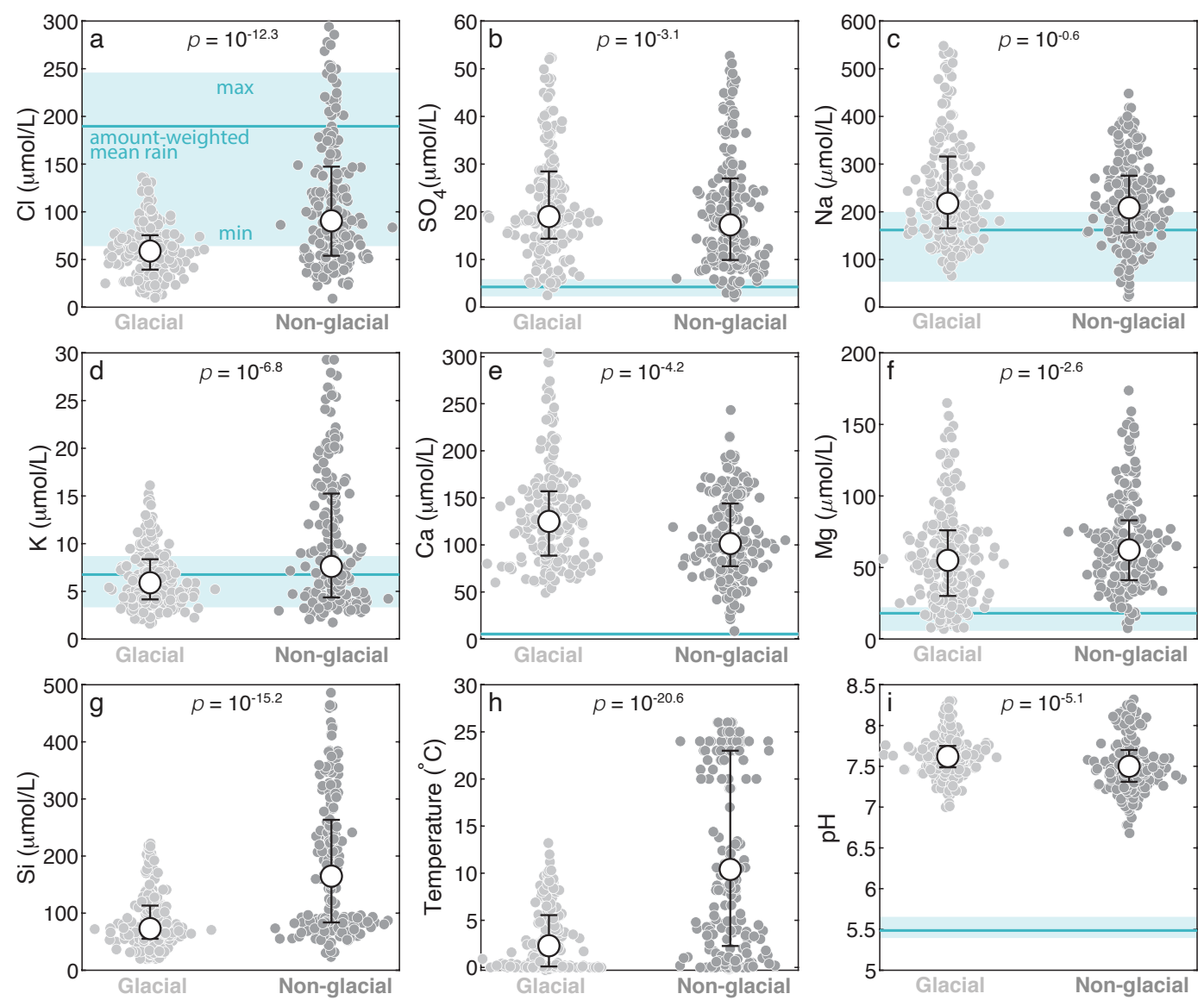

Figure 3. Jitter plots of solute concentrations, temperature, and $\mathrm{pH}$ for glacial (light gray) and non-glacial (dark gray) river waters. The black points indicate the median value for each data distribution and the range from the $25^{\text {th }}$ to $75^{\text {th }}$ percentiles of the data. Outliers from all data distributions have been removed for visualization and do not affect the outcomes of the Kolmogorov-Smirnov test used to asses differences between the data distributions (associated $p$ values are listed in each panel). The solid blue lines show the amount weighted mean values for rainwater from the Íráfoss site. The light blue rectangles show the range from the minimum to maximum rainwater values for each parameter. No rainwater values are shown for Si concentration (panel g) or temperature (panel h).

and $\mathrm{SO}_{4}$ relative to the non-glacial rivers (Figure 3). While glacial versus non-glacial rivers may reflect different data distributions, these distributions substantially overlap with each other for all measured properties (Figure 3).

When normalizing the river water data by sum of major cations $\left(\Sigma^{+}\right)$, the ratios $\mathrm{Na} / \Sigma^{+}, \mathrm{K} / \Sigma^{+}, \mathrm{Ca} / \Sigma^{+}, \mathrm{Mg} / \Sigma^{+}, \mathrm{Si} / \Sigma^{+}$, and $\mathrm{Cl} / \Sigma^{+}$have median values and ranges (given in parenthesis) of 0.55 (0.17 to 0.87 ), 0.02 (0.004 to 0.13 ), 0.26 (0.09 to 0.66 ), 0.15 (0.01 to 0.41$), 0.27$ (0.01 to 1.28 ), and 0.20 (0.03 to 0.87 ), respectively. These ranges do not exactly match what is observed in bulk basalts from the GEOROC database (Figure 2). In general, the river water data un-corrected for rainwater inputs are enriched in $\mathrm{Na} / \Sigma^{+}$ or, conversely, depleted in $\mathrm{Mg} / \Sigma^{+}$relative to bulk basalts (Figure 2a). Similar discrepancies are observed for the sub-surface water samples (Figure 2). As with the concentration data, a K-S test suggests significant differences in the distributions of elemen- 
tal ratios between glacial and non-glacial samples with the exception of $\mathrm{Na} / \Sigma^{+}$, which does not appear to have a significantly different distribution between the two river types. Relative to the non-glacial rivers, glacial rivers generally have higher $\mathrm{Ca} / \Sigma^{+}$values, but lower $\mathrm{K} / \Sigma^{+}, \mathrm{Mg} / \Sigma^{+}, \mathrm{Si} / \Sigma^{+}$, and $\mathrm{Cl} / \Sigma^{+}$values.

Atmospheric deposition and hydrothermal fluids are the only end-member water types that can contribute $\mathrm{Cl}$ to rivers. Most of the rain samples have $\mathrm{Cl} / \Sigma^{+}$values near 1 whereas hydrothermal fluids show lower and more variable $\mathrm{Cl} / \Sigma^{+}$values (Figure $2 \mathrm{~b}$ ). Both the rain water and hydrothermal fluid samples show elevated $\mathrm{Na} / \Sigma^{+}$values close to the seawater ratio of 0.86 (Figure $2 \mathrm{~b}$ ). Both the river and sub-surface waters are depleted in $\mathrm{Si} / \Sigma^{+}$relative to basalts, rhyolites, and hydrothermal fluids (Figure $2 \mathrm{~b}$ ).

\subsection{Saturation Indices}

Broadly, samples of most water types are under-saturated with respect to primary minerals (albite, anorthite, diopside, forsterite, calcite, and K-feldspar), but exceptions exists. For example, some river water samples are near saturation with respect to albite, K-feldspar, diopside, and calcite (Figure 4a,c,e,f). Most river water samples are supersaturated with respect to kaolinite and Ca-montmorillonite (Figure $4 \mathrm{~h}, \mathrm{k}$ ) whereas supersaturation with respect to illite, laumontite, sepiolite, and/or $\mathrm{AlOH}$, is less common or not observed (Figure $4 \mathrm{~g}, \mathrm{i}, \mathrm{j}, \mathrm{l}$ ). There is a tendency for the glacial rivers to show higher degrees of super-saturation with respect to the secondary minerals illite, kaolinite, and Ca-montmorillonite as compared to the non-glacial rivers (Figure $4 \mathrm{~g}, \mathrm{~h}, \mathrm{k}$ ). These results are broadly consistent with previous thermodynamic analyses of Icelandic rivers (e.g., Stefánsson et al., 2001).

\subsection{Principle Component Analysis}

When analyzing $c l r$-transformed $\mathrm{X} / \Sigma^{+}$values for a combined dataset of rivers and sub-surface water using PCA, $84 \%, 12 \%$, and $4 \%$ of the variance is explained by principle components 1, 2, and 3, respectively. The strongest variable loading on PC1 is for $\operatorname{clr}\left(\mathrm{Mg} / \Sigma^{+}\right)$(Figure 5). For PC2, the strongest variable loading is for $\operatorname{clr}\left(\mathrm{K} / \Sigma^{+}\right)$(Figure 5). A portion of the sub-surface water samples cluster together in PC1 separated from most of the river waters, which show higher PC1 values (Figure 5). The river water samples appear inconsistent with conservative mixing between solutes sourced from rainwater, hydrothermal fluids, as well as the dissolution of bulk basalts and/or bulk rhyolites (Figure 5b). This is because mixing relationships plot as a curve in (Figure 5b) that does not intersect with most of the data points. For the sub-surface water samples, PC1 scores are negatively correlated with the sample $\mathrm{pH}$ (Figure 5b).

\subsection{Source and sink apportionment}

Our solute mass balance model was able to reproduce all of the quality-controlled river water samples with valid mixing fractions with or without the added isotopic constraints. In Supplementary Figures S2-S5, we show the reconstructed river values for a subset of samples with $\mathrm{Mg}, \mathrm{Si}, \mathrm{Ca}$, and $\mathrm{Sr}$ isotopic ratios, which provides an assessment of how accurately the mixing fractions reproduce the observations. In Supplementary Figure S6, we show an example of how the slight model-data mismatches allowed in our analysis (see section 2.3.3) impact our results using the reconstructed value of ${ }^{87} \mathrm{Sr} /{ }^{86} \mathrm{Sr}$ and the predicted proportion of carbonate weathering $\left(R_{n e t}\right)$ as an example.

As we set our model to find up to 200 or 500 valid model results for each sample, each derived parameter, such as the net ratio of carbonate-derived cations to the sum of carbonate and silicate derived cations $\left(R_{n e t}\right.$; Equation 5$)$ is best described as a distribution of values (Figure 7). The exact shape of this distribution can be sensitive to the distributions used to draw end-member ratios and the applied simulation acceptance 

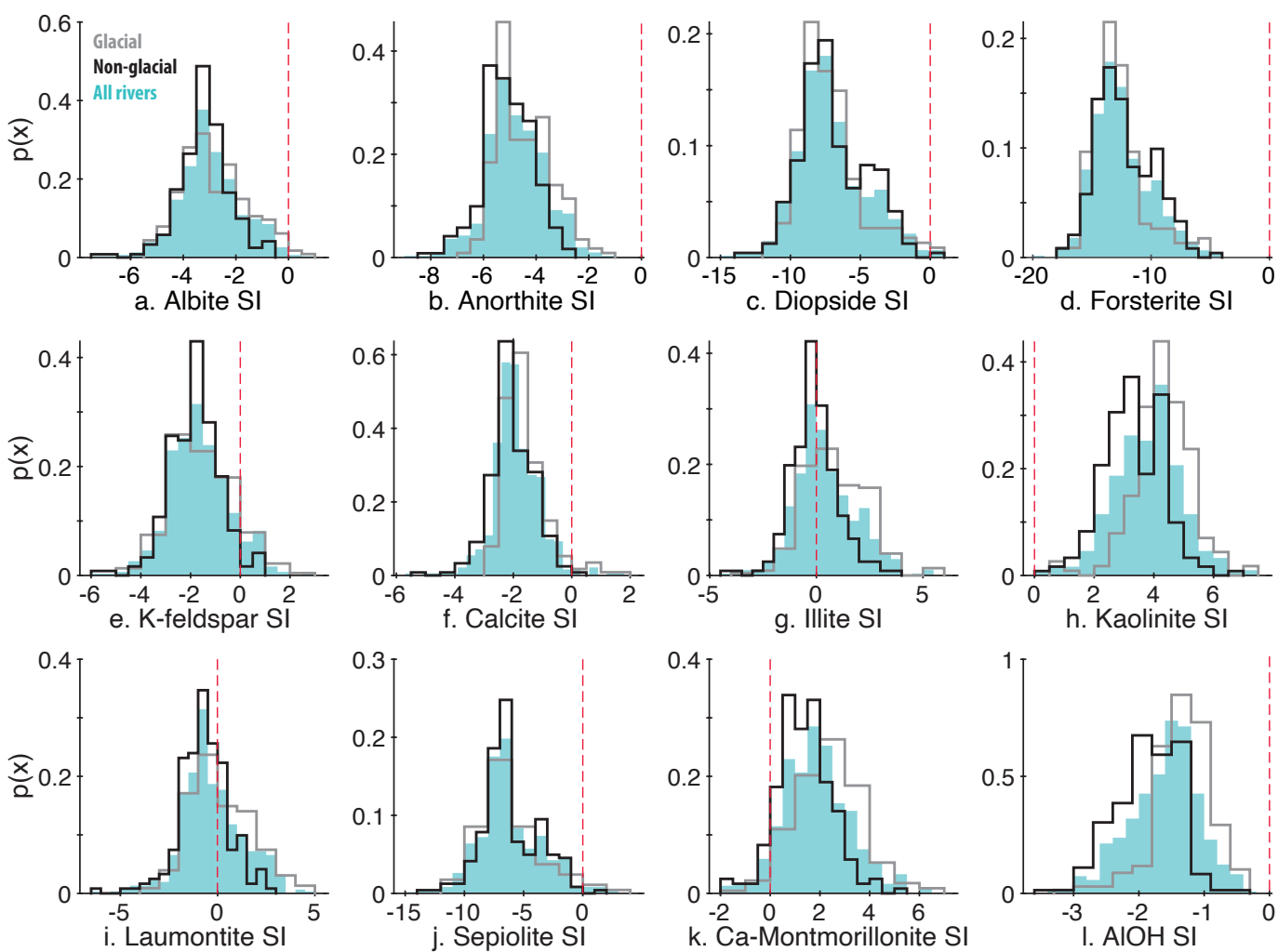

Figure 4. Probability density functions of mineral saturation indices for all rivers (filled light blue) and the subsets of glacial (open gray) and non-glacial (open black) rivers. The red dashed lines highlight a saturation index of 0 , which represents equilibrium.

criteria. As a result, the mean, median, or modal results need not be closer to the "true" value relative to some of the rarer results. To describe the distributions of model output variables, we calculate the $5^{\text {th }}, 25^{\text {th }}, 50^{\text {th }}, 75^{\text {th }}, 95^{\text {th }}$, and $99^{\text {th }}$ percentiles of the model results for each sample.

The a priori range of possible values span a known interval for all of the derived parameters we constrain with our model (i.e., $R_{\text {net }}$ can only range between 0 and 1 ). Therefore, the model provides new information when the range of results it returns spans a smaller range than the a priori range. For the parameters we investigate, which include $R_{\text {net }}$, the proportion of gross cation supply incorporated into clays $\left(F_{\text {clay }}^{\Sigma^{+}}\right)$, and the degree of primary mineral congruence, the model returns distributions that span narrower ranges than what is allowable and, as a result, these parameters are constrained by the model.

In addition to looking at the distributions of model parameters at the level of individual samples, we also look at the ranges of for each percentile across all samples. For example, we calculate the $5^{\text {th }}$ percentile of $F_{\text {clay }}^{\Sigma^{+}}$for each sample and then look at the distribution of the pooled $5^{\text {th }}$ percentile values. This approach of looking at the intersample distribution of a percentile value emphasizes the range of a particular statistic across all samples. Using the inter-sample distributions of pooled $95^{\text {th }}$ percentile values, we characterize the upper bound of a model result for "most" samples as the value that is higher than $60 \%$ of the samples. In Supplementary Figure 10, we show a schematic of our approach to visualizing the model results as inter-sample distributions of percentiles. 

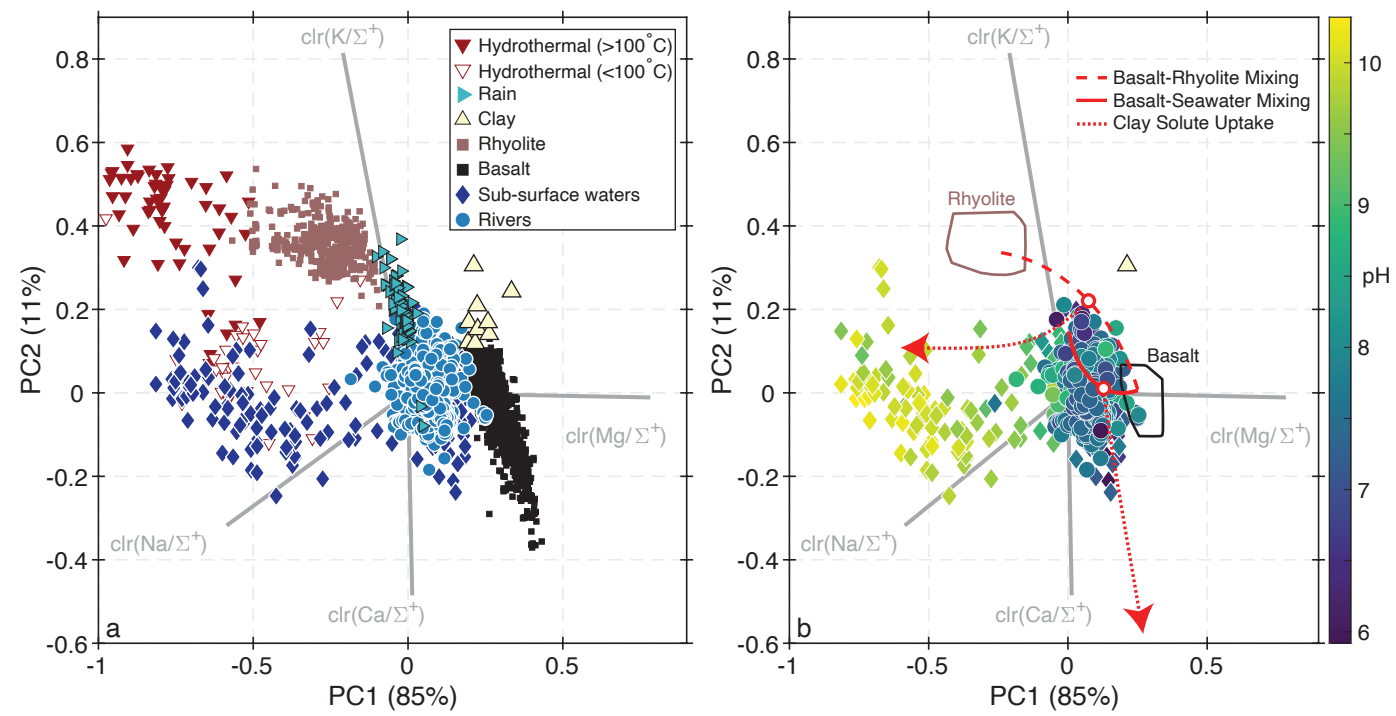

Figure 5. Principle component analysis using centered log-ratio (clr) transformed data. (a) Scatter plot of PC1 and PC2 defined using both the river (light blue circles) and sub-surface water (dark blue diamonds) datasets. Data for basalts (black squares), rhyolites (light red squares), hydrothermal fluids (red triangles), rain waters (light blue triangles), and clays (yellow triangles) are projected into the PCA space defined by the river and sub-surface water data. The gray lines show the principle component coefficients for the four clr-transformed variables. (b) PC1 and $\mathrm{PC} 2$ scores for the river (circles) and sub-surface water samples (diamonds) color-coded by $\mathrm{pH}$. The compositions of basalts and rhyolites are shown as outlines that encompass $90 \%$ of the variation in $\mathrm{PC} 1$ and $\mathrm{PC}$. The solid red line shows mixing between the mean basalt composition and seawater. The dashed red line shows mixing between mean basalt and mean rhyolite. The open red circles along each mixing line denote equal contributions from the end-members. The dotted red lines that originate from both mixing lines show the trends for clay solute uptake using the clay composition shown in the panel as a yellow triangle. These curves are modeled using Equation 2 .

\subsubsection{Predicted isotopic fractionation}

While isotopic data are only available for a small subset of our full dataset, they can offer important insights into the interpretation of the results derived using only major element concentrations as model constraints (Section 2.3). However, the degree to which the inversion model is constrained by including isotopic data depends on knowledge fractionation factors for the incorporation of elements into secondary minerals. Given limited direct measurements and/or experimental constraints (Section 2.3.5), we opted to include a wide range of values for a prior distributions of $\mathrm{Mg}$, $\mathrm{Si}$, and Ca fractionation factors (Equation 4). Using the posterior distributions of fractionation factors for each isotopic system, we can assess the model performance as, in some cases, values at the extreme ends of our prior distributions may be less likely and/or associated with specific processes or secondary mineral phases.

For Si isotopic ratios, all samples can be modelled with a negative fractionation factor $\left(\Delta^{30} \mathrm{Si}\right)$, which is the expectation for clay formation (Figure 6a; Ziegler, Chadwick, Brzezinski, \& Kelly, 2005; Cornelis et al., 2014; Baronas et al., 2020). Four out of the seven samples can be described by $\Delta^{30} \mathrm{Si}$ greater than or equal to zero, which is the expectation for amorphous Si (Roerdink et al., 2015; Zheng et al., 2019). Similarly, For Mg 


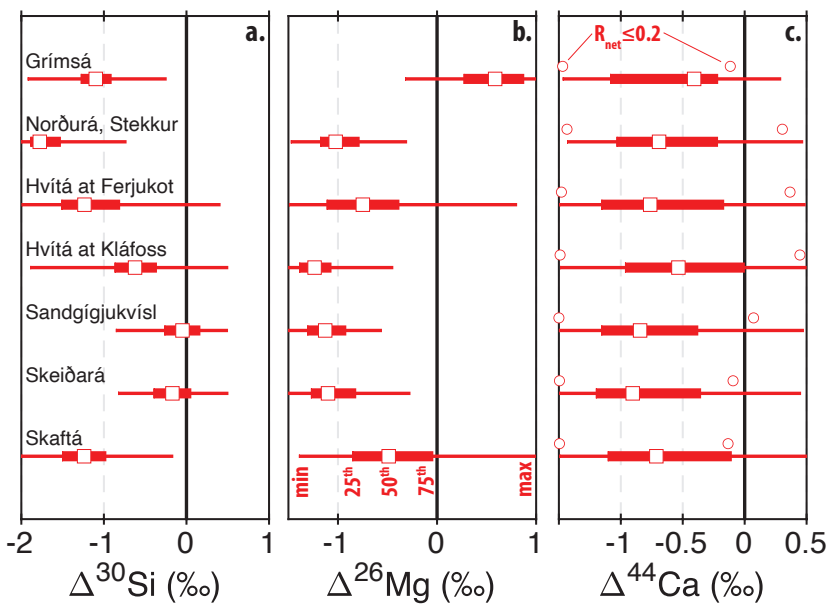

Figure 6. Inversion-constrained fractionation factors (Equation 4) for Si (panel a), Mg (panel b) and $\mathrm{Ca}$ (panel c) isotopic ratios. In each panel, the $\mathrm{x}$-axis scale spans the range of the prior distribution for each isotopic system. For each sample, the range from minimum to maximum allowable fractionation factor is shown as the thin bar. The thick bar shows the range from the $25^{\text {th }}$ to $75^{\text {th }}$ percentiles. The white square shows the median result. In panel c, the circles show that minimum to maximum range in $\Delta^{44} \mathrm{Ca}$ for each sample for the subset of simulations where the proportion of carbonate weathering $\left(R_{n e t}\right)$ is less than 0.2 .

isotopic ratios, all of the samples can be modeled with negative fractionation factors (Figure $6 \mathrm{~b}$ ), which is the expectation for smectite-group clays (Hindshaw et al., 2020). As with $\mathrm{Si}, \Delta^{26} \mathrm{Mg} \geq 0$ is allowable for three out of the seven samples.

Unlike for $\mathrm{Si}$ and $\mathrm{Mg}$ isotopic ratios, the posterior distributions of $\Delta^{44} \mathrm{Ca}$ values span nearly the same range as the prior distributions (Figure 6c). So, both positive and negative $\mathrm{Ca}$ isotopic fractionations are allowable. Similarly, all of the data can be modeled assuming that clay minerals do not fractionate $\mathrm{Ca}$ isotopic ratios (i.e., $\Delta^{44} \mathrm{Ca}=0$ ). Given that both carbonate dissolution and clay formation with a negative $\Delta^{44} \mathrm{Ca}$ value would tend to increase riverine $\delta^{44} \mathrm{Ca}$ (Hindshaw et al., 2013; Jacobson et al., 2015), it is reasonable to expect a trade-off where simulations with lower proportions of carbonate weathering $\left(R_{n e t}\right)$ are associated with lower $\Delta^{44}$ Ca values and vice versa. Such a tradeoff would be important to recognize as the limited experimental data for freshwater systems suggest $\Delta^{44} \mathrm{Ca}$ values of -0.1 to $-0.3 \%$ (Hindshaw et al., 2013; Brazier et al., 2019) rather than values closer to the lower bound of our prior distribution, which is informed on experiments conducted at high ionic strength (Ockert et al., 2013) and the range of global riverine measurements (Bouchez et al., 2013). With this in mind, we report the range of $\Delta^{44} \mathrm{Ca}$ values for the subset of simulations in each sample where $R_{n e t}$ is less than or equal to 0.2 (i.e., no more than $20 \%$ of the sum of carbonate and silicate alkalinity is derived from carbonate weathering in units of charge equivalents). While this range is shifted to lower $\Delta^{44} \mathrm{Ca}$ values relative to the full range of model simulations (Figure $6 \mathrm{c}$ ), there are still simulations for each sample where $\Delta^{44} \mathrm{Ca}$ values are entirely compatible with known Ca isotopic fractionation factors for adsorption onto clay surfaces in freshwater (Brazier et al., 2019). So, while our data can be modeled with large, negative $\Delta^{44} \mathrm{Ca}$ values, such values are not necessary to reproduce the observations even when assuming low contributions from carbonate weathering. 


\subsubsection{Comparison between results with and without added isotopic con- straints}

Given the ability of our model to fit all of the river samples with isotopic measurements using reasonable values for $\mathrm{Mg}, \mathrm{Si}$, and $\mathrm{Ca}$ fractionation factors (Figure 6), we can compare the results obtained using isotopic constraints to those obtained using only major element data for the same sample set (Figures 7). The purpose of this comparison is to identify whether or not including isotopic data substantially modifies the model results for the proportion of carbonate weathering $\left(R_{n e t}\right)$, the fraction of gross solute supply taken up into secondary clays $\left(F_{\text {clay }}^{ \pm}\right)$and the overall composition of the silicate endmember $\left(N a / \Sigma_{\text {sil }}^{+}\right)$. Ultimately, identifying any systematic differences will help us to better interpret the model results for the majority of samples where only major element data are available. We note, however, that the river samples with isotopic data do not span the full range of geochemical variability observed for all rivers in Iceland (Figure 2c,d). Specifically, Mg- and Ca-rich river water samples similar in composition to bulk Icelandic basalts have not been characterized for their $\mathrm{Mg}$, Si, Ca, or $\mathrm{Sr}$ isotopic compositions (Figure $2 \mathrm{c}, \mathrm{d})$.

For our estimates of $R_{n e t}$, the median results using isotopic constraints tend to be higher than the results using only major elements constraints (Figures 7a). However, in most cases, the $25^{\text {th }}$ to $75^{\text {th }}$ percentile ranges of $R_{n e t}$ values overlap for the model results with and without isotopic constraints (Figures 7a). In other words, the upper and lower bounds tend to be similar with and without isotopic constraints, but, within those bounds, the shape of the distribution can be substantially different (Figure 7a,d,g,j,m).

For $F_{\text {clay }}^{\Sigma^{+}}$, including isotopic constraints tends to decrease the median values for most samples (Figure $7 \mathrm{~b}$ ). In some cases, the upper bound on $F_{\text {clay }}^{\Sigma^{+}}$markedly decreases when isotopic constraints are included (e.g., Figure 7e,h). Accordingly, adding isotopic constraints appears to help to bound the role of cation uptake into clays. As such, the highest values of $F_{\text {clay }}^{\Sigma^{+}}$predicted for a sample using only major elements as constraints is likely an over-estimate for this parameter.

For $\mathrm{Na} / \Sigma_{\text {sil }}^{+}$, added isotopic constraints slightly increases the median values for most samples (Figure $7 \mathrm{c}$ ). Given the changes in both $F_{\text {clay }}^{\Sigma^{+}}$and $\mathrm{Na} / \Sigma_{\text {sil }}^{+}$, including isotopic constraints tends to favor results where there is relatively less secondary mineral incongruence and relatively more primary mineral incongruence (Figure 7b,c). For the sample set we test (Figure 2c,d), using $\delta^{26} \mathrm{Mg}$ and $\delta^{30} \mathrm{Si}$ as added constraints does not substantially change the distribution of model results relative to using just $\delta^{44} \mathrm{Ca}$ and ${ }^{87} \mathrm{Sr} /{ }^{86} \mathrm{Sr}$ (e.g., Figure 7d,f,k), but slight differences are apparent for some samples (e.g., Figure $7 \mathrm{j}, 1)$.

While there are coherent differences in median values of $R_{n e t}, F_{\text {clay }}^{ \pm}$, and $\mathrm{Na} / \Sigma_{\text {sil }}^{+}$ with and without the added constraints from isotopic ratios (Figure $7 \mathrm{a}-\mathrm{c}$ ), the different distributions tend to show very similar ranges for a given sample (e.g., Figure 7d,k). Therefore, it is likely reasonable to use the major element only version of the model to place upper and/or lower bounds on the model parameters for each sample. While the major element only model can overestimate the upper bound on $F_{\text {clay }}^{\Sigma^{+}}($e.g., Figure $7 \mathrm{e})$, the differences between the model results and without isotopic constraints vary by about 0.1 (Figure $7 \mathrm{~b}$ ), which provides some guidance for how precisely the results can be interpreted. For $\mathrm{Na} / \Sigma_{\text {sil }}^{+}$, the observation that the major element only model tends to under-predict this ratio (Figure 7c) suggests that the lower bound calculated using major elements alone is a conservative estimate. 
major element compared with isotope-constrained model (median \& range from $25^{\text {th }}$ to $75^{\text {th }}$ percentiles)
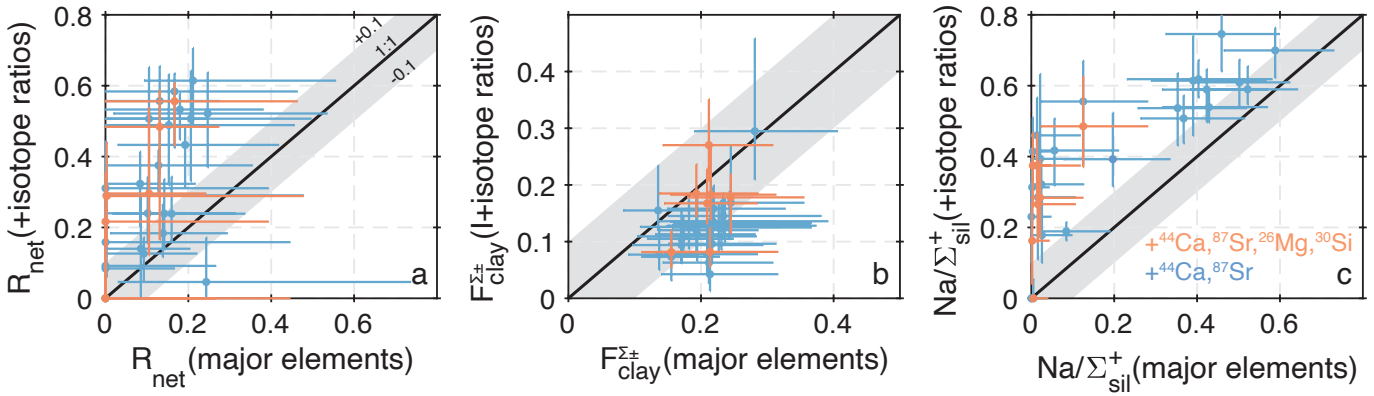

major element compared with isotope-constrained model (full distributions for select samples)
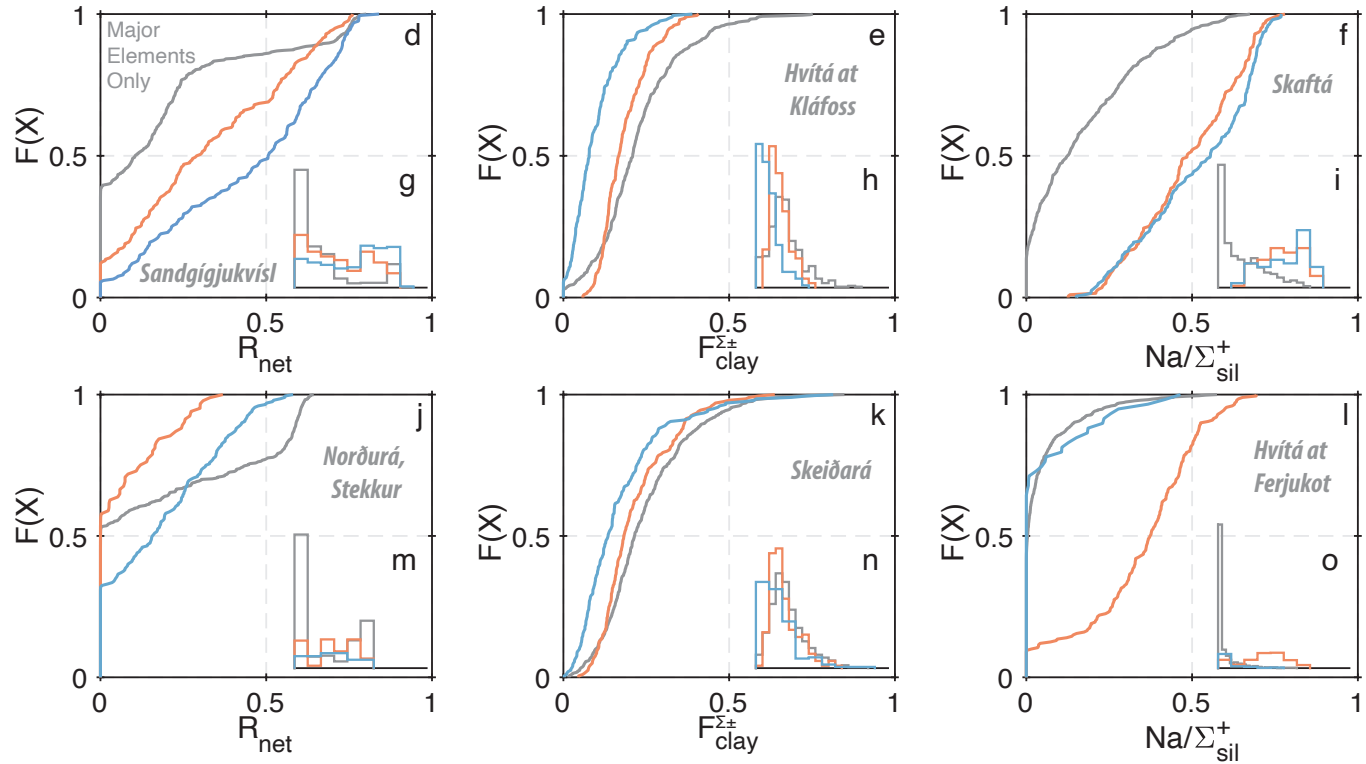

Figure 7. Comparison of solute mass balance model results with and without added isotopic constraints. Panels a-c compare the median (point) and $25^{\text {th }}$ to $75^{\text {th }}$ percentile range (error bar) results calculated using major elements only (x-axis) with the results calculated using added isotopic constraints for the proportion of carbonate weathering $\left(R_{n e t}\right.$; Equation 5; panel a), the fraction of solute uptake into clay $\left(F_{\text {clay }}^{ \pm}\right.$; Equation 7 ; panel b), and the $\mathrm{Na} / \Sigma^{+}$of the silicate end-member (Equation 6; panel c). For the results using isotopic constraints, we show the 24 samples with $\mathrm{Ca}$ and $\mathrm{Sr}$ isotopic data in blue. Seven of these 24 samples have additional measurements of $\mathrm{Mg}$ and $\mathrm{Si}$ isotopic ratios, so we show the inversion results using all 4 isotopic ratios in orange. The black line in the panel shows a 1:1 relationship with the gray shading showing \pm 0.1 . Panels d-o show full intra-sample distributions for the three model parameters using 6 individual rivers (Grimsá River not shown) where either major elements (gray), Ca and Sr isotopic ratios (solid blue), or $\mathrm{Mg}, \mathrm{Si}, \mathrm{Ca}$, and $\mathrm{Sr}$ isotopic ratios (solid orange) are used as model constraints. The main panels show cumulative distribution functions (panels d, e, f, j, k, and l) and the inset panels show probability density functions (panels $\mathrm{g}, \mathrm{h}, \mathrm{i}, \mathrm{m}, \mathrm{n}$ and o).

\section{Discussion}

Conservative mixing between solutes sourced from congruent basalt dissolution and atmospheric deposition fails to explain a majority of the river and sub-surface water data from Iceland (Figures 2, 5). This observation has been previously stated in some of the original literature from which our compilation is based (e.g., Gíslason et al., 1996), al- 
beit sometimes using different wording and/or data analysis techniques. Nevertheless, multiple competing mechanisms exist to explain this discrepancy between the null hypothesis for basaltic watersheds (congruent basalt weathering and atmospheric deposition are the sole solute sources) and the observations from Iceland.

The uptake of cations in secondary clays (secondary phase incongruence; Gíslason et al., 1996; Moulton et al., 2000; Stefánsson et al., 2001; Hindshaw et al., 2013), the dissolution of rhyolites (Louvat et al., 2008), and the dissolution of hydrothermal calcite (Georg et al., 2007; Jacobson et al., 2015; Andrews \& Jacobson, 2017) have all been proposed as additional factors that influence the chemical composition of Icelandic rivers. Here, we also consider the potential for individual minerals to react at distinct rates yielding a different geochemical signature than bulk basalt (primary mineral incongruence). To explore the different hypotheses and help discern their relative importance, we first analyze the data using mixing diagrams and then test the resulting inferences using the solute mass balance model. It is important to use these two steps together as individual mixing diagrams are often non-unique in their interpretation, but require few a priori assumptions about the underlying processes. While the solute mass balance model leverages all available constraints at once, it requires more restrictive assumptions about the compositions of solute sources and sinks.

As detailed below, we find evidence that both primary and secondary mineral incongruence contribute to observed chemical composition of Icelandic rivers. Carbonate weathering is not strictly required by any of the river water samples in our database, but carbonate contributions are permissible in all samples. In order for carbonate weathering to contribute more to the total cation budget, the relative importance of incongruent weathering must be increased. Below, we describe the evidence for each of these findings, discuss the apparent differences between water sample types (i.e., glacial versus nonglacial and river vs. sub-surface), and provide potential mechanisms underlying the apparently incongruent weathering taking place in Iceland.

\subsection{Evidence for cation uptake by secondary clays (secondary phase in- congruence)}

A majority of the river water samples are relatively depleted in $\mathrm{Mg}, \mathrm{K}$, and Si relative to what would be expected from conservative mixing between solutes sourced from basalt dissolution and atmospheric deposition (Figure 2a,b). Interpreting this to reflect some uptake of $\mathrm{Si}, \mathrm{Mg}$, and $\mathrm{K}$ into secondary clays is consistent with our PHREEQC calculations of super-saturation with respect to clays (Figure $4 \mathrm{~g}, \mathrm{~h}, \mathrm{i}, \mathrm{j}, \mathrm{k}$ ) as well as available measurements of fine-grained sediments in Iceland, which can be enriched in $\mathrm{Si}, \mathrm{Mg}$, and K relative to bulk basalts (Figure 2a,b; Moulton et al., 2000; Thorpe et al., 2019). Selectively removing a specific cation or set of cations affects all element to $\Sigma^{+}$ratios by modifying the denominator term. Assuming clays do not take up much $\mathrm{Na}$, which is consistent with the available sediment measurements (Figure 2; Moulton et al., 2000; Thorpe et al., 2019), clay formation would act to increase $\mathrm{Na} / \Sigma^{+}$relative to what is expected for basalt dissolution and atmospheric deposition (Figure $5 \mathrm{~b}$ ). Such enrichment in $\mathrm{Na} / \Sigma^{+}$ is observed in most of the river water data (Figure 2a).

In principle, the extent of Mg-depletion and Na-enrichment could be due to contributions from hydrothermal fluids (Figure 2a), though this would not explain the observed extent of Si depletion as most hydrothermal fluids have high $\mathrm{Si} / \Sigma^{+}$(Figure $2 \mathrm{~b}$ ). While such a scenario appears plausible when looking at individual mixing diagrams, visualizing the data using PCA more clearly shows that the extent of Na-enrichment in the river water data is unlikely to be driven exclusively by hydrothermal contributions (Figure 5a). Relative to conservative mixing between rain water and bulk basalts, the river water data are shifted in PC1 and/or PC2 (Figure 5). The low PC2 scores of the river water data do not match expectations for hydrothermal fluid contributions as this 
end-member is characterized by much higher PC2 scores (Figure 5a). These interpretations based on the PCA are consistent with the results of the isotope-constrained mixing model, which constrains the gross contribution of hydrothermal fluids to the $\Sigma^{+}+\mathrm{SO}_{4}$ budget to be less $20 \%$ using the median values for 22 of the 24 samples constrained with $\mathrm{Ca}$ and $\mathrm{Sr}$ isotopic ratios (the Sandgígjukvísl and Grimsá River have higher median hydrothermal contributions of $31 \%$ and $43 \%$, respectively).

The uptake of cations into clay minerals in Icelandic watersheds has been suggested previously using the concentrations and isotopic compositions of both major and trace elements in both the solid and dissolved phase (Gíslason et al., 1996; Moulton et al., 2000; Stefánsson et al., 2001; P. A. Pogge von Strandmann et al., 2006; Georg et al., 2007; Vigier et al., 2009; Ehlmann et al., 2012; Hindshaw et al., 2013; Thorpe et al., 2019). Nevertheless, the magnitude of cation uptake remains poorly constrained on account of differences between the methods used to quantify clay uptake in prior work as well as few direct measurements of clay compositions. Using the solute mass balance, we refine estimates of clay cation uptake for all of the samples with major element data. Importantly, differences between the MEANDIR model results with and without isotopic constraints suggest that the major element only version of the model slightly over-estimates the maximum allowable amount of cation uptake into clays (Figure $7 f, 1)$. Below, we account for this by using estimates of the $95^{\text {th }}$ percentile for each sample distribution. Moreover, we do not use the largest $95^{\text {th }}$ percentile value from the pool of all river sample distributions and instead find the value that is greater than $60 \%$ of the samples and use this as an upper bound.

Taking into account model biases, we estimate that no more than $\sim 60 \%$ of the cations released by weathering (or provided by atmospheric deposition and/or hydrothermal fluid discharge) is likely taken up into secondary clays (Figure 8a). A few samples allow for zero cation uptake into clays whereas others require, at a minimum, $\sim 10 \%$ of the total cation supply to have been sequestered into secondary clays (see upper bound of $5^{\text {th }}$ percentile curve in Figure 8a). For $\mathrm{Mg}$ and $\mathrm{K}$, clay formation tends to account for a larger proportion of the gross solute release compared to $\mathrm{Na}$ and $\mathrm{Ca}$ (Figure 8b-e). The distribution of $95^{\text {th }}$ percentile values suggest that, for most $(60 \%)$ samples, up to roughly $26 \%, 95 \%, 67 \%, 81 \%$, and $95 \%$ of $\mathrm{Na}, \mathrm{K}, \mathrm{Ca}, \mathrm{Mg}$, and $\mathrm{Si}$ are taken up to clays, respectively (Figure 8b-f). Using the distribution of median values, most samples suggest that up to roughly $6 \%, 81 \%, 30 \%, 45 \%, 90 \%$ of $\mathrm{Na}, \mathrm{K}, \mathrm{Ca}, \mathrm{Mg}$, and $\mathrm{Si}$ are taken up to secondary clays, respectively (Figure $8 \mathrm{~b}-\mathrm{f}$ ).

\subsection{Evidence for preferential $\mathrm{Na}$ release from silicates (primary mineral incongruent weathering)}

While clay mineral formation acts to increase riverine $\mathrm{Na} / \Sigma^{+}$, it is likely insufficient to explain the full extent of $\mathrm{Na}$ enrichment evident in the river water data such that an additional mechanism for $\mathrm{Na}$ enrichment is required. In part, this is because the magnitude of cation uptake into clays is limited by the Si budget (Figure 8f) and the relatively low $\Sigma^{+} /$Si ratios of measured Icelandic clays (Figure $2 \mathrm{~b}$ ). While contributions from atmospheric deposition and/or hydrothermal fluids also act to increase $\mathrm{Na} / \Sigma^{+}$, this mechanism cannot explain the high $\mathrm{Na} / \Sigma^{+}$values observed for river samples with relatively low $\mathrm{Cl} / \Sigma^{+}$(Figure $2 \mathrm{~b}$ ). To explore the possibility of preferential Na-release from rocks $/$ minerals, we utilize our reconstruction of the overall silicate end-member from the four individual components (Equation 6).

For many river water samples, the calculated overall silicate end-member using the default model does not match the $\mathrm{Na}+\mathrm{K} / \Sigma^{+}, \mathrm{Ca} / \Sigma^{+}$, and $\mathrm{Mg} / \Sigma^{+}$values observed for bulk basalts in the GEOROC database (Figure 9). Instead, the model returns an overall silicate end-member that is relatively depleted in $\mathrm{Ca}$ and enriched in $\mathrm{Na}$ compared to bulk basalts (Figure 9). The visualization in Figure 9a shows the calculated silicate 

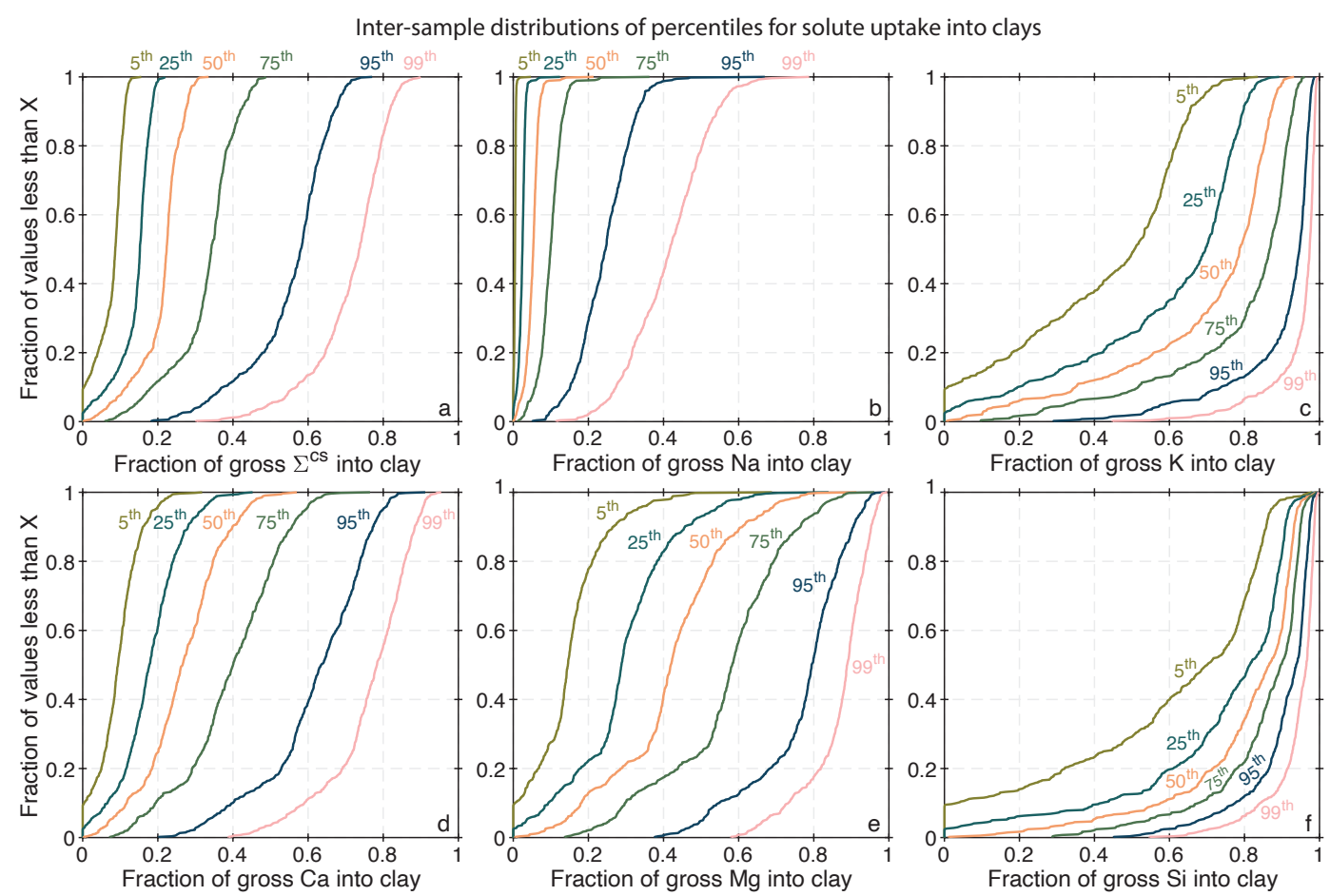

Figure 8. Fractions of gross solute release sequestered into secondary clays. Each panel shows the inter-sample variability (as an empirical cumulative distribution function) in the $5^{\text {th }}, 25^{\text {th }}$, $50^{\text {th }}, 75^{\text {th }}, 95^{\text {th }}$, and $99^{\text {th }}$ percentiles calculated from the 500 simulations for each sample. For example, the blue curve labeled " $95^{\text {th }}$ " in panel a shows the range in the $95^{\text {th }}$ percentile of the fraction of gross $\Sigma^{+}$sequestered into secondary clay calculated from each individual sample. Panels a-d show the fraction of the gross amount of $\Sigma^{+}$, Na, K, Ca, Mg, and Si sourced to each sample that was sequestered into secondary clays, respectively.

end-member compositions for all of the river water samples using only major elements as model constraints. For clarity, results where $\mathrm{Na} / \Sigma_{\text {sil }}^{+}, \mathrm{Ca} / \Sigma_{\text {sil }}^{+}$, or $\mathrm{Mg} / \Sigma_{\text {sil }}^{+}$were less than 0.01 or $\mathrm{K} / \Sigma_{\text {sil }}^{+}$was less than 0.001 were filtered out. By grouping all of the data together, this visualization highlights the silicate end-member compositions that are shared by the most samples. The modal result in Figure $9 \mathrm{a}$ is outside of the $1^{\text {st }}$ to $99^{\text {th }}$ percentile range of basaltic compositions and falls along the mixing trend from basaltic to rhyolitic rock compositions (i.e., it is more Na-rich than expected for the congruent weathering of basalts).

While Figure 9a emphasizes end-member compositions that are shared between river samples, it is also the case that different river samples are characterized by different silicate end-member compositions. In Figure $9 \mathrm{~b}$, we show the $5^{\text {th }}$ to $95^{\text {th }}$ percentile results for the inversion constrained $\mathrm{Na} / \Sigma^{+}$value for the silicate end-member using the 24 samples with $\mathrm{Ca}$ and $\mathrm{Sr}$ isotopic constraints. In 9 of these samples, $\mathrm{Na} / \Sigma_{\text {sil }}^{+}$is higher than bulk Icelandic basalts (Figure $9 \mathrm{~b}$ ). In contrast, only 4 samples return model results that only match basaltic $\mathrm{Na} / \Sigma_{\text {sil }}^{+}$values (Figure $9 \mathrm{~b}$ ). The remaining 11 samples can be fit by either a basaltic or rhyolitic $\mathrm{Na} / \Sigma_{\text {sil }}^{+}$value (Figure $9 \mathrm{~b}$ ). 

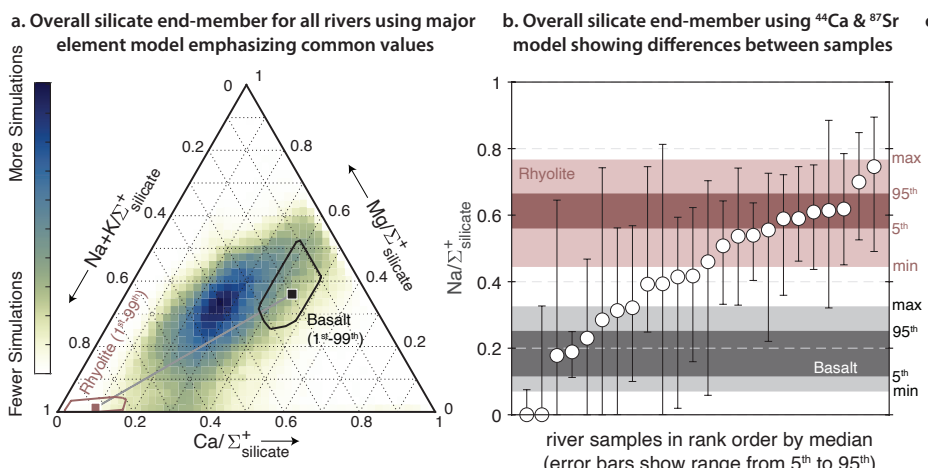

c. Overall silicate end-member for all simulations from isotope-constrained samples showing incongruence

Figure 9. Inversion constrained composition of the silicate end-member. (a) ternary diagram of the proportions of $\mathrm{Na}+\mathrm{K}, \mathrm{Ca}$, and $\mathrm{Mg}$. The MEANDIR results using only major element data are represented as a $2 \mathrm{D}$ histogram where darker colors reflect more simulations from each sample producing an end-member composition with that particular value. For comparison, we show the compositions of basalts and rhyolites as black and light red squares with outlines that encompass $98 \%$ of the measured variability. The gray line connecting the black and light red squares is the mixing line between mean basalt and mean rhyolite. (b) Inversion constrained values for the $\mathrm{Na} / \Sigma^{+}$using $\mathrm{Ca}$ and $\mathrm{Sr}$ isotopic data as model constraints. The white circles show the median values calculated using the model and the error bars show the range from the $5^{\text {th }}$ to $95^{\text {th }}$ percentiles. For comparison, we show the minimum/maximum (light shading) and $5^{\text {th }} / 95^{\text {th }}$ percentile (dark shading) ranges of $\mathrm{Na} / \Sigma^{+}$for Icelandic basalts (black) and rhyolites (light red). (c) Incongruent release of $\mathrm{Na}$ relative to $\mathrm{K}$ evident in the isotope-constrained solute mass balance model simulations. The blue ( $\mathrm{Ca}$ and $\mathrm{Sr}$ isotope constrained; $\mathrm{n}=24)$ and orange $(\mathrm{Mg}, \mathrm{Si}, \mathrm{Ca}$, and Sr isotope constraints; $n=7$ ) points show the predicted composition of the silicate end-member for each individual simulation for all rivers considered. Similar results (i.e., incongruent release of Na relative to K) are also obtained using only major elements as constraints.

\subsubsection{Potential mechanisms of preferential Na release during silicate weathering}

Roughly $10 \%$ of Iceland is underlain by rhyolitic bedrock (Gíslason et al., 1996; Louvat et al., 2008), fine-grained rhyolitic tephra is deposited on catchment surfaces by local volcanic eruptions (Larsen \& Eiriksson, 2008; Óskarsson et al., 2012), rhyolitic glass can be present as an interstitial phase in basalts (Meyer \& Sigurdsson, 1978) and, in laboratory experiments, rhyolitic glass dissolves as fast as crystalline basalt (Wolff-Boenisch et al., 2004). Similarly, basalts contain albite $\left(\mathrm{NaAlSi}_{3} \mathrm{O}_{8}\right)$ as a major phase and laboratory experiments are consistent with albite dissolution rates matching the dissolution rate of anorthite $\left(\mathrm{CaAl}_{2} \mathrm{Si}_{2} \mathrm{O}_{8}\right)$ at circum-neutral $\mathrm{pH}$ values after surface area normalization (Brantley et al., 2008). It follows that some contribution from the weathering of Na-rich lithologies and/or minerals could explain the general enrichment in $\mathrm{Na} / \Sigma^{+}$of the overall silicate end-member determined from the river water data (Figure 9).

If the Na-enrichment of the silicate end-member is due to the preferential weathering of interstitial rhyolitic glass or albite in basalts, then it can reasonably be classified as primary mineral incongruence. If instead it derives from the weathering of rhyolite outcrops or ash deposits (Louvat et al., 2008), then it is more appropriately thought of as multiple silicate end-members. Some model results do not produce a silicate endmember that exactly matches mixing between bulk basalts and bulk rhyolites (Figures 9a,c and 10b). Instead, the calculated silicate end-members can be K-poor (Figure 9c) 

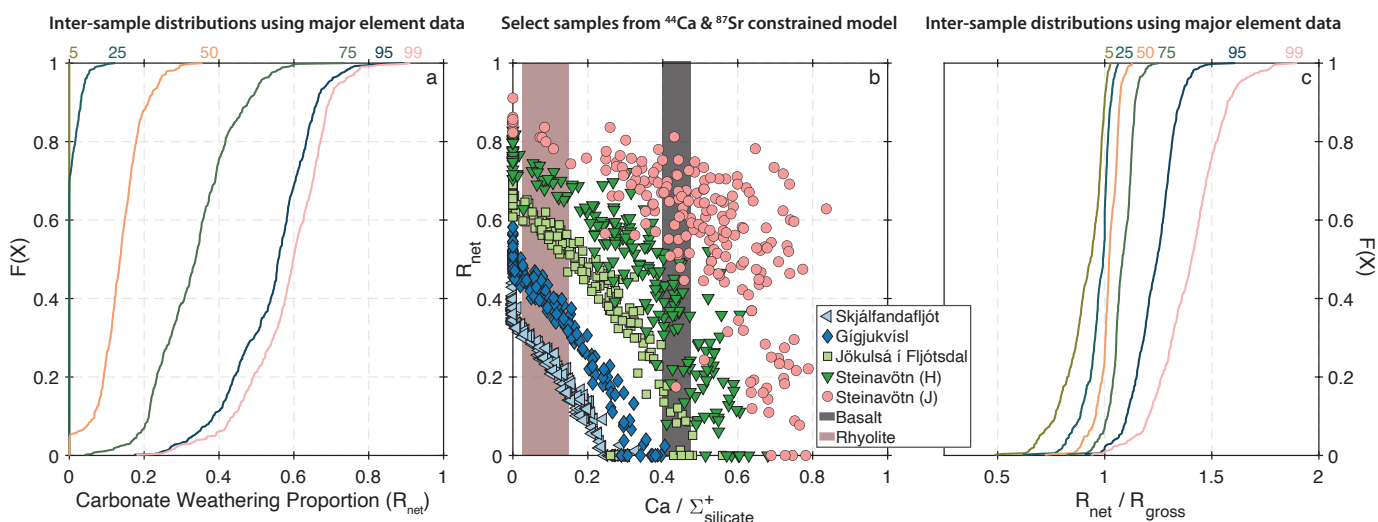

Figure 10. Constraints on carbonate contributions from the solute mass balance model. (a) Empirical cumulative distribution functions of the inter-sample variability in the $5^{\text {th }}, 25^{\text {th }}, 50^{\text {th }}$, $75^{\text {th }}, 95^{\text {th }}$, and $99^{\text {th }}$ percentiles of the carbonate weathering proportion ( $R_{n e t}$; Equation 5$)$. (b) The values for the $\mathrm{Ca} / \Sigma^{+}$of the silicate end member and $\mathrm{R}_{n e t}$ for individual simulations for a subset of 5 samples with $\mathrm{Ca}$ and $\mathrm{Sr}$ isotopic constraints. Each point is a single simulation and the different colors correspond to different river water samples. The ranges of $\mathrm{Ca} / \Sigma^{+}$for basalts and rhyolites from the GEOROC database are shown as black and salmon rectangles, respectively.

(c) The ratio of net carbonate contributions to gross carbonate contributions calculated from the inversion of major element data only shown as an inter-sample distribution of percentiles.

or Ca-rich (Figure 10b) relative to expectations for contributions from congruent rhyolite dissolution and basalt weathering. As such, even if the Na-enrichment is due to the dissolution of rhyolitic outcrops or ash deposits, the weathering of this more felsic material is characterized by primary mineral incongruence, especially with respect to K (Figure $9 \mathrm{c})$.

Ultimately, classifying the observed silicate end-member as resulting from primary mineral incongruence versus multiple silicate end-members is important as the exact mechanism(s) underlying the dissolved $\mathrm{Na}$ enrichment of Icelandic watersheds, which persists after clay formation, atmospheric deposition, or hydrothermal fluid discharge are taken into account, underlies the applicability of studies from Iceland to other volcanic systems (Börker et al., 2019). Future work looking at the compositions of soils, fluvial sediment, and weathered rocks may provide helpful constraints to address this knowledge gap.

\subsection{Constraints on carbonate contributions to Icelandic rivers}

The dissolution of trace calcite formed during the hydrothermal alteration of basalts could potentially contribute some proportion of the total Ca measured in Icelandic rivers (Georg et al., 2007; Jacobson et al., 2015; Andrews \& Jacobson, 2017). However, given the overall trend of dissolved Na-enrichment in Icelandic rivers (Figure 2a), contributions from carbonate weathering alone cannot explain the full range of river water chemistry without also including primary and secondary mineral incongruence. Nevertheless, the $\mathrm{C}$ cycling implications of carbonate weathering are very different than silicate weathering, so it is important to determine what proportion of the cation budget may be derived from carbonates even if carbonate weathering does not generate the first-order trends apparent in the hydrochemical data (Figure 2a).

The results for $R_{n e t}$ from the solute mass balance model imply that the dissolution of carbonate is not required to explain the elemental and isotopic composition of 
Icelandic rivers (Figure 10a). Specifically, using the $5^{\text {th }}$ percentile of $R_{\text {net }}$ as a guide for the minimum carbonate contribution, the largest value we find for any river sample is $0.0004 \%$ and thus represents a negligible contribution from carbonate dissolution. Using the $95^{\text {th }}$ percentile of the range of model results for each sample, most samples are incompatible with substantial carbonate contributions as a minority $(<40 \%)$ of samples yield inversion results where $>60 \%$ of the cation budget derives from carbonate weathering (Figure 10a). The few samples that are suggestive of large carbonate contributions are characterized by distinctly low $\mathrm{Na} / \Sigma^{+}$and high $\mathrm{Ca} / \Sigma^{+}$values relative to most of the other river water data. However, for these same samples, model solutions with low values of $R_{n e t}$ that match elemental and isotopic constraints are also found where the solution chemistry is explained by the preferential release of Ca from silicate minerals (Figure 10b).

Considering all samples together, the aggregate distribution of $R_{\text {net }}$ can be interpreted as having two modes (e.g., Figures $7 \mathrm{~d} \& 10 \mathrm{~b}$ ): one with a low carbonate contribution $\left(R_{n e t}<0.1\right)$ and one with a higher carbonate contribution $\left(R_{n e t}>0.5\right)$. Stated another way, the model results indicate a trade-off between the degree of primary mineral incongruence and carbonate contributions (Figure 10b). Specifically, in order to get large carbonate contributions (high $R_{n e t}$ ), it is necessary to have a silicate end-member that is more depleted in Ca relative to bulk basalts (Figure 10b).

This trade-off between the composition of the overall silicate end-member and the proportion of cations from carbonate weathering reflects the ambiguity of our selected tracers, but can be leveraged to improve estimates in future studies if any of these sources or processes can be independently constrained with additional analyses. Here, we discuss two approaches that can be used to further constrain $R_{n e t}$ and apply them to the subset of the data where it is possible. Importantly, both of these approaches act to decrease the amount of carbonate weathering allowable in each sample. Accordingly, we posit that silicate weathering dominates the alkalinity budget of chemical weathering in Iceland.

One additional tracer useful for constraining $R_{n e t}$ is the ${ }^{14} \mathrm{C}$ content of dissolved inorganic carbon (DIC). This is because the dissolution of hydrothermal calcite is expected to provide radiocarbon-dead DIC decreasing the ${ }^{14} \mathrm{C}$ content of riverine DIC relative to expectations from DIC derived from the atmosphere and/or soil respiration, which will both have higher ${ }^{14} \mathrm{C}$ contents. Unlike $\delta^{13} \mathrm{C},{ }^{14} \mathrm{C}$ measurements are unaffected by degassing and are thus easier to interpret as a constraint on DIC sources.

As a proof-of-concept, we use our model output from MEANDIR to predict the ${ }^{14} \mathrm{C}$ content of DIC taking into account uncertainties in the isotopic composition of soil respiration using soil carbon data from Torres et al. (2020). We then compare these predictions to riverine measurements of ${ }^{14} \mathrm{C}$ from (Sveinbjörnsdóttir et al., 2020), which are available for 108 of the samples in our database with measurements of major element concentrations and MEANDIR model predictions. A full description of this calculation is included in the Supplementary Materials. Unfortunately, there is no overlap between samples with measurements of $\mathrm{Mg}, \mathrm{Si}, \mathrm{Ca}$, and $\mathrm{Sr}$ isotopic ratios and those with ${ }^{14} \mathrm{C}$ measurements, but we suggest that this would be a useful goal for future work.

While adding $\mathrm{Mg}, \mathrm{Si}, \mathrm{Ca}$, and $\mathrm{Sr}$ isotopic constraints helps to bound cation uptake into clays (Figure 7e,k), we find that $\mathrm{C}$ isotopic ratios help to bound possible carbonate contributions and our estimates of $R_{\text {net }}$. For the 108 samples with ${ }^{14} \mathrm{C}$ measurements, we find that there is a shared upper bound where the highest ${ }^{14} \mathrm{C}$ value that can be generated depends on $R_{\text {net }}$ (Figure 11a). By fitting this upper bound with a linear relationship (Figure 11a), we are able to convert all of the measurements of ${ }^{14} \mathrm{C}$ (Figure 11b) into estimates of the maximum allowable $R_{n e t}$ for each sample. We find that measurements of ${ }^{14} \mathrm{C}$ greatly decrease the highest allowable value of $R_{\text {net }}$ based on major element constraints for most samples (Figure 11c). For example, $90 \%$ of samples with C 
isotopic data have $R_{\text {net }}$ values of less that 0.52 with most having $R_{n e t}$ less than 0.4 (Figure 11c).

River samples in the Sveinbjörnsdóttir et al. (2020) dataset are super-saturated with respect to $\mathrm{CO}_{2}$ and can have $\delta^{13} \mathrm{C}$ values that do not match equilibrium with atmospheric $\mathrm{CO}_{2}$. Consequently, the high ${ }^{14} \mathrm{C}$ values are unlikely to represent exchange with atmospheric $\mathrm{CO}_{2}$ and instead can can reasonably be interpreted as a constraint on DIC sources. The high measured values of ${ }^{14} \mathrm{C}$ for most samples are incompatible with large carbonate contributions to the alkalinity budget (Figure 11c). Importantly, ${ }^{14} \mathrm{C}$ only constrains the maximum allowable $\mathrm{R}_{n e t}$ and, for all samples, lower values that the upper bound provided by ${ }^{14} \mathrm{C}$ are permissible. Given the overall rarity of any samples with a maximum allowable $\mathrm{R}_{n e t}$ of greater than 0.5 (i.e., equal contributions of carbonate and silicate-derived alkalinity), we conclude that silicate weathering dominates the alkalinity budget of weathering in Iceland.
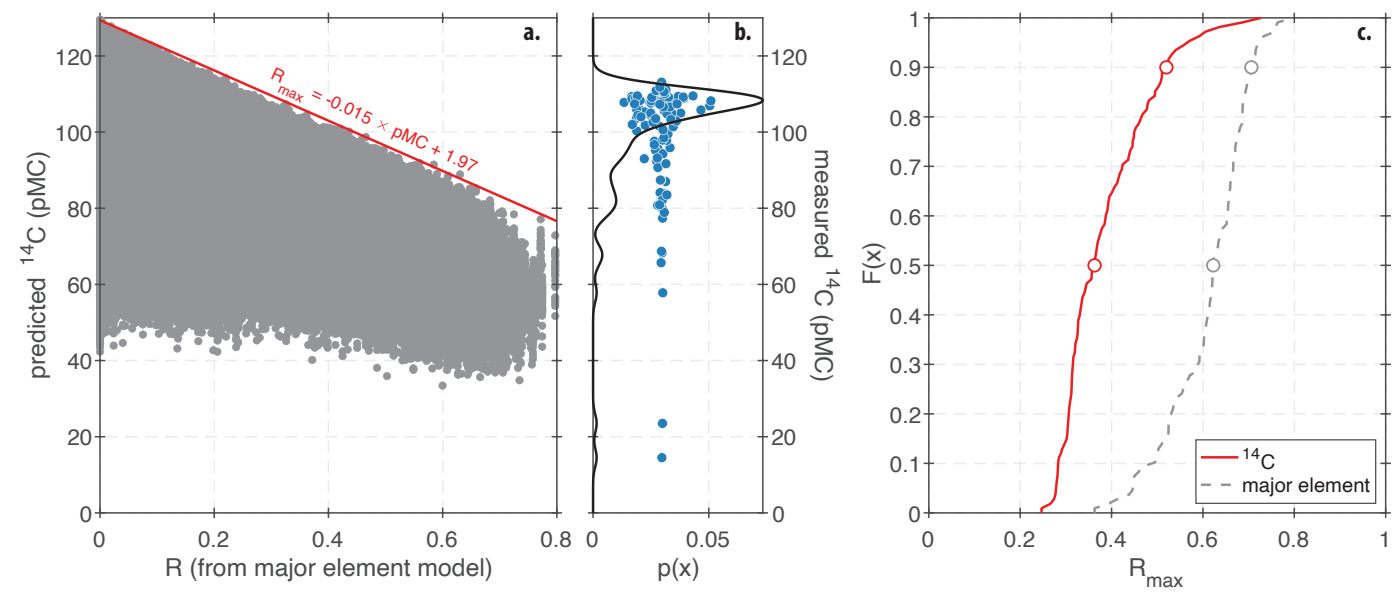

Figure 11. Carbon isotopic modelling. (a) The grey points show predictions of ${ }^{14} \mathrm{C}$ based on MEANDIR output for all 108 samples with C isotopic measurements. The red line shows a fitted upper bound based on all samples and simulations. (b) Field measurements of the ${ }^{14} \mathrm{C}$ content of DIC for the subset of river measurements presented by Sveinbjörnsdóttir et al. (2020) that also have major element data. The blue points show the individual measurements while the black line shows a kernel density estimate of their probability distribution. (c) Empirical cumulative distribution functions of the maximum allowable value of $\mathrm{R}_{n e t}$ based on modelling major elements using MEANDIR (gray dashed line) or a combination of MEANDIR and ${ }^{14} \mathrm{C}$ data (red line).

As an orthogonal approach to further constrain $R_{n e t}$, we take advantage of the fact that some of the samples in our dataset are time-series collected from single sampling locations. One hypothesis is that all of the samples in a time-series from a single location should share the same silicate end-member composition given that they share the same catchment area. Such a prediction may be reasonable for sites where bedrock is present at or near the surface and soils are relatively thin and poorly developed. This hypothesis can be applied to a time-series to constrain $R_{n e t}$ by removing simulations from each individual sample where the calculated silicate end-member composition is not shared with every other sample from the same location. Here, we select the seven sites with at least 20 time-series measurements and investigate how the distribution of $R_{n e t}$ changes when the constraint of shared silicate end-member compositions is imposed for each site.

For each of the seven sites, we find that the $95^{\text {th }}$ percentile of the distribution of $R_{n e t}$ values tends to decrease when all samples are required to sample the same silicate 

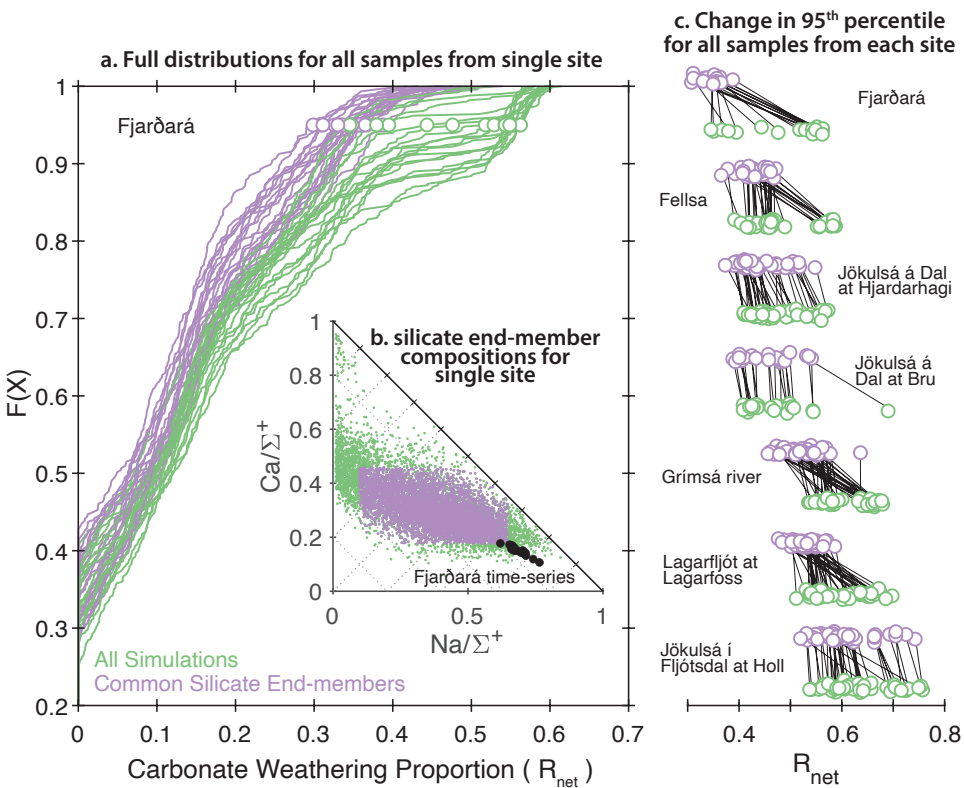

Figure 12. Constraining the carbonate weathering proportion $\left(R_{n e t}\right)$ using time-series data.

(a) Empirical cumulative distributions of $R_{n e t}$ for all time-series samples from a single site along the Fjarðará River (Eiriksdottir et al., 2013). The green curves show all model simulations while the purple curves show the subset of model simulations with the same range of silicate endmember compositions. (b) Silicate end-member compositions from the Fjarðará showing the full range (green) and the range shared by all samples from the time-series (purple). (c) Change in the $95^{\text {th }}$ percentile of $R_{n e t}$ for all sites with long time-series after requiring all samples from a site to share the same range in silicate end-member compositions.

end-members (Figure 12a,c). The magnitude of the decrease is variable sample to sample and, in some instances, little to no change is observed. At the same time, we do not observe any samples where the $95^{\text {th }}$ percentile is meaningfully increased (Figure 12c). While imposing shared silicate end-members on each time-series is an assumption, we note that mixing trends apparent in the dataset are not inconsistent with shared endmembers (Figure 12b). Given that high values of $R_{n e t}$ are rare overall and that including additional constraints has a tendency to further decrease $R_{n e t}$, we conclude most of the alkalinity generated by chemical weathering in Iceland is sourced from the dissolution of silicates as opposed to carbonates.

\subsubsection{Net versus gross carbonate contributions}

The evidence for cation-bearing clay formation during chemical weathering in Iceland implies that the partitioning of solutes between carbonate and silicate sources can be done for both gross (before clay formation) and net (after clay formation) weathering fluxes. These two approaches to source partitioning need not yield identical results given that 1) carbonate and silicate minerals contribute differently to the budget of each major cation and 2) secondary clays preferentially uptake specific cations. Since Icelandic carbonates are observed to have low K and Mg contents (Harstad \& Stipp, 2007) and Icelandic phyllosilicates are K- and Mg-rich (Moulton et al., 2000; Thorpe et al., 2019), net weathering fluxes should show a higher contribution from carbonates relative to gross fluxes. Comparing the budgets for net and gross weathering reveals whether the magnitude of the carbonate contribution is driven primarily by greater reactivity (gross bud- 
get) versus inflation due to the uptake of primarily silicate-derived cations via secondary clay formation (net budget). Ultimately, it is the net weathering flux that impacts the ocean/atmosphere chemistry and Earth's climate.

The fractional contributions from each of the solute sources can be summed and re-normalized to this total to calculate their individual contributions to the gross budget for the normalization variable $\left(\Sigma^{+}+\mathrm{SO}_{4}\right)$. This re-normalization accounts for the fact that the raw fractions from each solute source calculated using the inversion model do not sum to 1 on account of solute uptake into clays. The gross $\Sigma^{+}+\mathrm{SO}_{4}$ budget can then be used to calculate gross budgets for each individual solute using the corresponding endmember definitions. Finally, the gross budgets for each solute can be applied to the observed (i.e., net) concentrations to determine the cation and $\Sigma^{+}+\mathrm{SO}_{4}$ budgets for net weathering.

As expected, we find that some samples return model solutions where the proportion of cations in the river water derived from carbonate dissolution is apparently higher as a result of the preferential uptake of $\mathrm{Mg}$ and $\mathrm{K}$ into clays (Figure 10c). The exact increase in $R_{n e t}$ as a consequence of clay formation is uncertain and variable between samples, but increases of up to $20 \%$ are allowable in most samples (Figure 10c). So, it is possible that estimates of carbonate contributions in Iceland are elevated because of clay formation and not just the abundance and reactivity of carbonate in the weathering zone. We also note that some samples show model solutions with ratios of net to gross carbonate proportions that are lower than one, which reflects the incorporation of carbonate derived $\mathrm{Ca}$ into clays, which is discussed further below.

\subsection{Implications of incongruent weathering for cation mobility}

In prior publications on data from Icelandic rivers (e.g., Gíslason et al., 1996; Stefánsson \& Gíslason, 2001), the "mobility" of different elements during weathering has been calculated as:

$$
X \text { mobility }=100 \times \frac{X^{*} / N a_{\text {river }}^{*}}{X / N a_{\text {basalt }}}
$$

where the superscript asterisk refers to solute concentrations that have been corrected for contributions from atmospheric deposition using $\mathrm{Cl}$ concentrations and end-member element to $\mathrm{Cl}$ ratios. This approach conflates both types of incongruent weathering by assuming that the expected ratio of solutes in river waters (after correction for atmospheric contributions) is given by bulk basalts. As described above, our data suggests that the effective silicate end-member for most rivers in Iceland is not bulk basalts and is instead more Na-rich. As a result, the elemental mobility inferred from Equation 8 might be artificially decreased. Identifying this potential bias is important as it underlies the calibration of some isotopic tools for reconstructing weathering processes in the past (e.g., $\delta^{7} \mathrm{Li}$; P. A. E. Pogge von Strandmann, Fraser, et al., 2019).

Past estimates of element mobility in Iceland using Equation 8 are difficult to directly compare to our results using the solute mass balance model for multiple reasons. Firstly, Equation 8 produces mobility values greater than $100 \%$ for some elements in some river samples (Stefánsson \& Gíslason, 2001). Additionally, our solute mass balance model allows solutes sourced from rainwater or carbonates to ultimately be incorporated into clays, which is not accounted for in Equation 8. Such behavior is consistent with measurements of soil profiles in other volcanic landscapes where atmosphere-derived cations are incorporated into solid-phases (Huh et al., 2004; Chadwick et al., 2009; Dessert et al., 2020). The large uncertainty in our estimates of mobility for individual samples also makes it difficult to quantify biases that might result from Equation 8. For example, uncertainty in clay compositions and other model parameters can increase mobility estimates relative to what is predicted using Equation 8 despite the fact that a more Narich silicate end-member tends to decrease mobility estimates in general. 

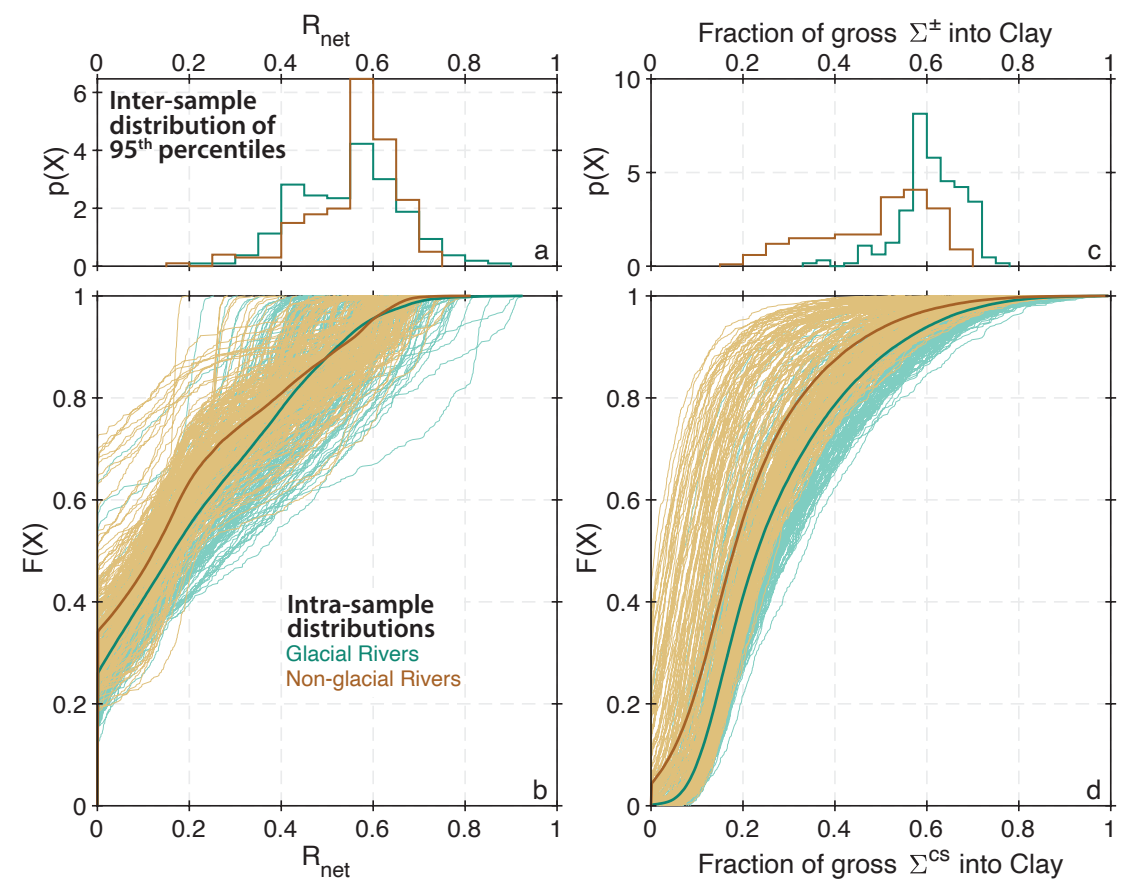

Figure 13. Solute mass balance model predictions for glaciated versus non-glaciated watersheds. (a) Inter-sample distribution of $95^{\text {th }}$ percentile values for the proportion of carbonate weathering $\left(R_{n e t}\right)$ for glaciated (blue) and non-glaciated (brown) river samples. (b) Full distributions of $R_{n e t}$ for all glacial and non-glacial river samples. The thin, lighter-colored lines show individual samples whereas the thicker, darker-colored lines show the distributions for all samples combined. (c) same as in panel a, but showing the inter-sample distributions for the fraction of $\Sigma^{+}+\mathrm{SO}_{4}$ uptake into clays $\left(F_{\text {clay }}^{\Sigma^{ \pm}}\right)$. (d) same as in panel b but showing the full distributions of $F_{\text {clay }}^{\Sigma^{ \pm}}$for glaciated and non-glaciated watersheds.

To make a simplified comparison to previous work, we note that Gíslason et al. (1996) report that $\mathrm{K}$ is more mobile than $\mathrm{Ca}$ in Icelandic watersheds, which is not supported by our analysis (Figure 8c,d). Similarly, Gíslason et al. (1996) suggest that up to $90 \%$ of Ca is sequestered into clays, which is a much higher proportion than our upper bound of less than $70 \%$ (Figure 8d). Superficially, our results appear more similar to what is reported in Stefánsson and Gíslason (2001) for overall mobility ranges, though we still expect to find differences between our different approaches on the level of individual samples. Additional constraints on clay compositions in Iceland as well as the degree and character of primary incongruence will likely be useful to better constrain solute mobility in Icelandic watersheds.

\subsection{Processes affecting glacial versus non-glacial rivers}

Differences between glacial and non-glacial river waters in Iceland have been noted in some of the original publications from which this compilation is based (e.g., Hindshaw et al., 2013; Jacobson et al., 2015). Similar differences like the enrichment in sulfate and calcium ion (Figure 3b,e) are also observed between glacial and non-glacial rivers globally (Torres et al., 2017).

The results of the solute mass balance model are uncertain, but the few samples with the highest median carbonate contributions are from glacierized catchments (Fig- 
ure 13a,b). Though this is apparently consistent with the hypothesis of Jacobson et al. (2015) that contributions from trace reactive phases are enhanced by glaciers in Iceland, we note that the majority of glacial rivers in our database do not show evidence for elevated carbonate contributions relative to non-glacial rivers (Figure 13b). Specifically, the inter-sample distributions of $95^{\text {th }}$ percentile values for glacial versus non-glacial rivers are not substantially different from each other (Figure 13a).

The results of our solute mass balance model do not rule out the hypothesis of Hindshaw et al. (2013) that glaciation enhances clay formation as the proportion of the total cation budget taken up into clays may be slightly elevated in the glacierized catchments relative to non-glacial rivers (Figure 13c,d). Specifically, despite substantial overlap, the intersample distribution of $95^{\text {th }}$ percentile values for $F_{\text {clay }}^{c s}$ is shifted to higher values for the the glacial river samples compared to those from non-glaciated watersheds (Figure 13c).

Not all basalts contain significant carbonate as its formation is restricted to the portions of geothermal systems that experience boiling (Arnórsson, 1989; Neuhoff et al., 1999; Weisenberger \& Selbekk, 2009). So, the observation that most of river water samples from Iceland, including those from glaciated watersheds, do not show evidence for large carbonate contributions could imply a heterogeneous distribution of different hydrothermal alteration minerals rather than an effect of distinctive surface processes on chemical weathering (i.e., glacial versus fluvial erosion). The idea that glaciation enhances cation uptake into clays (Hindshaw et al., 2013) is not expected and, technically, not required by the results of our analysis. However, it is consistent with the results of our solute mass balance model and the higher degree of secondary clay mineral super-saturation observed for river water samples from glaciated catchments (Figure $4 \mathrm{~g}, \mathrm{~h}, \mathrm{i}, \mathrm{k}$ ).

\subsection{Implications for the long-term $\mathrm{C}$ cycle}

The general Na enrichment of the river waters on account of both types of incongruent weathering may have implications for the long-term $\mathrm{C}$ cycle. At timescales shorter than or similar to the residence time of $\mathrm{Ca}$, all silicate-derived alkalinity will impact atmospheric $\mathrm{pCO}_{2}$ through its effects on the oceanic carbonate system (Middelburg et al., 2020). The unclear fate of silicate-derived $\mathrm{Na}$ and uncertainty in the timescale(s) associated with its removal processes (e.g., "reverse" weathering; F. T. Mackenzie, 1995) complicate longer-term inferences about its role in the global C cycle. Nevertheless, assuming that reverse weathering processes are "slow" relative to carbonate burial, which is not altogether unreasonable on account of the longer oceanic residence time of $\mathrm{Na}$ relative to $\mathrm{Ca}$, the "transient" effect of increased silicate $\mathrm{Na}$ fluxes on atmospheric $\mathrm{CO}_{2}$ may be long relative to climate and carbon cycle perturbations observed in geologic history. In general, the abundance of silicate-derived $\mathrm{Na}$ in weathering "hot spots" such as Iceland highlights the need for future research on how to best account for all silicate-derived alkalinity in the global $\mathrm{C}$ cycle.

\section{Conclusions}

While the chemistry of Icelandic waters has been extensively studied in the past, no previous analyses have used an inverse model that allows for both types of incongruent weathering (i.e., solute sinks vs. variable primary mineral dissolution rates) and key solute sources other than basalts (e.g., carbonates) simultaneously. Such models are necessary as neglecting to include all processes can significantly bias the model results (Bickle et al., 2015; Emberson et al., 2017, 2018). Using this approach, we identify that both types of incongruent weathering play a role in setting the chemistry of Icelandic watersheds, which is distinct from previous interpretations that have mostly focused on the role of secondary clay minerals. Our evidence for the preferential release of silicate-derived $\mathrm{Na}$ relative to what is expected for bulk basalts implies that some previous estimates of cation mobility may have over-estimated the role of clays as solute sinks. 
Our results also constrain the potential magnitude of carbonate contributions in Icelandic watersheds and suggest that silicate contributions dominate overall such that Iceland is an important locus of $\mathrm{CO}_{2}$ draw down. In part, this may reflect the heterogeneous distribution of hydrothermal calcite given its specific formation mechanisms and the observations that only a few samples within our database are consistent with large carbonate contributions.

The bedrock lithology of Iceland is comparatively simple to other rivers with mixed igneous and sedimentary bedrock. The complexity of weathering processes identified using our analysis thus highlights the need for using more robust inverse approaches when attempting to partition solutes between carbonate and silicate sources.

Table 1. End-member compositions used in the solute mass balance model

\begin{tabular}{|c|c|c|c|c|c|c|c|c|c|c|c|}
\hline & & Pyrite & Precipitation & Hot spring & Clay & Carbonate & Na-silicate & $\mathrm{K}$-silicate & NaK-silicate & Mg-silicate & Ca-silicate \\
\hline $\mathrm{Na} / \Sigma^{ \pm}$ & Min & & 0.6 & 0.8 & 0 & & 1 & & 0 & & \\
\hline $\mathrm{Na} / \Sigma^{ \pm}$ & $\operatorname{Max}$ & & 0.9 & 0.95 & 0.25 & & 1 & & 1 & & \\
\hline$K / \Sigma^{ \pm}$ & Min & & 0.02 & 0.05 & 0.05 & & & 1 & 0 & & \\
\hline$K / \Sigma^{ \pm}$ & $\operatorname{Max}$ & & 0.2 & 0.12 & 0.3 & & & 1 & 1 & & \\
\hline $\mathrm{Ca} / \Sigma^{ \pm}$ & Min & & 0.02 & 0 & 0.2 & 0.95 & & & & & 1 \\
\hline $\mathrm{Ca} / \Sigma^{ \pm}$ & $\operatorname{Max}$ & & 0.1 & 0.01 & 0.45 & 1 & & & & & 1 \\
\hline $\mathrm{Mg} / \Sigma^{ \pm}$ & Min & & 0.05 & & 0.75 & 0 & & & & 1 & \\
\hline $\mathrm{Mg} / \Sigma^{ \pm}$ & $\operatorname{Max}$ & & 0.1 & & 1 & 0.05 & & & & 1 & \\
\hline $\mathrm{Cl} / \Sigma^{ \pm}$ & Min & & 0.6 & 0.4 & & & & & & & \\
\hline $\mathrm{Cl} / \Sigma^{ \pm}$ & $\operatorname{Max}$ & & 1.2 & 0.9 & & & & & & & \\
\hline $\mathrm{SO}_{4} / \Sigma^{ \pm}$ & Min & 1 & 0.014 & 0 & & & & & & & \\
\hline $\mathrm{SO}_{4} / \Sigma^{ \pm}$ & $\operatorname{Max}$ & 1 & 0.1 & 0.1 & & & & & & & \\
\hline $\mathrm{Sr} / \Sigma^{ \pm}$ & Min & & $1.00 \mathrm{E}-04$ & $1.00 \mathrm{E}-06$ & $1.00 \mathrm{E}-05$ & $1.00 \mathrm{E}-06$ & $1.00 \mathrm{E}-06$ & $1.00 \mathrm{E}-06$ & $1.00 \mathrm{E}-06$ & $1.00 \mathrm{E}-06$ & $1.00 \mathrm{E}-06$ \\
\hline $\mathrm{Sr} / \Sigma^{ \pm}$ & $\operatorname{Max}$ & & $3.00 \mathrm{E}-04$ & $1.00 \mathrm{E}-04$ & $3.00 \mathrm{E}-03$ & $1.00 \mathrm{E}-04$ & $1.00 \mathrm{E}-03$ & $1.00 \mathrm{E}-03$ & $1.00 \mathrm{E}-03$ & $1.00 \mathrm{E}-04$ & $1.00 \mathrm{E}-03$ \\
\hline${ }^{87} \mathrm{Sr} /{ }^{86} \mathrm{Sr}$ & Min & & 0.7091 & 0.703 & source & 0.7031 & 0.703 & 0.703 & 0.703 & 0.703 & 0.703 \\
\hline${ }^{87} \mathrm{Sr} /{ }^{86} \mathrm{Sr}$ & $\operatorname{Max}$ & & 0.7093 & 0.704 & source & 0.7034 & 0.704 & 0.704 & 0.704 & 0.704 & 0.704 \\
\hline $\mathrm{Si} / \Sigma^{ \pm}$ & Min & & & 0.2 & 2 & & 1 & 1 & 1 & 1 & 1 \\
\hline $\mathrm{Si} / \Sigma^{ \pm}$ & $\operatorname{Max}$ & & & 3 & 10 & & 3 & 3 & 3 & 2 & 2 \\
\hline$\Delta^{44} \mathrm{Ca}$ & Min & & & & -1 & & & & & & \\
\hline$\Delta^{44} \mathrm{Ca}$ & $\operatorname{Max}$ & & & & +0.5 & & & & & & \\
\hline$\Delta^{26} \mathrm{Mg}$ & Min & & & & -1.5 & & & & & & \\
\hline$\Delta^{26} \mathrm{Mg}$ & $\operatorname{Max}$ & & & & +1 & & & & & & \\
\hline$\Delta^{30} \mathrm{Si}$ & Min & & & & -2 & & & & & & \\
\hline$\Delta^{30} \mathrm{Si}$ & $\operatorname{Max}$ & & & & +0.5 & & & & & & \\
\hline$\delta^{44} \mathrm{Ca}$ & Min & & 0 & -1.1 & & -0.9 & & & & & -2 \\
\hline$\delta^{44} \mathrm{Ca}$ & $\operatorname{Max}$ & & 0 & -0.8 & & -0.5 & & & & & -1 \\
\hline$\delta^{26} \mathrm{Mg}$ & Min & & -0.83 & & & -4 & & & & -0.5 & \\
\hline$\delta^{26} \mathrm{Mg}$ & $\operatorname{Max}$ & & -0.81 & & & -0.2 & & & & -0.2 & \\
\hline$\delta^{30} \mathrm{Si}$ & Min & & & -0.5 & & & -0.5 & -0.5 & -0.5 & -0.5 & -0.5 \\
\hline$\delta^{30} \mathrm{Si}$ & Max & & & 1 & & & -0.2 & -0.2 & -0.2 & -0.2 & -0.2 \\
\hline
\end{tabular}

\section{Data Availability}

The basalt and rhyolite bulk geochemistry data used in this study is available at http://georoc.mpch-mainz.gwdg.de/georoc/. The fine-grained sediment data used in this study is available in the original publications (Moulton et al., 2000; Thorpe et al., 2019). The hydrochemistry data used in this study will be archived along with the analysis code on Zenodo upon acceptance (data files available for review as supplementary material).

The MEANDIR model code is available at github.com/PrestonCosslettKemeny. The MEANDIR input files used in this study will be available at github.com/torres-lab and archived on Zenodo upon acceptance of the paper for publication (included as supplementary data for review).

\section{Acknowledgments}

Torres acknowledges support from the Sloan Foundation and NSF-EAR 2017106. Cole acknowledges support from the Mills Bennett Fellowship. Kemeny acknowledges support from the Fannie and John Hertz Foundation Cohan-Jacobs and Stein Families Fellowship and the National Defense Science and Engineering Graduate (NDSEG) Fellowship (DoD, Air Force Office of Scientific Research, 32 CFR 168a). All authors thank Drs. 
Cin-Ty Lee, Kirsten Siebach, and Laurence Yeung for helpful comments prior to submission.

\section{References}

Aitchison, J. (1983). Principal component analysis of compositional data. Biometrika, 70(1), 57-65.

Andrews, M. G., \& Jacobson, A. D. (2017). The radiogenic and stable Sr isotope geochemistry of basalt weathering in Iceland: Role of hydrothermal calcite and implications for long-term climate regulation. Geochimica et Cosmochimica Acta, 215, 247-262.

Arnórsson, S. (1989). Deposition of calcium carbonate minerals from geothermal waters - theoretical considerations. Geothermics, 18(1-2), 33-39.

Arnórsson, S., Gunnarsson, I., Stefánsson, A., Andrésdóttir, A., \& Sveinbjörnsdóttir, A. E. (2002, June). Major element chemistry of surface- and ground waters in basaltic terrain, N-Iceland. I. Primary mineral saturation. Geochimica et Cosmochimica Acta, 66(23), 4015 - 4046.

Baronas, J. J., West, A. J., Burton, K. W., Hammond, D. E., Opfergelt, S., Pogge von Strandmann, P. A., .. Rouxel, O. J. (2020). Ge and si isotope behavior during intense tropical weathering and ecosystem cycling. Global Biogeochemical Cycles, 34(8), e2019GB006522.

Berner, R. A., Lasaga, A. C., \& Garrels, R. M. (1983). The Carbonate-Silicate Geochemical Cycle And Its Effect on Atmospheric Carbon Dioxide Over the Past 100 Million Years. American Journal of Science, 283(7), 641-683.

Bickle, M. J., Tipper, E. D., Galy, A., Chapman, H., \& Harris, N. (2015). On discrimination between carbonate and silicate inputs to Himalayan rivers. American Journal of Science, 315, 120-166.

Blattmann, T. M., Wang, S.-L., Lupker, M., Märki, L., Haghipour, N., Wacker, L., ... Eglinton, T. I. (2019). Sulphuric acid-mediated weathering on taiwan buffers geological atmospheric carbon sinks. Scientific reports, 9(1), 1-8.

Bluth, G. J. S., \& Kump, L. R. (1994). Lithologic and climatologic controls of river chemistry. Geochimica et Cosmochimica Acta, 58(10), 2341-2359.

Börker, J., Hartmann, J., Romero-Mujalli, G., \& Li, G. (2019). Aging of basalt volcanic systems and decreasing co 2 consumption by weathering. Earth Surface Dynamics, 7(1), 191-197.

Bouchez, J., von Blanckenburg, F., \& Schuessler, J. a. (2013). Modeling novel stable isotope ratios in the weathering zone. American Journal of Science, 313(4), 267-308.

Brantley, S. L., Kubicki, J. D., \& White, A. F. (2008). Kinetics of water-rock interaction (S. L. Brantley, J. D. Kubicki, \& A. F. White, Eds.). $\quad$ New York: Springer.

Brazier, J.-M., Schmitt, A.-D., Gangloff, S., Pelt, E., Chabaux, F., \& Tertre, E. (2019). Calcium isotopic fractionation during adsorption onto and desorption from soil phyllosilicates (kaolinite, montmorillonite and muscovite). Geochimica et Cosmochimica Acta, 250, 324-347.

Broecker, W. S., \& Sanyal, A. (1998). Does atmospheric $\mathrm{CO}_{2}$ police the rate of chemical weathering? Global Biogeochemical Cycles, 12(3), 403-408.

Chadwick, O., Derry, L., Bern, C., \& Vitousek, P. (2009). Changing sources of strontium to soils and ecosystems across the hawaiian islands. Chemical Geology, 267(1-2), 64-76.

Chen, Y., \& Brantley, S. L. (1997). Temperature-and ph-dependence of albite dissolution rate at acid ph. Chemical Geology, 135(3-4), 275-290.

Cornelis, J.-T., Weis, D., Lavkulich, L., Vermeire, M.-L., Delvaux, B., \& Barling, J. (2014). Silicon isotopes record dissolution and re-precipitation of pedogenic clay minerals in a podzolic soil chronosequence. Geoderma, 235-236, 19-29. 
Crovisier, J.-L., Honnorez, J., Fritz, B., \& Petit, J.-C. (1992). Dissolution of subglacial volcanic glasses from iceland: laboratory study and modelling. Applied Geochemistry, 7, 55-81.

Dessert, C., Clergue, C., Rousteau, A., Crispi, O., \& Benedetti, M. F. (2020). Atmospheric contribution to cations cycling in highly weathered catchment, guadeloupe (lesser antilles). Chemical Geology, 531, 119354.

Dessert, C., Dupre, B., Gaillardet, J., Francois, L. M. M., \& Allegre, C. J. J. (2003). Basalt weathering laws and the impact of basalt weathering on the global carbon cycle. Chemical Geology, 202(3-4), 257-273.

Druhan, J. L., \& Maher, K. (2017). The influence of mixing on stable isotope ratios in porous media: A revised rayleigh model. Water Resources Research, 53(2), $1101-1124$.

Ehlmann, B., Bish, D., Ruff, S., \& Mustard, J. (2012). Mineralogy and chemistry of altered icelandic basalts: Application to clay mineral detection and understanding aqueous environments on mars. Journal of Geophysical Research: Planets, 117(E11).

Eiriksdottir, E. S., Gislason, S. R., \& Oelkers, E. H. ～(2013). Does temperature or runoff control the feedback between chemical denudation and climate? Insights from NE Iceland. Geochimica et Cosmochimica Acta, 107, 65-81.

Elderfield, H., \& Greaves, M. J. (1981). S Strontium isotope geochemistry of icelandic geothermal systems and implications for sea water chemistry. Geochimica et Cosmochimica Acta, 45(11), 2201-2212.

Emberson, R., Galy, A., \& Hovius, N. (2017). Combined effect of carbonate and biotite dissolution in landslides biases silicate weathering proxies. Geochimica et Cosmochimica Acta, 213, 418-434.

Emberson, R., Galy, A., \& Hovius, N. (2018). Weathering of reactive mineral phases in landslides acts as a source of carbon dioxide in mountain belts. Journal of Geophysical Research: Earth Surface, 123(10), 2695-2713.

Ferrier, K. L., \& Kirchner, J. W. (2008). Effects of physical erosion on chemical denudation rates: A numerical modeling study of soil-mantled hillslopes. Earth and Planetary Science Letters, 272(3-4), 591-599.

Gannoun, A., Burton, K. W., Vigier, N., Gíslason, S. R., Rogers, N., Mokadem, F., \& Sigfússon, B. (2006). The influence of weathering process on riverine osmium isotopes in a basaltic terrain. Earth and Planetary Science Letters, 243(3-4), 732-748.

Garrels, R. M., \& Mackenzie, F. T. (1967). Origin of the chemical compositions of some springs and lakes. Equilibrium concepts in natural water systems, 222 242 .

Georg, R. B., Reynolds, B. C., West, a. J., Burton, K. W., \& Halliday, A. N. (2007). Silicon isotope variations accompanying basalt weathering in Iceland. Earth and Planetary Science Letters, 261, 476-490.

Gislason, S. R., \& Arnórsson, S. (1993). Dissolution of primary basaltic minerals in natural waters: saturation state and kinetics. Chemical Geology, 105(1-3), $117-135$.

Gislason, S. R., \& Eugster, H. P. （1987, October). Meteoric water-basalt interactions. I: A laboratory study. Geochimica et Cosmochimica Acta, 51(10), 28272840.

Gislason, S. R., \& Oelkers, E. H. (2003). Mechanism, rates, and consequences of basaltic glass dissolution: II. An experimental study of the dissolution rates of basaltic glass as a function of $\mathrm{pH}$ and temperature. Geochimica et Cosmochimica Acta, 67(20), 3817-3832. doi: 10.1016/S0016-7037(03)00176-5

Gíslason, S. R., Snorrason, A., Ingvarsson, G. B., Sigfússon, B., Eiríksdóttir, E. S., Elefsen, S., ... Torssander, P. (2006). Chemical composition, discharge and suspended matter of rivers in north-western iceland: The database of the science institute, university of iceland, and the hydrological service of the national 
energy authority. Raunvísindastofnun Háskólans.

Gudbrandsson, S., Wolff-Boenisch, D., Gíslason, S. R., \& Oelkers, E. H. (2008). Dissolution rates of crystalline basalt at $\mathrm{pH} 4$ and 10 and $25-75^{\circ} \mathrm{C}$. Mineralogical Magazine, 72(1), 155-158. doi: 10.1180/minmag.2008.072.1.155

Gíslason, S. R., Arnórsson, S., \& Ármannsson, H. (1996). Chemical weathering of basalt in southwest Iceland: Effects of runoff, age of rocks and vegetative/glacial cover. American Journal of Science, 296, 837-907.

Harstad, A., \& Stipp, S. L. S. (2007). Calcite dissolution: Effects of trace cations naturally present in iceland spar calcites. Geochimica et Cosmochimica Acta, $71(1), 56-70$.

Hemingway, J. D., Olson, H., Turchyn, A. V., Tipper, E. T., Bickle, M. J., \& Johnston, D. T. (2020). Triple oxygen isotope insight into terrestrial pyrite oxidation. Proceedings of the National Academy of Sciences, 117(14), 7650-7657.

Hindshaw, R. S., Bourdon, B., Pogge von Strandmann, P. A., Vigier, N., \& Burton, K. W. (2013). The stable calcium isotopic composition of rivers draining basaltic catchments in Iceland. Earth and Planetary Science Letters, 374, 173-184. doi: 10.1016/j.epsl.2013.05.038

Hindshaw, R. S., Tosca, R., Tosca, N. J., \& Tipper, E. T. $\quad$ (2020). $\quad$ Experimental constraints on $\mathrm{mg}$ isotope fractionation during clay formation: Implications for the global biogeochemical cycle of mg. Earth and Planetary Science Letters, 531,115980 .

Huh, Y., Chan, L.-H., \& Chadwick, O. A. (2004). Behavior of lithium and its isotopes during weathering of hawaiian basalt. Geochemistry, Geophysics, Geosystems, 5(9).

Ibarra, D. E., Caves, J. K., Moon, S., Thomas, D. L., Hartmann, J., Chamberlain, C. P., \& Maher, K. (2016). Differential weathering of basaltic and granitic catchments from concentration-discharge relationships. Geochimica et Cosmochimica Acta, 190, 265-293. doi: 10.1016/j.gca.2016.07.006

Jacobson, A. D., Grace Andrews, M., Lehn, G. O., \& Holmden, C. (2015). Silicate versus carbonate weathering in Iceland: New insights from Ca isotopes. Earth and Planetary Science Letters, 1, 1-11.

Kemeny, P., Lopez, G., Dalleska, N., Torres, M., Burke, A., Bhatt, M., ... Adkins, J. (2020). Sulfate sulfur isotopes and major ion chemistry reveal that pyrite oxidation counteracts $\mathrm{CO}_{2}$ drawdown from silicate weathering in the langtangtrisuli-narayani river system, nepal himalaya. Geochimica et Cosmochimica Acta.

Kemeny, P., \& Torres, M. (2021). Presentation and applications of Modeling Elements ANd Dissolved Isotopes in Rivers (MEANDIR), a customizable MATLAB model for Monte Carlo inversion of dissolved river chemistry. American Journal of Science.

Kemeny, P. C., Torres, M. A., Lamb, M. P., Webb, S. M., Dalleska, N., Cole, T., .. . Fischer, W. W. (2021). Organic sulfur fluxes and geomorphic control of sulfur isotope ratios in rivers. Earth and Planetary Science Letters, 562, 116838.

Larsen, G., \& Eiriksson, J. (2008). Late quaternary terrestrial tephrochronology of iceland - frequency of explosive eruptions, type and volume of tephra deposits. Journal of Quaternary Science: Published for the Quaternary Research Association, 23(2), 109-120.

Li, D., Jacobson, A. D., \& McInerney, D. J. (2014). A reactive-transport model for examining tectonic and climatic controls on chemical weathering and atmospheric CO2 consumption in granitic regolith. Chemical Geology, 365, $30-42$.

Li, G., \& Elderfield, H. (2013). Evolution of carbon cycle over the past 100 million years. Geochimica et Cosmochimica Acta, 103, 11-25.

Li, G., Hartmann, J., Derry, L. A., West, A. J., You, C.-F., Long, X., ... others (2016). Temperature dependence of basalt weathering. Earth and Planetary 
Science Letters, 443, 59-69.

Louvat, P., Gislason, S. R., \& Allègre, C. J. (2008). Chemical and mechanical erosion rates in Iceland as deduced from river dissolved and solid material. American Journal of Science, 308(5), 679-726. doi: 10.2475/05.2008.02

Mackenzie, F., \& Garrels, R. (1966). Chemical mass balance between rivers and oceans. American Journal of Science, 264, 19.

Mackenzie, F. T. (1995). Reverse Weathering, Clay Mineral Formation, and Oceanic Element Cycles. Science, 270(5236), 586-587.

Meyer, P. S., \& Sigurdsson, H. (1978). Interstitial acid glass and chlorophaeite in iceland basalts. Lithos, 11(3), 231-241.

Middelburg, J. J., Soetaert, K., \& Hagens, M. (2020). Ocean alkalinity, buffering and biogeochemical processes. Reviews of Geophysics, 58(3), e2019RG000681.

Misra, S., \& Froelich, P. N. (2012). Lithium isotope history of Cenozoic seawater: changes in silicate weathering and reverse weathering. Science, 335(6070), 818-823.

Moulton, K. L., West, J., \& Berner, R. A. $\quad$ (2000). Solute flux and mineral mass balance approaches to the quantification of plant effects on silicate weathering. American Journal of Science, $300(7), 539$.

Mutonga, M. W., Sveinbjornsdottir, A., Gislason, G., \& Amannsson, H. (2010). The isotopic and chemical characteristics of geothermal fluids in hengill area, sw-iceland (hellisheidi, hveragerdi and nesjavellir fields). In Proceedings of the world geothermal congress, bali, indonesia (pp. 1-13).

Négrel, P., Allegre, C. J., Dupré, B., \& Lewin, E. (1993). Erosion sources determined by inversion of major and trace element ratios and strontium isotopic ratios in river water: The Congo Basin case. Earth and Planetary Science Letters, 120(1-2), 59-76.

Neuhoff, P. S., Fridriksson, T., Arnorsson, S., \& Bird, D. K. (1999). Porosity evolution and mineral paragenesis during low-grade metamorphism of basaltic lavas at teigarhorn, eastern iceland. American Journal of Science, 299(6), 467-501.

Ockert, C., Gussone, N., Kaufhold, S., \& Teichert, B. (2013). Isotope fractionation during ca exchange on clay minerals in a marine environment. Geochimica et Cosmochimica Acta, 112, 374-388.

Olsson, J., Stipp, S., Makovicky, E., \& Gislason, S. (2014). Metal scavenging by calcium carbonate at the Eyjafjallajökull volcano: A carbon capture and storage analogue. Chemical Geology, 384, 135-148.

Opfergelt, S., Burton, K., Von Strandmann, P. P., Gislason, S., \& Halliday, A. (2013). Riverine silicon isotope variations in glaciated basaltic terrains: Implications for the si delivery to the ocean over glacial-interglacial intervals. Earth and Planetary Science Letters, 369, 211-219.

Óskarsson, B. V., Riishuus, M. S., \& Arnalds, Ó. (2012). Climate-dependent chemical weathering of volcanic soils in iceland. Geoderma, 189, 635-651.

Oskarsson, F., Armannsson, H., Olafsson, M., Sveinbjornsdottir, A. E., \& Markusson, S. H. (2013). The theistareykir geothermal field, ne iceland: Fluid chemistry and production properties. Procedia Earth and Planetary Science, 7, 644 $-647$.

Park, Y., Maffre, P., Goddéris, Y., Macdonald, F. A., Anttila, E. S., \& SwansonHysell, N. L. (2020). Emergence of the southeast asian islands as a driver for neogene cooling. Proceedings of the National Academy of Sciences, 117(41), $25319-25326$.

Pearson, K. (1897). Mathematical contributions to the theory of evolution. - on a form of spurious correlation which may arise when indices are used in the measurement of organs. Proceedings of the royal society of london, 60(359-367), 489-498.

Pogge von Strandmann, P., Burton, K. W., James, R. H., van Calsteren, P., Gislason, S. R., \& Sigfusson, B. (2008). The influence of weathering processes on 
riverine magnesium isotopes in a basaltic terrain. Earth and Planetary Science Letters, 276 (1-2), 187-197.

Pogge von Strandmann, P. A., Burton, K. W., James, R. H., van Calsteren, P., Gíslason, S. R., \& Mokadem, F. (2006). Riverine behaviour of uranium and lithium isotopes in an actively glaciated basaltic terrain. Earth and Planetary Science Letters, 251(1-2), 134-147. doi: 10.1016/j.epsl.2006.09.001

Pogge von Strandmann, P. A. E., Fraser, W. T., Hammond, S. J., Tarbuck, G., Wood, I. G., Oelkers, E. H., \& Murphy, M. J. (2019). Experimental determination of li isotope behaviour during basalt weathering. Chemical Geology, 517, $34-43$.

Pogge von Strandmann, P. A. E., Olsson, J., Luu, T.-H., Gislason, S. u. R., \& Burton, K. W. (2019). Using Mg Isotopes to Estimate Natural Calcite Compositions and Precipitation Rates During the 2010 Eyjafjallajökull Eruption. Frontiers in Earth Science, 7, 6.

Rickli, J., Frank, M., Stichel, T., Georg, R. B., Vance, D., \& Halliday, A. N. (2013). Controls on the incongruent release of hafnium during weathering of metamorphic and sedimentary catchments. Geochimica et Cosmochimica Acta, 101, 263-284.

Roerdink, D. L., van den Boorn, S. H., Geilert, S., Vroon, P. Z., \& van Bergen, M. J. (2015). Experimental constraints on kinetic and equilibrium silicon isotope fractionation during the formation of non-biogenic chert deposits. Chemical Geology, 402, 40-51.

Ryu, J. S., Jacobson, A. D., Holmden, C., Lundstrom, C., \& Zhang, Z. (2011) The major ion, d44/40Ca, d44/42Ca, and d26/24Mg geochemistry of granite weathering at $\mathrm{pH}=1$ and $\mathrm{T}=25 \mathrm{C}$ : power-law processes and the relative reactivity of minerals. Geochimica et Cosmochimica Acta, 75, 6004-6026.

Ryu, J.-S., Vigier, N., Lee, S.-W., Lee, K.-S., \& Chadwick, O. A. (2014). Variation of lithium isotope geochemistry during basalt weathering and secondary mineral transformations in hawaii. Geochimica et Cosmochimica Acta, 145, 103-115.

Savage, P. S., Georg, R. B., Williams, H. M., Burton, K. W., \& Halliday, A. N. (2011). Silicon isotope fractionation during magmatic differentiation. Geochimica et Cosmochimica Acta, 75 (20), 6124-6139.

Schaef, H., \& McGrail, P. (2009). Dissolution of Columbia River Basalt under mildly acidic conditions as a function of temperature: Experimental results relevant to the geological sequestration of carbon dioxide. Applied Geochemistry, 24(5), 980-987. doi: 10.1016/j.apgeochem.2009.02.025

Scott, S., Gunnarsson, I., Arnórsson, S., \& Stefánsson, A. (2014). Gas chemistry, boiling and phase segregation in a geothermal system, hellisheidi, iceland. Geochimica et Cosmochimica Acta, 124, 170-189.

Stefánsson, A., Gíslason, S. R., \& Arnórsson, S. (2001). Dissolution of primary minerals in natural waters II . Mineral saturation state. Chemical Geology, 172(34), 251-276.

Stefánsson, A., \& Gíslason, S. R. (2001). Chemical weathering of basalts, southwest Iceland: effect of rock crystallinity and secondary minerals on chemical fluxes to the ocean. American Journal of Science, 301(6), 513-556. doi: 10.2475/ajs.301.6.513

Sveinbjörnsdóttir, Á. E., Stefánsson, A., Heinemeier, J., Arnórsson, S., Eiríksdóttir, E. S., \& Ólafsdóttir, R. (2020). Assessing the sources of inorganic carbon in surface-, soil-and non-thermal groundwater in iceland by $\delta 13 \mathrm{c}$ and $14 \mathrm{c}$. Geochimica et Cosmochimica Acta, 279, 165-188.

Taylor, A. S., Blum, J. D., \& Lasaga, A. C. (2000). The dependence of labradorite dissolution and $\mathrm{Sr}$ isotope release rates on solution saturation state. Geochimica et Cosmochimica Acta, 64(14), 2389-2400.

Thorpe, M. T., Hurowitz, J. A., \& Dehouck, E. (2019). Sediment geochemistry and 
mineralogy from a glacial terrain river system in southwest Iceland. Geochimica et Cosmochimica Acta, 263, 140-166. doi: 10.1016/j.gca.2019.08.003

Torres, M. A., Baronas, J. J., Clark, K. E., Feakins, S. J., \& West, A. J. (2017). Mixing as a driver of temporal variations in river hydrochemistry: 1. Insights from conservative tracers in the Andes-Amazon transition. Water Resources Research, 53(4), 3102-3119.

Torres, M. A., Kemeny, P. C., Lamb, M. P., Cole, T. L., \& Fischer, W. W. (2020). Long-term storage and age-biased export of fluvial organic carbon: Field evidence from west iceland. Geochemistry, Geophysics, Geosystems, 21(4), e2019GC008632.

Torres, M. A., West, A. J., Clark, K. E., Paris, G., Bouchez, J., Ponton, C., ... Adkins, J. F. (2016). The acid and alkalinity budgets of weathering in the Andes-Amazon system: Insights into the erosional control of global biogeochemical cycles. Earth and Planetary Science Letters, 450, 381-391.

Vigier, N., Burton, K., Gislason, S., Rogers, N., Duchene, S., Thomas, L., ... Schaefer, B. (2006). The relationship between riverine U-series disequilibria and erosion rates in a basaltic terrain. Earth and Planetary Science Letters, 249(34), 258-273.

Vigier, N., Gislason, S., Burton, K., Millot, R., \& Mokadem, F. (2009). The relationship between riverine lithium isotope composition and silicate weathering rates in Iceland. Earth and Planetary Science Letters, 287(3-4), 434-441.

Wada, K., Arnalds, O., Kakuto, Y., Wilding, L., \& Hallmark, C. (1992). Clay minerals of four soils formed in eolian and tephra materials in iceland. Geoderma, 52(3-4), 351-365.

Weisenberger, T., \& Selbekk, R. S. (2009). Multi-stage zeolite facies mineralization in the hvalfjördur area, iceland. International Journal of Earth Sciences, 98(5), 985-999.

West, A. J., Galy, A., \& Bickle, M. (2005). Tectonic and Climatic Controls on Silicate Weathering. Earth and Planetary Science Letters, 235, 211-228.

White, A. F., Bullen, T. D., Vivit, D. V., Schulz, M. S., \& Clow, D. W. (1999). The role of disseminated calcite in the chemical weathering of granitoid rocks. Geochimica et Cosmochimica Acta, 63(13), 1939-1953.

White, A. F., Schulz, M. S., Lowenstern, J. B., Vivit, D. V., \& Bullen, T. D. (2005). The ubiquitous nature of accessory calcite in granitoid rocks: Implications for weathering, solute evolution, and petrogenesis. Geochimica et Cosmochimica Acta, 69(6), 1455-1471.

Wolff-Boenisch, D., Gislason, S. R., Oelkers, E. H., \& Putnis, C. V. (2004). The dissolution rates of natural glasses as a function of their composition at $\mathrm{pH} 4$ and 10.6, and temperatures from 25 to $74^{\circ} \mathrm{C}$. Geochimica et Cosmochimica Acta, 68 (23), 4843-4858. doi: 10.1016/j.gca.2004.05.027

Zheng, X.-Y., Beard, B. L., \& Johnson, C. M. (2019). Constraining silicon isotope exchange kinetics and fractionation between aqueous and amorphous si at room temperature. Geochimica et Cosmochimica Acta, 253, 267-289.

Ziegler, K., Chadwick, O. a., Brzezinski, M. A., \& Kelly, E. F. (2005, October). Natural variations of $\delta 30 \mathrm{Si}$ ratios during progressive basalt weathering, Hawaiian Islands. Geochimica et Cosmochimica Acta, 69(19), 4597-4610.

Ziegler, K., Chadwick, O. a., White, A. F., \& Brzezinski, M. A. $\quad(2005) . \quad \delta^{30}$ Si systematics in a granitic saprolite, Puerto Rico. Geology, 33(10), 817. 


\title{
Supporting Information for "The hydrochemical signature of incongruent weathering in Iceland"
}

\author{
Trevor L. Cole ${ }^{1}$, Mark A. Torres ${ }^{1}$, Preston C. Kemeny ${ }^{2}$ \\ ${ }^{1}$ Rice University Department of Earth, Environmental, and Planetary Sciences \\ ${ }^{2}$ California Institute of Technology Division of Geological and Planetary Sciences
}

Contents of this file

1. Text 1

2. Figures S1 to S10

\section{Additional Supporting Information (Files uploaded separately)}

1. MEANDIR input files for review

2. Hydrochemical data compilation for review

3. Data analysis code for review

Text S1. Carbon isotopic modelling

To model $\mathrm{C}$ isotopic ratios, we use a separate offline calculation based on output from MEANDIR. We prefer this approach in part because $\mathrm{CO}_{2}$ degassing and/or exchange with the atmosphere can modify the isotopic composition of DIC and these processes are difficult to model. By using a separate calculation, we can more loosely apply $\mathrm{C}$ isotopic constraints and thus circumvent directly modelling degassing and exchange. Additionally, 
directly including $\mathrm{C}$ isotopic ratios also adds computation expense as the $\mathrm{C}$ isotopic ratios of weathering end-members vary independently of their $\mathrm{X} / \Sigma^{ \pm}$values thus requiring more random draws to find acceptable solutions.

For the purposes of approximating the DIC budget, we equate the positive alkalinity provided by each end-member to its DIC concentration:

$$
D I C_{j}=\left(f_{j, N a} \cdot[N a]_{r i v}\right)+\left(f_{j, K} \cdot[K]_{\text {riv }}\right)+\left(2 \cdot f_{j, C a} \cdot[C a]_{r i v}\right)+\left(2 \cdot f_{j, M g} \cdot[M g]_{r i v}\right)-\left(f_{j, C l} \cdot[C l]_{r i v}\right)-\left(2 \cdot f_{j, S O_{4}} \cdot\left[S O_{4}\right]_{r i v}\right)
$$

This assumes all DIC is speciated as $\mathrm{HCO}_{3}^{-}$, which is reasonable given observations of riverine $\mathrm{pH}$ values. Using Monte-Carlo simulation, we take the apportionment of DIC budget between silicate, carbonate, rain water, and hydrothermal fluids for each simulation from each sample and compute a range of possible riverine $\mathrm{C}$ isotopic ratios given the a priori ranges in the different end-member $\mathrm{C}$ isotopic ratios using the equations:

$$
\delta^{13} C_{\text {riv,pred }}=\sum_{j=1}^{4} f_{D I C, j} \cdot \delta^{13} C_{j}
$$

and

$$
{ }^{14} C_{\text {riv }, \text { pred }}=\sum_{j=1}^{4} \overbrace{f_{D I C, j}}^{\text {from MEANDIR }} \cdot \underbrace{{ }^{14} C_{j}}_{\text {random variable }}
$$

The output of these equations can then be compared with the actual $\mathrm{C}$ isotopic measurement, which avoids having to require the model to exactly match the observations given that, for example, measured $\delta^{13} \mathrm{C}$ values may be elevated as a consequence of $\mathrm{CO}_{2}$ degassing.

For the purposes of modelling $\mathrm{C}$ isotopic ratios, we assume that any DIC from rainwater has a $\delta^{13} \mathrm{C}$ of $-7 \%$ and ${ }^{14} \mathrm{C}$ abundance of 105 percent modern carbon (pMC) following Sveinbjörnsdóttir et al. (2020). 
For DIC from hydrothermal fluids, we assume a uniform distribution of $\delta^{13} \mathrm{C}$ values between -18.8 and $+4.4 \%$ following Barry, Hilton, Füri, Halldórsson, and Grönvold (2014) and ${ }^{14} \mathrm{C}$ of 0 pMC.

Based on measurements of Icelandic spar from Landis (1983) and (Smalley et al., 1989), we assume a uniform distribution of carbonate $\delta^{13} \mathrm{C}$ values from -5 to $-3 \%$ and a ${ }^{14} C$ abundance of 0 pMC. For carbonate weathering driven by carbonic acid, half of the DIC will derive from the carbonic acid such that the overall values of $\delta{ }^{13} \mathrm{C}$ and ${ }^{14} C$ will not match pure carbonates:

$$
\mathrm{CaCO}_{3}+\mathrm{H}_{2} \mathrm{CO}_{3} \longleftrightarrow \mathrm{Ca}^{2+}+2 \mathrm{HCO}_{3}^{-}
$$

Here, we assume that carbonic acid derives from a mixture of atmospheric $\mathrm{CO}_{2}\left(\delta^{13} \mathrm{C}\right.$ $=-7 \% ;{ }^{14} \mathrm{C}=105 \mathrm{pMC}$ ) and $\mathrm{CO}_{2}$ from soil respiration. Based on direct measurements of soil organic matter from Icelandic river catchments (Torres et al., 2020), we assume a uniform distribution of $\delta^{13} \mathrm{C}$ values between -32 and $-24 \%$ and a uniform distribution of ${ }^{14} \mathrm{C}$ abundances from 60 to $130 \mathrm{pMC}$ for the soil respiration end-member.

Similar to how to model carbonate weathering, we assume that DIC from silicate weathering has $\mathrm{C}$ isotopic compositions given by a mixture of atmospheric $\mathrm{CO}_{2}$ and $\mathrm{CO}_{2}$ derived from soil respiration. We draw the end-member $\mathrm{C}$ isotopic ratios for silicate weathering separately from carbonate weathering, which in effect allows for different $\mathrm{CO}_{2}$ sources to drive the weathering of different mineral phases.

\section{References}

Barry, P., Hilton, D., Füri, E., Halldórsson, S., \& Grönvold, K. (2014). Carbon isotope and abundance systematics of icelandic geothermal gases, fluids and subglacial 
$\mathrm{X}-4$

basalts with implications for mantle plume-related co2 fluxes. Geochimica et Cosmochimica Acta, 134, 74-99.

Landis, G. P. (1983). Harding iceland spar: A new $\delta 180-\delta 13 \mathrm{c}$ carbonate standard for hydrothermal minerals. Chemical Geology, 41, 91-94.

Smalley, P., Stijfhoorn, D., Råheim, A., Johansen, H., \& Dickson, J. (1989). The laser microprobe and its application to the study of $\mathrm{c}$ and o isotopes in calcite and aragonite. Sedimentary Geology, 65(3-4), 211-221.

Sveinbjörnsdóttir, Á. E., Stefánsson, A., Heinemeier, J., Arnórsson, S., Eiríksdóttir, E. S., \& Ólafsdóttir, R. (2020). Assessing the sources of inorganic carbon in surface-, soil-and non-thermal groundwater in iceland by $\delta 13 \mathrm{c}$ and $14 \mathrm{c}$. Geochimica et Cosmochimica Acta, 279, 165-188.

Torres, M. A., Kemeny, P. C., Lamb, M. P., Cole, T. L., \& Fischer, W. W. (2020). Long-term storage and age-biased export of fluvial organic carbon: Field evidence from west iceland. Geochemistry, Geophysics, Geosystems, 21(4), e2019GC008632. 

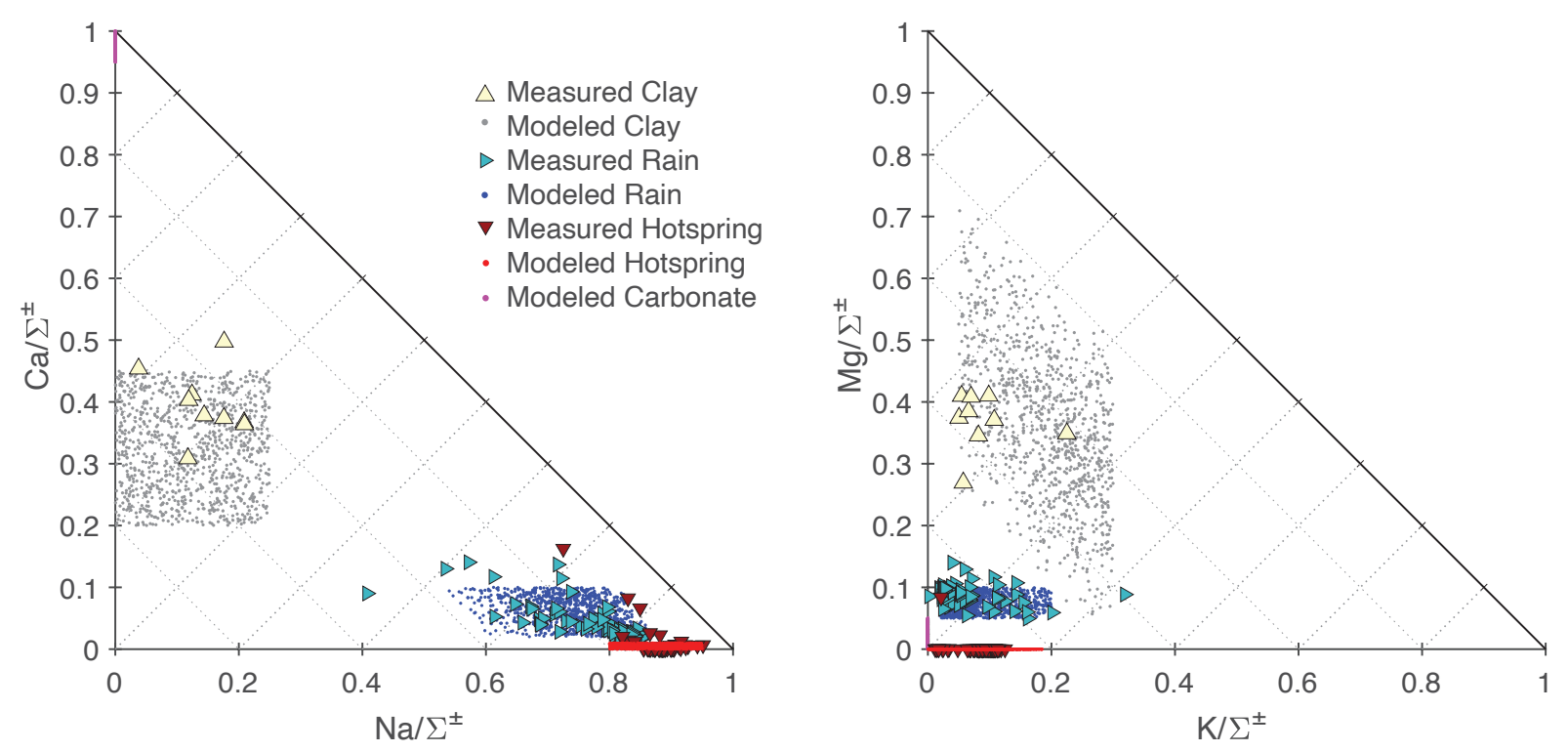

Figure S1. End-member cation compositions used in the solute mass balance model compared to field observations. 

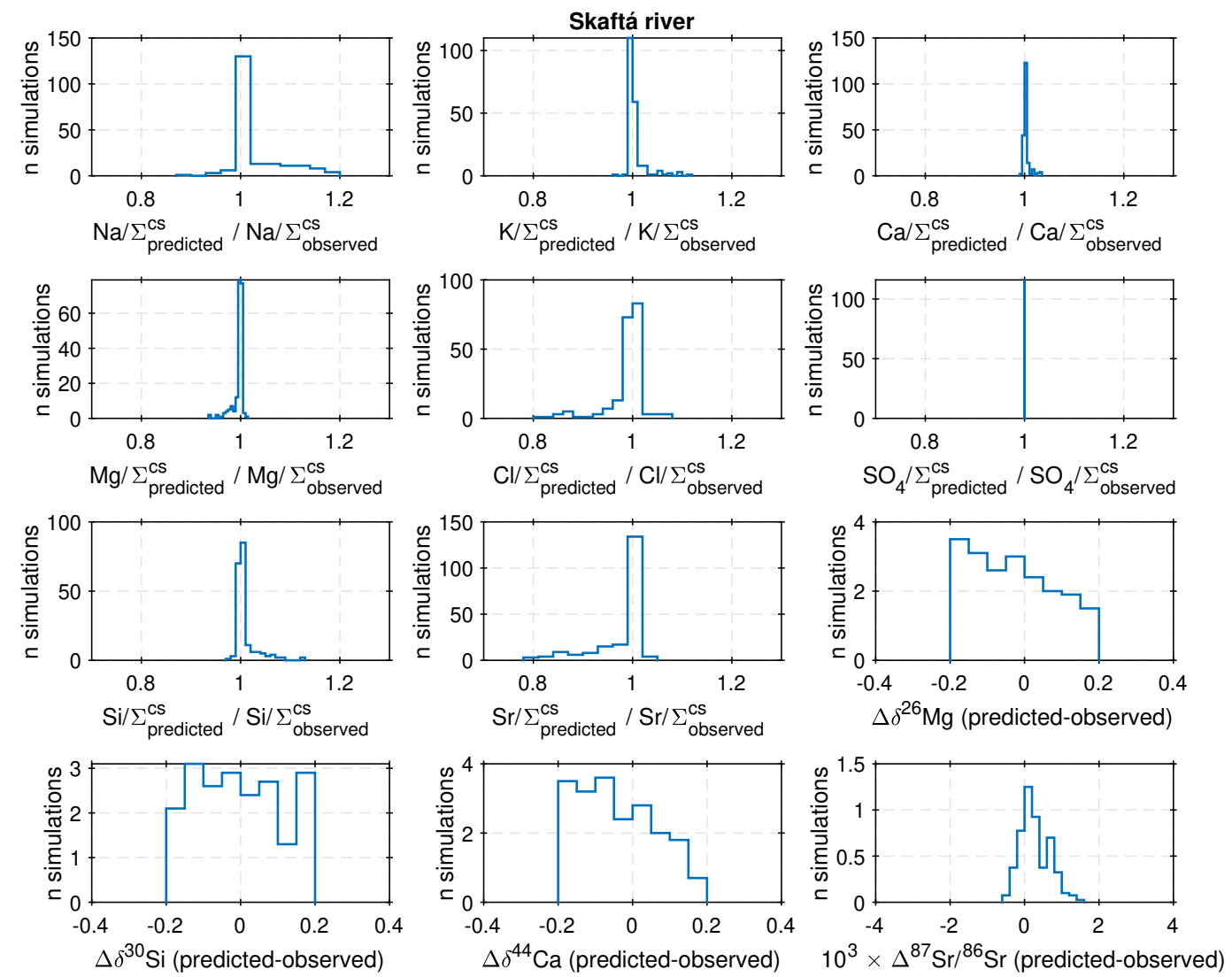

Figure S2. Histograms of the model reconstructed values for all of inputs for the Skaftá River. 

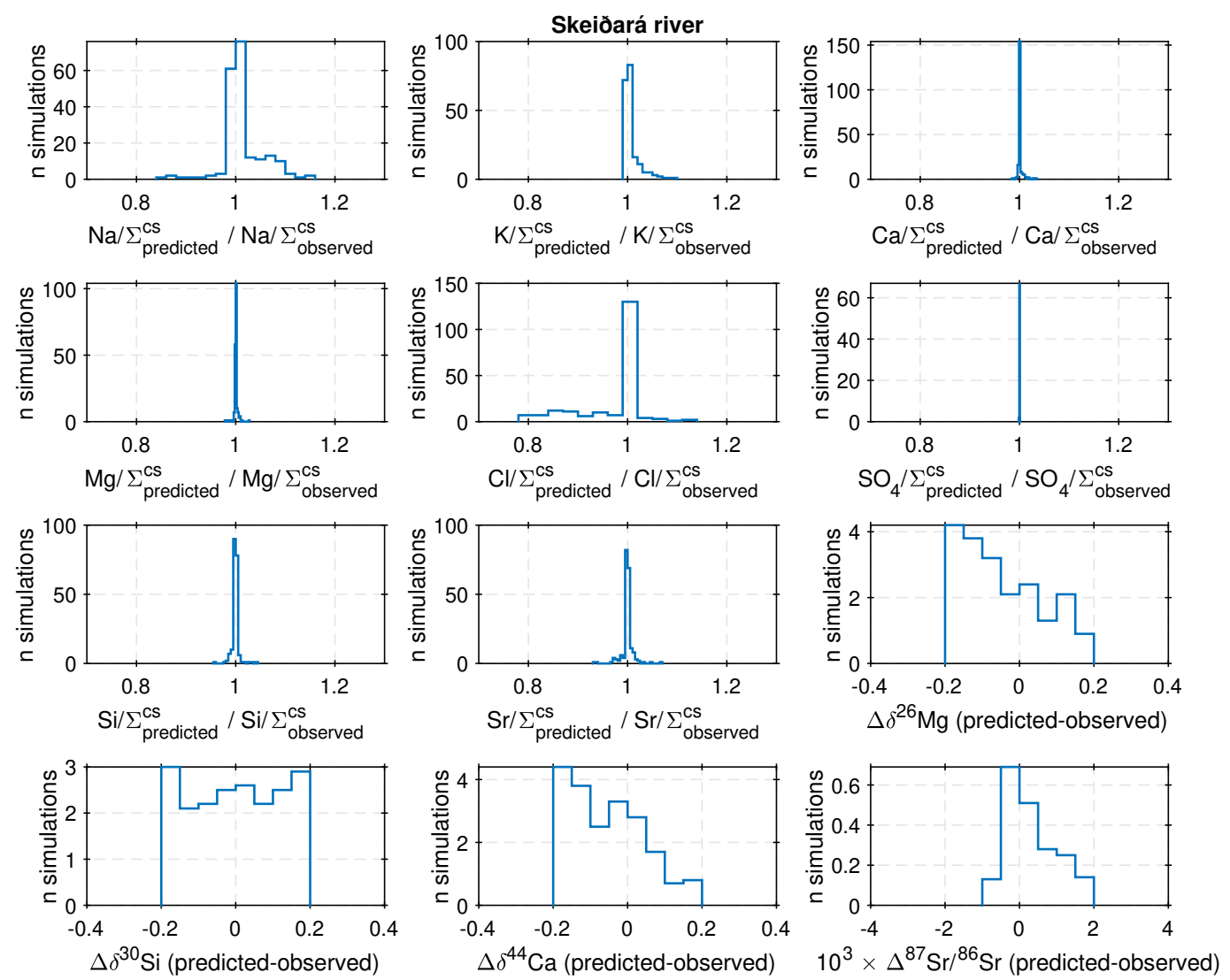

Figure S3. Histograms of the model reconstructed values for all of inputs for the Skeiðará River. 

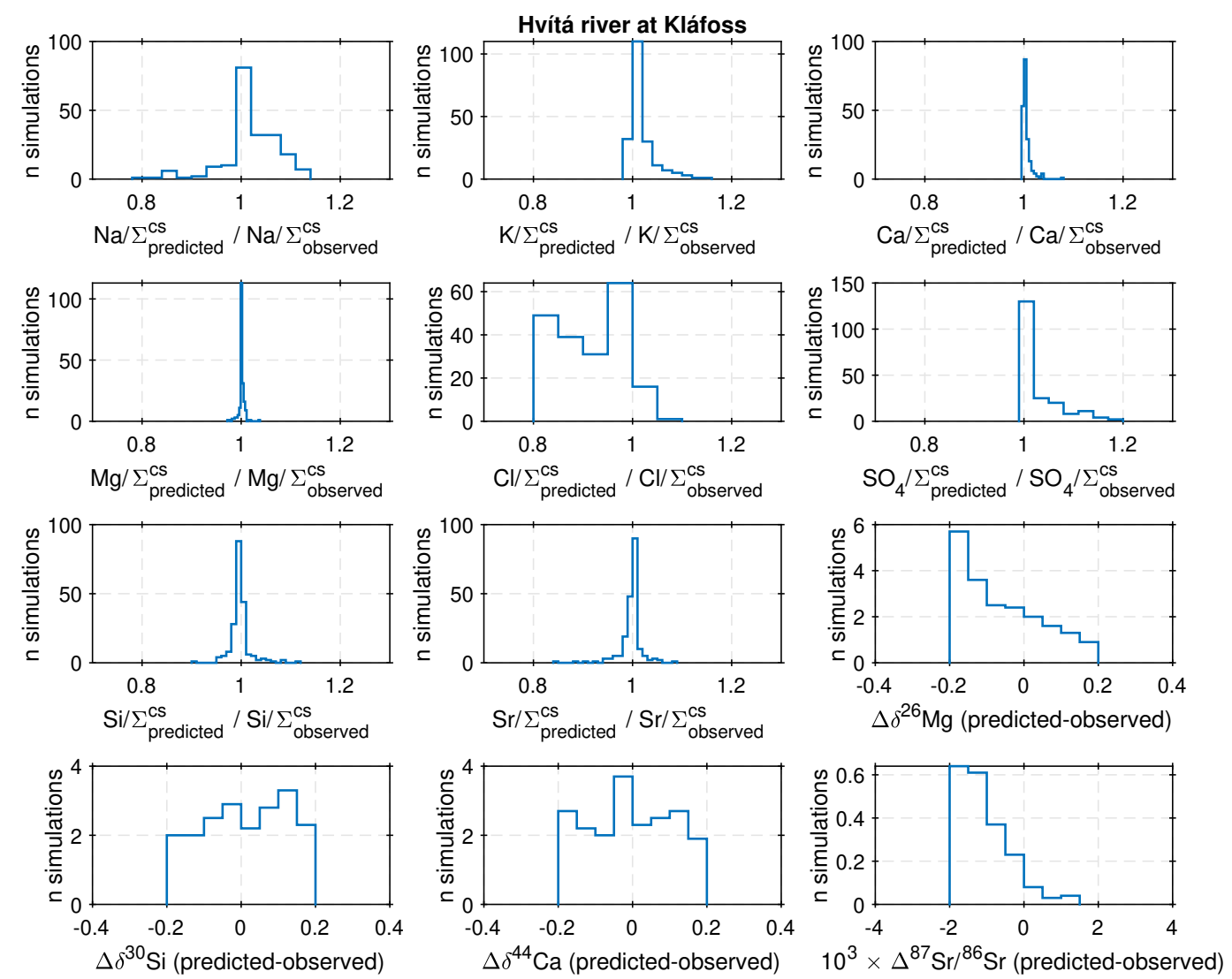

Figure S4. Histograms of the model reconstructed values for all of inputs for the Hvitá River at Kláfoss. 

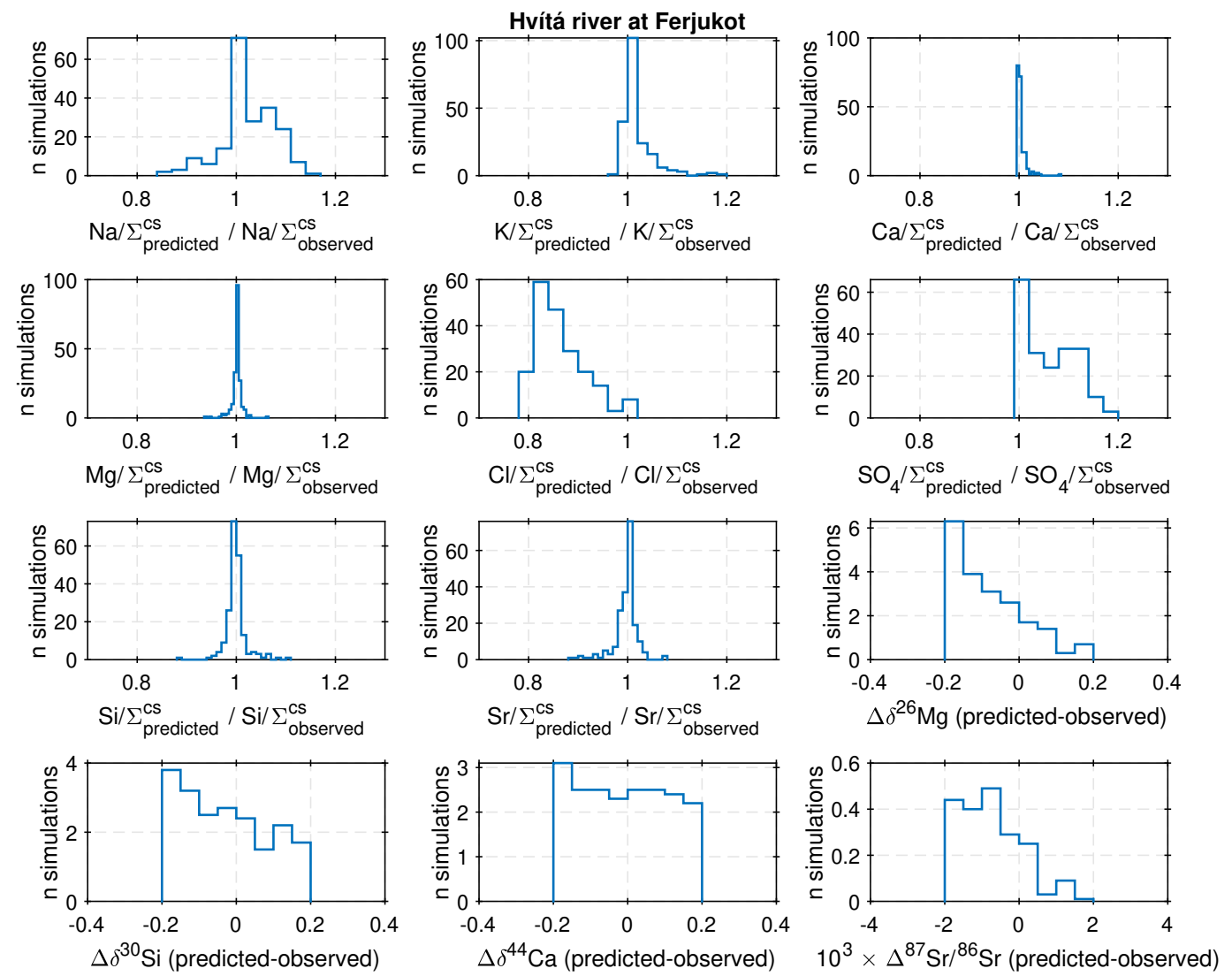

Figure S5. Histograms of the model reconstructed values for all of inputs for the Hvitá River at Ferjukot. 

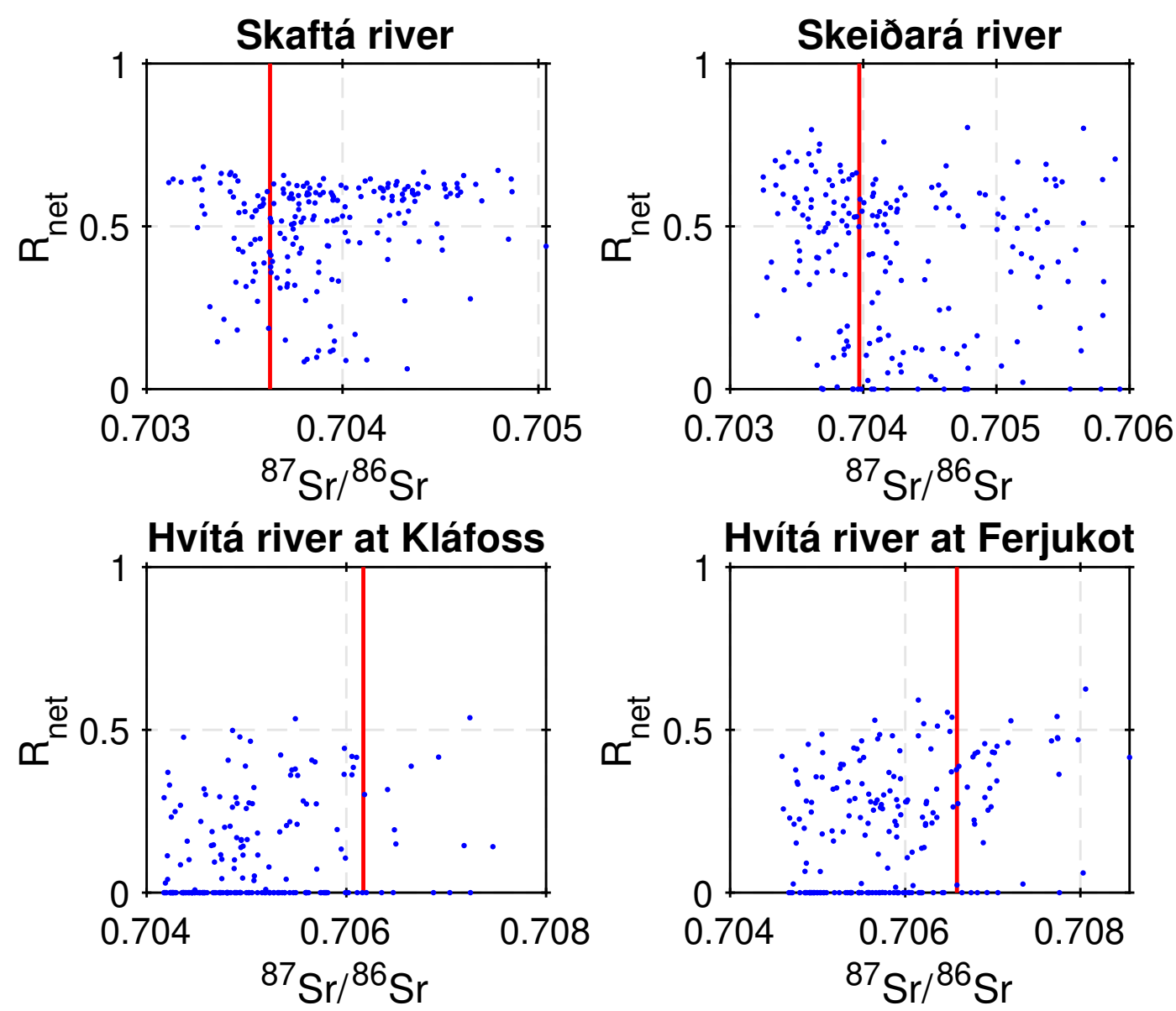

Figure S6. Comparison between the reconstructed ${ }^{87} \mathrm{Sr} /{ }^{86} \mathrm{Sr}$ and predicted proportion of carbonate weathering $\left(R_{n e t}\right)$ for the rivers shown in Figures S2-S5 with all 4 isotopic constraints (blue dots). In each plot, the red line shows the measured ${ }^{87} \mathrm{Sr} /{ }^{86} \mathrm{Sr}$. Importantly, these data show that further culling the model results to only accept the best-fitting ${ }^{87} \mathrm{Sr} /{ }^{86} \mathrm{Sr}$ values would not substantially change our inferences of the model-constrained range in $R_{n e t}$. 


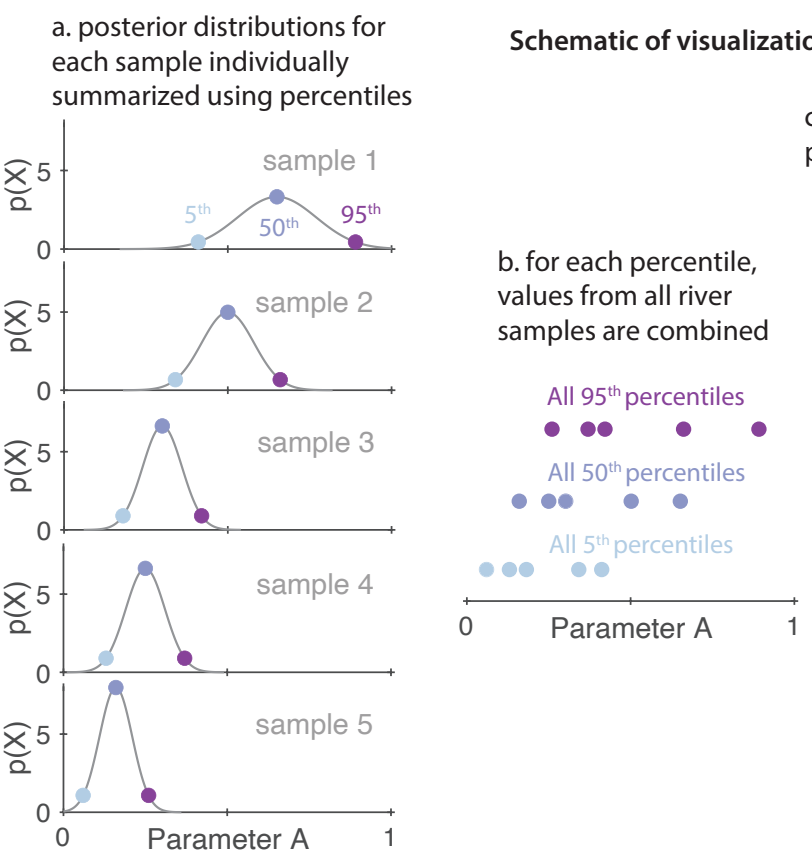

approach for inter-sample distributions

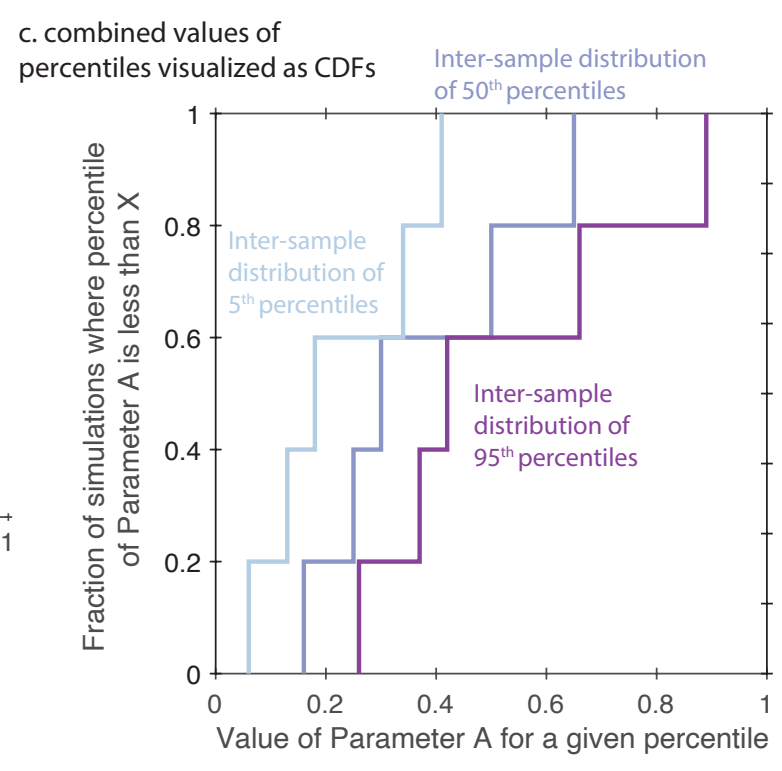

Figure S7. Schematic showing how inter-sample distributions of percentiles are calculated from the individual sample distributions. 